\title{
WestVirginiaUniversity
}

THE RESEARCH REPOSITORY @ WVU

Graduate Theses, Dissertations, and Problem Reports

2018

\section{Medical Celebrity in Eighteenth-Century Britain}

\author{
Katherine Richards \\ krrichards@mix.wvu.edu
}

Follow this and additional works at: https://researchrepository.wvu.edu/etd

Part of the Literature in English, British Isles Commons

\section{Recommended Citation}

Richards, Katherine, "Medical Celebrity in Eighteenth-Century Britain" (2018). Graduate Theses,

Dissertations, and Problem Reports. 3734.

https://researchrepository.wvu.edu/etd/3734

This Dissertation is protected by copyright and/or related rights. It has been brought to you by the The Research Repository @ WVU with permission from the rights-holder(s). You are free to use this Dissertation in any way that is permitted by the copyright and related rights legislation that applies to your use. For other uses you must obtain permission from the rights-holder(s) directly, unless additional rights are indicated by a Creative Commons license in the record and/ or on the work itself. This Dissertation has been accepted for inclusion in WVU Graduate Theses, Dissertations, and Problem Reports collection by an authorized administrator of The Research Repository @ WVU.

For more information, please contact researchrepository@mail.wvu.edu. 


\title{
Medical Celebrity in Eighteenth-Century Britain
}

\section{Katherine R. Richards}

\author{
Dissertation submitted \\ to the Eberly College of Arts and Sciences \\ at West Virginia University \\ in partial fulfillment of the requirements for the degree of \\ Doctor of Philosophy in \\ English Literature
}

\author{
Marilyn Francus, Ph.D., chair \\ Laura Engel, Ph.D. \\ Lara Farina, Ph.D. \\ Catherine Gouge, Ph.D. \\ John Lamb, Ph.D. \\ Department of English \\ Morgantown, West Virginia \\ 2018
}

Keywords: Eighteenth Century, Celebrity Studies, Medical History, Britain Copyright 2018 Katherine Richards 


\section{Abstract \\ Medical Celebrity in Eighteenth-Century Britain}

\section{Katherine Richards}

Medical Celebrity in Eighteenth-Century Britain argues that the cultural mechanisms responsible for creating and sustaining celebrity culture helped create and sustain commercialized medicine in eighteenth-century Britain. I identify the process by which celebrity and medical culture impact one another as a sociocultural phenomenon that I term medical celebrity. The following chapters present four case studies of how medical celebrity impacted the development of the medical profession, the medical market, cultural representations and perceptions of health and illness, and the patient experience. I engage with the work done by scholars in contemporary and early celebrity studies to shed light on the memoirs, biographies, letters, etc. of culturally significant medical practitioners and patients. As such, I create case studies of the famous surgeons John and William Hunter, the infamous pamphlet war following Robert Walpole's medical treatment and death, two notoriously ill and healthy actresses, Susannah Cibber and Margaret "Peg" Woffington, and Frances Burney's infamous letter detailing her mastectomy. This dissertation serves as a typology of medical celebrity, thereby identifying the sociocultural phenomenon at the root of the discussions by medical historians and eighteenth-century scholars who examine intersections between celebrity and medical culture. Ultimately, I argue that eighteenth-century medical celebrity was foundational to contemporary British and American culture and we must examine the function of medical celebrity in contemporary culture in order to understand the development of the medical profession, lived experiences of patients and practitioners, cultural representations and perceptions of medicine, and the medical market. 


\section{Dedication}

To Hannah and to Him. Without you--none of this. 


\section{Acknowledgements}

I would like to first thank my Dissertation Chair, Dr. Marilyn Francus, for her persistent dedication to me and to this project; without her eye for detail, questions, suggestions, and incredible hard work, this project would certainly never have come to fruition. I would also like to thank the members of my committee: Dr. Laura Engel, Dr. Lara Farina, Dr. Catherine Gouge, and Dr. John Lamb. Thank you for all of your feedback, the time and energy you put into the project, and all of your hard work.

I would not have been able to complete this dissertation without the generous funding I received from the Department of English and Eberly College of Arts and Sciences at West Virginia University. I am very grateful for the various fellowships and scholarships I received to complete this project.

Thank you to my friends and colleagues who were with me in the program: Hatley Clifford, Allyson Demaagd, and Rachel Hoag. You each brought fun and happiness to an incredibly arduous process.

To my mom and dad, Pam and Milani Richards - thank you for always supporting me, always offering encouragement, always providing a much-needed place to escape, and always loving me. You both taught me at an early age that my thoughts and opinions mattered. Thank you.

To Donna-you saw me, and you told me I could do this long ago, and that has shaped the last decade of my life. Thank you.

To Blake and Lauren-you will never know how much joy you both bring to my life. This could not have been completed without those surprising moments of laughter and happiness. Thank you.

To Melissa and Matt—for so much. Thank you.

To Hannah-I wrote over 200 pages about the eighteenth century, and I am never short for words on any subject. For your devotion, dedication, countless readings and edits, immeasurable patience, and inherent belief in me-for all of this I have no words except that I owe this to you. Thank you. 


\section{Table of Contents}

$\begin{array}{ll}\text { Introduction } & 1\end{array}$

Chapter $1 \quad 35$

Blood Brothers: The Medical Celebrity and Fame of John and William Hunter

Chapter 2

97

"that Mankind might reap the proper benefit": John Ranby's Narrative of

Sir Robert Walpole's Final Illness, Celebrity, and the Medical Market

Chapter 3

136

The Medical Celebrity of Actresses: Susannah Cibber's Illness and Margaret

"Peg" Woffington's Health

Chapter 4

183

Medical Celebrity and the Patient Experience: Celebrity and Fame in Frances

Burney's Mastectomy Letter

Coda

Works Cited 


\section{$\underline{\text { Introduction }}$}

In the 1994 film The Madness of King George, based on the play by Alan Bennett, the king is bound and gagged by his physician, who is willing to torture his patient for the sake of making him well. At the conclusion of this gripping scene, Nigel Hawthorne, who plays George III, shouts in disbelief, "I am the king of England!" to which the physician, played by Sir Ian Holm, replies with self-righteous indignation, "No, sir! You are the patient!” This scene illustrates how perceptions of the most powerful and revered figures can change when that person is faced with illness, but it also demonstrates the power that medical practitioners in the eighteenth century had to influence those perceptions. While the movie dramatizes portions of the story, "the mad king who lost America" is often remembered in relation to his illness and experience as a patient in addition to his duties and role as king.

George III's periods of ill health began in the 1780s, forty years before his death, and plagued much of his reign (Macleod 54). His illness affected his mental faculties significantly, and in 1811 the Regency Act was passed, which allowed his son to perform many of his father's royal duties (Black 407). This illness, which we now attribute to a blood disorder known as porphyria, was common knowledge at court and throughout the nation during the time, so much so that in 1789, the Brook's Club at the King's Theatre threw a gala featuring famous performers to celebrate one of his periods of good health and clarity (Hogan 1148). While George III had a tremendous amount of celebrity prior to his illness, once he became ill, the public's fascination with the king shifted. He became someone who was not simply famous, but famous for being ill, a sentiment which carried through into modern depictions such as Bennett's play. With the change in public perception of the king's body came the disillusionment of a separate body physical and body politic, as the king's medical body became neither sacred nor private. Rather, 
his medical condition, state of health, treatment, and physicians became objects of fascination and discussion for the public.

But the public's curiosity in the medical experience of a famous figure was not limited to George III. Similar instances occurred throughout the century, such as Queen Anne's public battle with gout or the public frenzy around newspaper reports of Mary Toft who claimed to give birth to rabbits. These instances reveal that illness, treatment, patients, medical practices, anatomy, and the medical experience of an individual often captured public interest. A quick perusal through eighteenth-century newspapers, magazines, novels, caricatures, and other forms of print media provides an abundance of advertisements for medicines and medical treatments, reports of sickness and death, individuals who experience all forms of illness and treatment, medical practitioners parodied on stage, images of quack physicians behaving nefariously, and more. These representations of medical culture and the culture's experience with medicine exist in far greater numbers than in previous centuries. From our vantage point, eighteenth-century Britain, as a result, seems particularly preoccupied with both medical and scientific subjects.

However, public interest in such matters was not unique to the eighteenth century; rather, it was in the eighteenth century that industries capable of producing content for that public interest arose. These industries, such as the manufacturing of consumer goods and print media, were part of the increase in cultural mechanisms for creating and sustaining public interest in individuals as subjects. These cultural mechanisms that elevate the experience of the individual to the level of public interest are those cultural mechanisms that celebrity theorists such as Joseph Roach, Chris Rojek, and Graeme Turner argue create and maintain celebrity. They include but are not limited to reputation, desire, publicity, media production, representation, public personas, public perception, narrative, marketing, and advertising. These cultural 
mechanisms enabled the rise of celebrity culture in the eighteenth century, but more importantly they enabled the ontological shift in public interest, curiosity, and even obsession towards the everyday lived experiences, preferences, movements, and opinions of individuals. Sometimes those individual experiences intersected with illness, medical practice, and treatment. In those instances, the cultural mechanisms of celebrity buoyed those medical experiences and the representations of them to the attention of the public and for their consumption.

This dissertation argues that those cultural mechanisms responsible for creating and sustaining celebrity also helped create and sustain commercialized medicine in eighteenthcentury Britain. Medical historians and eighteenth-century scholars have studied the rise of commercialized medicine within the context of economic, political, religious and social changes that occurred, and there has been much research into the cultural representations and depictions of medicine in the eighteenth century, by Roy Porter, most notably, but also Ralph A. Houlbrooke, Christopher Lawrence, Ludmilla Jordanova, and others. Additionally, scholars such as David E. Shuttleton, Clark Lawlor, and Carolyn A. Day have studied the effects of the cultural mechanisms of celebrity on the role of medicine in the culture, including the ways that the development of consumer print culture impacted the medical market or how illnesses became fashionable through popular representation. However, heretofore, no one has claimed that the cultural mechanisms that created eighteenth-century celebrity are the same mechanisms that helped create medical culture, and more importantly, no one has investigated what that overlap means. Common cultural conceptions of celebrity and medicine (or science in general) imagine these two realms as separate from one another, where scientists work outside of the trappings of popular culture, self-fashioning, reputation, marketing, and advertising. Indeed, that common cultural misconception shows up in the scholarship, where there is the implicit assumption that 
medical culture and celebrity culture are separate. This dissertation argues that the exact opposite is true, that, in fact, these cultures helped shape one another in the eighteenth century, and they continue to do so in contemporary British and American culture.

I call the sociocultural phenomenon in which medical and celebrity cultures shape one another medical celebrity. Medical Celebrity in Eighteenth-Century Britain creates a typology of this sociocultural phenomenon through four case studies that present the ways that medical celebrity exists in the lives, careers, and experiences of both medical practitioners and patients. Additionally, these case studies demonstrate several ways in which the cultural mechanisms that enabled celebrity dramatically impacted the cultural role of medicine in four different areas of medical culture: the medical profession, the consumer medical market, cultural perceptions of illness versus health, and representations of medical treatment. Ultimately, I argue that identifying and analyzing medical celebrity as a sociocultural phenomenon allows us to see how it constructs practitioners' and patients' lived experience of, relationship to, and perception of medicine. The typology that follows serves as a foundation to future work on medical celebrity that would identify and analyze many other types of the sociocultural phenomenon and its impact on the culture. The dissertation provides a new theoretical framework to the interdisciplinary fields of celebrity studies, eighteenth-century studies, and medical history. As such, I will review the state of each of these fields to explain the framework of my analysis and the historical and theoretical framework that defines medical celebrity.

\section{$\underline{\text { Celebrity Studies }}$}

As a work within the field of celebrity studies, Medical Celebrity historicizes the rise of modern medicine within the context of the rise of celebrity culture. Histories of celebrity locate the beginning of contemporary celebrity in the British eighteenth century. Cheryl Wanko 
describes that subfield as "early celebrity studies" ("Celebrity" 351). Rather than claim that contemporary celebrity is mirrored in eighteenth-century examples, these scholars work under the premise that contemporary celebrity "is different in scale and intensity, rather than in kind, to what preceded it," a concept identified by Graeme Turner in his seminal work Understanding Celebrity (11). In other words, celebrity as it existed in the British eighteenth century cannot be analyzed as a parallel to contemporary celebrity, but it can be analyzed as an antecedent. The field of early celebrity studies analyzes the formation of celebrity in the eighteenth century; identifies and establishes what is required to maintain celebrity; and theorizes the role of fans, media, reputation, audiences, and consumers in the construction of celebrity as an industry and cultural phenomenon. Because early celebrity studies is a subfield of celebrity studies, scholars often utilize similar methodologies and theories as contemporary celebrity theorists. Medical Celebrity also relies on the foundational work done by these scholars.

As a whole, celebrity studies is an inter- and multidisciplinary field of inquiry which analyzes celebrity as a cultural phenomenon and answers questions such as: what constitutes celebrity? What are the mechanisms by which it is created? And what is its cultural impact? Contemporary celebrity studies began with inquiries about individual celebrities and their potentially negative impact on society, and progressed to examinations of celebrity as a cultural formation to be explored in every aspect of contemporary life. One of the most influential works in the field that informs this dissertation is Chris Rojek's Celebrity (2001). In it, he constructs a theoretical system for analyzing the process of celebrity formation and how celebrity is maintained. This system categorizes celebrity into three types: “ascribed, achieved, and attributed" (Rojek 17). These types refer to the circumstances whereby an individual becomes a celebrity: "Ascribed celebrity concerns lineage: status typically follows from blood- 
line... achieved celebrity derives from the perceived accomplishments of the individual in open competition...[and attributed celebrity]...is largely the result of the concentrated representation of an individual as noteworthy or exceptional by cultural intermediaries" (17-18). This dissertation focuses exclusively on achieved celebrity in order to create a theoretical approach rooted in similar types of celebrity. Moreover, Rojek identifies three methodological approaches for celebrity studies: "subjectivism, structuralism, and post-structuralism" (29). As is the case with most recent contributions to celebrity studies, this dissertation takes a post-structuralist approach to address celebrity as "a field of production, representation, and consumption" and as "the emerging property of interactions in a determinate field of interests" (45). Rojek's methodology establishes the foundation for examining of celebrity as a nexus of almost every aspect of American and British culture.

Similarly, in Understanding Celebrity (2004), Graeme Turner traces the theoretical trends in celebrity studies, synthesizes their definitions of celebrity, and summarizes it as "a genre of representation and a discursive effect; it is a commodity traded by the promotions, publicity, and media industries that produce these representations and their effects; and it is a cultural formation that has social function we can better understand" (Turner 10). Medical Celebrity's conceptualization of celebrity arises from Turner's definition in which celebrity can be analyzed through representations of public figures, industries that draw attention to public figures, and ultimately how celebrity not only impacts contemporary culture but also shapes how individuals participate in and interact with the world around them. Moreover, Turner and Rojek's conception of the ubiquity of celebrity and its all-encompassing sphere of influence can be traced back to the eighteenth century. 
The most widely recognized foundation of the history of celebrity is Leo Braudy's The Frenzy of Renown (1986). In it, he traces the history of fame since Alexander the Great to "understand the place of fame in our culture... [and] its relation to a history of Western ideas of what an individual is" (Braudy 15). Other prominent histories include Mary Luckhurst and Jane Moody's Theatre and Celebrity in Britain 1660-2000 (2005), and the more recent contributions made by Fred Inglis in A Short History of Celebrity (2010). In all of these histories of celebrity, scholars have established the eighteenth century as the birthplace of modern celebrity. This is referred to as the rise of celebrity, or the ways in which the cultural mechanisms that form and maintain celebrity (fans, reputation, media production, publicity, etc.) shifted in the eighteenth century because of larger economic, political, and social changes. These scholars claim that, as a result, celebrity culture existed in the eighteenth century. The scholarship on the history of celebrity culture — its origins, perpetuation, and its sociocultural impact—provides the foundation and theoretical approach to eighteenth-century British culture in this dissertation.

\section{Eighteenth-Century Celebrity Culture}

Fame, renown, notoriety, and the ability for certain figures to be well known — and achieve more cultural recognition and influence as a result — are not original or exclusive to eighteenth-century culture. But scholars do argue that modern celebrity, a phenomenon that is different from but related to fame and recognition, begins in eighteenth-century British consumer culture. Numerous cultural and ideological shifts contributed to the rise of celebrity in the eighteenth century, but theorists identify the changes in politics, religion, economics, and media production as the primary factors that created the environment for the birth of modern celebrity.

The Restoration, which marks the beginning of the long eighteenth century, completely altered cultural ideas about the role of the individual in relation to social hierarchy, providence, 
and political rule. The rise of celebrity in the eighteenth century was a result of the shift in power from the monarch to the individual, and "the eighteenth century mark[ed] the beginning of an international European fame culture in which an enormous variety of new social, economic, and political groups use[d] the expanded powers of media to press themselves and their individual members into the vacuum of cultural authority, challenging the monarchies and aristocracies that had previously been the sole custodians of such singularity" (Braudy 371). In Britain, the individuals who sought to fill that vacuum included writers, performers, artists, politicians, and anyone who could distinguish themselves not because of their birth but because of their efforts and action. Fame was no longer given; it was earned. ${ }^{1}$ Certainly, rising celebrities in the eighteenth century did not completely outshine those of noble birth who captivated the public's attention, but after the Restoration, ascribed celebrity was no longer guaranteed nor was it the only way to achieve cultural authority. Writers, artists, and criminals who acquired fame were no longer oddities, but instead they had the ability, through various forms of media, to deeply influence the culture and gain authority as a result.

These ideological shifts coincided with developments in technology, manufacturing, and the economy, which ultimately emphasized the importance of the consumer in an increasingly commercial culture. Improvements in the production of print material drastically impacted the amount of print material, both written and visual, that was consumed. Print emerged as a more widely accessible platform by which individuals could communicate with and influence members of the public. A growing middle class with more expendable income could purchase cheaply printed pamphlets and newspapers; whereas a generation or two earlier, the printed

\footnotetext{
1 This statement is not to deny the existence of celebrity that is bestowed at birth in eighteenth-century or contemporary culture. Chris Rojek argues that both of these forms of celebrity still exist as ascribed and attributed celebrity. The point here is to emphasize that the eighteenth century allowed for a new type of celebrity to exist, which Rojek refers to as achieved celebrity.
} 
material they owned may have consisted of only one or two books. Developments in manufacturing and trade made more goods readily available and middle class consumers possessed more purchasing power. Scholars point to this as the birth of consumer culture, wherein "major political, intellectual, and social adjustments" occurred simultaneously with economic and manufacturing shifts to create conditions that drastically changed the ability for people to consume things (McKendrick et al. 2). In their seminal work The Birth of a Consumer Society: The Commercialization of Eighteenth-Century England (1982), Neil McKendrick and J.H. Plumb argue that as individuals gained purchasing power as consumers, the commercialization of the economy — in fashion, goods, art, and politics—as a whole occurred. As consumers in a commercialized society, people, particularly in urban areas like London, could consume not just physical objects and material but also the subjects of print, visual culture, theatre, and art. In other words, eighteenth-century Londoners had more opportunities to consume the lives and personas of people. In Roles of Authority: Thespian Biography and Celebrity in Eighteenth-Century Britain (2003), Cheryl Wanko argues this led to changing ideas about who could and should be famous: "the eighteenth century's...obsession with performers, their changing social presence, the increase in popular visual imagery, and the growth of cheaper, more widely distributed print all contribute to a culture that began to esteem different public figures than it had previously, figures who are similar to those commanding people's attention today" (4-5). Wanko argues that this combination of mechanisms of production and changing ideology enabled a new kind of fame to emerge: celebrity, which she defines as "a form of large-scale public attention customarily labeled 'fame' in previous times...[and] a new market-and-media-driven form of attention that differs greatly from a traditional, neoclassical idea of fame" (5). She identifies a key prerequisite of celebrity widely 
agreed upon by both early and contemporary celebrity scholars - that in order for fame to be classified as celebrity, it must be a market and media production.

While fame is the amount of recognition one receives relative to audience size, celebrity is fame, recognition, renown, and/or notoriety commodified and produced through various forms of media, which directly impacts both the market and the culture. As Luckhurst and Moody state, "The eighteenth century is widely recognized as the historical moment when fame takes a recognizably modern form... The rationale for this argument arises from the conviction that celebrity is above all a media production: only in the eighteenth century does an extensive apparatus for disseminating fame emerge" (3). Identifying celebrity as a media production emerges in early celebrity studies as the clearest thread connecting eighteenth-century celebrity to contemporary celebrity. Teasing out this thread allows us to identify the shift in the social status and importance of the celebrity that scholars like Claire Brock have discussed. As a media production capable of influencing an increasingly consumer-oriented market, celebrities suddenly had more cultural authority that carried more weight in a culture shifting away from religious and royal authority. This meant that the relationship between audiences or consumers and those who had or were hoping to acquire fame was more significant and valuable within the culture. As Brock says, "For the first time, due to the expansion of print culture, the public not only had access to information about their heroes and heroines, but were often the means of maintaining their celebrated idol status" (9). She identifies this not just as a development but as a new kind of skill: "To be thrust into the public glare, unwilling and unable to take advantage of this position, ensures that publicity is achieved in only one respect: that of a visible public image. By contrast, actively to capitalize upon one's place under the glare of media attention, to manipulate the forces of fame becomes a new achievement in its own right" (10). Scholars like 
Laura Engel refer to this new achievement as the self-fashioning of fame. The self-fashioning of fame refers to a famous person's ability to manipulate their public and private personas, audiences' perceptions, and the mechanisms of cultural and media production to influence market forces, cultural perceptions, and social structures.

Medical Celebrity builds upon this concept of celebrity, which Turner's definition helpfully summarizes as "a genre of representation and a discursive effect; it is a commodity traded by the promotions, publicity, and media industries that produce these representations and their effects; and it is a cultural formation that has a social function" (9). Where Medical Celebrity differs is that while most early celebrity scholars investigate and theorize celebrity within the realms of theatre, print culture, art, and politics of eighteenth-century culture, I interrogate the role of celebrity within medical culture.

While early celebrity studies has been extensive, it has also been somewhat uneven in its focus, honing in on certain cultural intersections with celebrity and ignoring others. Wanko's recent critical history of the field identifies the following as the most common lines of inquiry: establishing the celebrity of individual public figures; the role of celebrities, specifically performers, in "cultural and political discourse"; the self-fashioning of celebrity by actresses; authorial celebrity specifically of women writers; celebrity's intersection with print culture; cultural productions and representations of celebrity, specifically through visual culture; and political celebrity. As a way to open up the field of inquiry, Wanko also identifies the "many topics along which celebrity cuts: art, music, theater; exhibitions, concerts, performance/spectacle; print culture, art media, music publishing, biography, journalism, advertising; patronage, politics, sport, science, military, remuneration and buying power, law, criminality—etcetera” (“Celebrity” 352-353). Despite celebrity's almost ubiquitous presence in 
eighteenth-century culture, several large questions remain neglected in the scholarship such as the discussions of celebrity in areas like sports, science, or opera, in addition to questions about transatlantic celebrity (Wanko, “Celebrity,” 358-359). An implicit call-to-action emerges from the work of eighteenth-century celebrity studies for future scholars to explore those aspects of culture which celebrity influenced beyond the realms of theatre, performance, politics, and the most prominent figures from the time period. Medical Celebrity answers this call-to-action by suggesting that not only should we examine how celebrity intersected with other cultural arenas, medicine being one of them, but we should examine how celebrity helped form and shape those areas as well. If we do so, celebrity culture emerges not as a subset of eighteenth-century culture, but as a means of cultural formation.

According to Graeme Turner, celebrity is not just a cultural phenomenon which happens out there - whether out there is in Hollywood, on social media, or on the eighteenth-century stage. Instead, celebrity is a "cultural formation," or a sociocultural phenomenon that is "not only...implicated in the production of communities such as fan groups or subcultures, not only does it generate celebrity culture and social networks, it also participates in the field of expectations that many... have of everyday life" (14). By applying this theory to eighteenthcentury celebrity culture and its impact on the role of medicine in the culture, I will analyze how celebrity helped shape the expectations and experience of medicine that practitioners and patients had in everyday life.

\section{Eighteenth-Century Medical Culture}

\section{The Evolution of Medical Knowledge}

The eighteenth century is not known as an age of great medical discovery or progress. That distinction is reserved for the breakthroughs made in the nineteenth and twentieth centuries 
in regard to certain fundamentals of modern medicine: antiseptics, sanitation practices, understanding the role of bacteria and germs, use of anesthetics, medical studies which utilize large quantities of data through technology, and many other characteristics we now consider to be fundamental to medical knowledge and practices. However, while the eighteenth century seemed to lack some of these fundamentals, much of the theoretical work of scientists, physicians, and natural philosophers served as the foundation to the discoveries and breakthroughs made in the nineteenth and twentieth centuries. The cultural, political, economic, social, and philosophical shifts which occurred in the eighteenth century, primarily through the writings and ideas of Enlightenment thinkers, expanded on the work of early modern scientists and philosophers to create a system of medical knowledge that prioritized empirical experimentation, which is the foundation of modern medical research.

As Roy Porter describes in The Greatest Benefit to Mankind (1997), his history of medicine since antiquity, despite the high mortality rates at the turn of the century because of "warfare, worldwide trading webs, giant cities...the thronging poor," plague, and epidemics, the progress made in early modern medicine inspired a new approach to science and medicine (245). Early modern science and medicine made incredible breakthroughs, such as the discovery of the circulation of blood, which paved the way for eighteenth-century medicine to make significant advancements in the treatment of illness and in lowering the mortality rate (Porter 245). But before those advancements could be made, medical research practices founded on empirical experimentation and evidence-based conclusions had to be developed, which required a change in the training of medical practitioners.

In early modern England, "only those found duly qualified by the Bishop of London or Dean of St Pauls [could] practis[e] physic. The basis on which the qualification was determined 
was generally the possession of a degree from Oxford or Cambridge, which would inevitably have been a classical one, ensuring a knowledge of Latin and Greek, Philosophy and Logic, with some studying of ancient medical treatises" (Haslam 14). As a result, medical knowledge remained primarily theoretical with little attention to the anatomy and biology of the human body. However, as cultural emphasis shifted from religious and royal authority to the reasoned, empirical arguments of Enlightenment thinkers, the study of medicine increasingly prioritized a scientific approach to medicine. Theories and methodologies established by Isaac Newton paved the way for prominent scientists like Herman Boerhaave to model "experimental natural philosophy" in the pursuit of successful scientific research (Porter 246). Boerhaave and others took a "mechanistic" approach to the treatment of the human body and the diagnosis of disease (Porter 246). Within a mechanistic approach, the body is made up of a series of systems that connect and relate to each other, and in order to diagnose and treat disease, each minute detail and function of each system must be understood. Under this premise, a great deal of experimentation and classification needed to take place in order to understand the entire machine of the human body. What this approach ignored was the logical question of how the machine became and remained animated. What, in other words, makes the machine live?

Many natural philosophers, medical practitioners, and scientists sought to answer this question, and factions within eighteenth-century medicine resulted. After all, "eighteenth-century scientific medicine was far from monolithic" (Porter 247). Divided and individualized as it was, eighteenth-century medicine is now characterized by researchers' attempts to understand how the body worked both as a machine and as something that appeared to be animated from a divine, or at least invisible, source. As Porter tells us, "There was more to life than the mechanical philosophy had dreamt of. But how was it to be explained in an era no longer prepared to 
entertain miracles or Galenic innate virtues?" (Porter 249-250). What resulted in this age of Enlightenment that valued tangible evidence, classification, order, and reason was a new field of scientific medicine based on empirical experimentation. Eighteenth-century medicine essentially started what we now refer to and "what was by 1800" referred to as biology (Porter 253).

Modern medicine could not exist without the theoretical work done during this time that helped establish how the human body and all other species work as biological systems. If the nineteenth and twentieth centuries are characterized by success breakthroughs in the practice of medicine, the eighteenth century should be thought of as the brainstorming and experimentation period that occurred before those practices could be successful.

\section{The Evolution of Medical Practice}

While many medical historians trace the professionalization of medicine to the government reforms and clinic-style hospitals of the nineteenth century, others, like Porter, trace it to the eighteenth-century Enlightenment. The physicians, surgeons, and apothecaries of the eighteenth century may have been less regulated, but that freedom enabled them to establish scientific medicine predicated on empiricism, experimentation, and analysis. This of course is not to imply that such inquiries were not made prior to the eighteenth century, but scholars have distinguished the time period for the significant change in the practice and experience of medicine that occurred as a result of larger cultural shifts in religion, politics, and knowledge. And as the stratification of the culture at large shifted, so too did the hierarchy of medical practitioners.

Early modern medical practitioners were primarily physicians who treated the aristocracy, and midwives or female healers using family recipe books treated everyone else. Medical practitioners of the eighteenth century consisted of physicians who treated the 
aristocracy and patients in a growing middle class; surgeons who gained professional recognition by the mid-eighteenth century; and man-midwives, apothecaries, and quacks. Several factors influenced the stratification and professionalization of the community of medical practitioners. First, the emphasis on university education for physicians and apprenticeships for surgeons as a means of professional credentials helped to marginalize women from practicing medicine. Second, the practice of medicine as a profession was largely unregulated in Britain. Porter reminds us that while countries such as France regulated education and licensing through universities, England's Royal College of Physicians lost most of its regulatory power as an institution during the Restoration (Porter 287-288). It confined its fellowships only to "graduates of Oxford and Cambridge and members of the Church of England," and as a result there were a large number of highly qualified physicians, surgeons, and apothecaries who did not receive a university education and were not part of the Royal College of Physicians (Porter 288). Physicians possessed a higher social position than most other types of medical practitioners for most of the century, and they were generally the most expensive medical service within the hierarchy of medical practice. They typically treated patients of the upper class and those becoming more affluent among the middling classes. Diagnosis involved a few common methods of sensory induction: smelling or tasting urine, palpating the patient's body, smelling the patient's breath, and a visual examination of certain parts of the body like the eyes, tongue, and general appearance. Treatment typically involved a dietary plan, a regimen for exercise or rest, and advice to take any myriad of drugs, most of which would look like natural remedies to contemporary patients.

Surgeons were significantly below physicians in terms of social and professional position. Before 1745, they were still associated with barbers, with the implication being that 
they were not medical practitioners but merely skilled labor. However, most surgeons went through extensive apprenticeships as well as a formal education. As the Company of Surgeons was formed and as surgery developed as a more scientific and technical field, their reputation in society increased. Surgery in the eighteenth century had the worst reputation in contemporary culture because the discovery of anesthesia did not occur until the nineteenth century. Surgeons, as a result, were not typically a welcome presence for eighteenth-century patients. They could perform any number of operations including amputation, but the most common procedures were the removal and laceration of boils, polyps, and teeth. They were also often responsible for bloodletting, a very common treatment wherein a small laceration was made for blood to leave the body in the hopes of restoring the body's natural equilibrium of fluids. Surgery was also cheaper than seeing a physician, and so surgeons sometimes served as both physician and surgeon to patients with lower incomes or in rural areas.

Apothecaries were responsible for making and selling the tinctures and drugs prescribed by physicians. Their medical services were the cheapest, and they were the least respected medical practitioners in society. Because of the free-market philosophy behind medical licensing and drug manufacturing, apothecaries could easily take advantage of patients by selling fake treatments. This was especially true outside of London, where "unregulated chemists and druggists blossomed, together with quacks and unorthodox practitioners. Beyond London, there was de facto liberty to practice, and a free-for-all ensued" (Porter 288-289). They are the precursor to contemporary pharmacists and the work done by many, despite more nefarious work done by others, provided necessary treatment to patients who could not afford surgeons or physicians. Moreover, apothecaries advanced the eighteenth-century development of drugs and treatment. 
Overall, medical practice was both helpful and unreliable because of a lack of regulation. Rather than a clear hierarchy of trusted medical practitioners, patients were faced with consumeroriented medical market geared towards making money. As a result, despite the vast advances being made in scientific research by eighteenth-century medical practitioners, medical practice itself as a profession and as an industry lacked credibility. Rather than a system that rewarded achievement in education, training, or success with patients, success in the medical free-market "depended upon a capacity to satisfy the public — by being expensive, by flattery, or by cutting a dash" (Porter 289). As such, the medical practitioner capable of, as Brock says, "actively... capitaliz[ing] upon one's place under the glare of media attention, [and] manipulate the forces of fame" could achieve greater success (10).

\section{Consumer Responses to Medicine}

Simultaneously, a consumer capitalist market was emerging as goods and services most people in previous centuries could have never afforded or have access to became increasingly available. As a free market was bolstered by increased interest in natural science, the medical market's supply and demand changed significantly. More people could access medical practitioners, knowledge about illnesses, and medical treatment. Prior to the eighteenth century, the vast majority of lay patients accessed medicine through recipe books, local midwives, and knowledge passed down through family members. The large cultural, economic, and political shifts that took place during and after the Restoration impacted that experience with medicine in several monumental ways. With the growing middle class of the eighteenth century, came an increase in patients who could pay to be treated by a physician, surgeon, or apothecary. With the rise of print culture and its increasing affordability, came medical tracts and advertisements 
offering patients information about illness and potential treatments. With a growing consumer culture, came a higher demand for medical practitioners and treatments.

These economic shifts enabled more patients to purchase medical services, and the number of medical practitioners grew to meet this demand. This growing consumer, capitalist market extended the demand for medical treatments and drugs as well. And these market forces encouraged competition amongst physicians and apothecaries to sell their services. The result of these economic influences was an unregulated commercialized medical market which Roy Porter has discussed at length, and his work informs a good deal of the analysis of commercialized medicine as depicted in Medical Celebrity. According to Porter, "In many respects eighteenthcentury medicine operated more like a trade than the lofty profession with which it has since sought to be identified. Patient-doctor relations were fluid; in a social regime dominated by patronage and clientage, physicians inevitably deferred to social superiors, and powerful patients expected doctors to fall in with their self-diagnoses and pet treatments... The sick felt no compunction about shopping around for second and third opinions, and made free use of quack, family and unorthodox remedies as well, adopting a try-anything mentality" (Porter 286). As was the case with theatre, literature, visual arts, politics, and other aspects of eighteenth-century culture, medical culture responded to patients who were increasingly becoming consumers. However, Enlightenment ideas were not accepted unilaterally or uniformly, and many patients, specifically those in rural areas and in the lower classes, still relied heavily on family recipe books, religious healers, and pseudo-scientific practices (Porter 282). Many of these practices were not without merit, and considering the treatments some physicians in London used on the wealthy, patients' decisions to self-medicate were often sound. A rising middle class with more expendable income to spend on physicians, nostrums, and antidotes sought medical 
treatment outside of the home. As such, a consumer-oriented medical market emerged: "With the rise of a literate public eager to exercise its judgment and consumer power, demand welled up for all sorts of healing, and the more the state and the medical authorities tried to clamp down on them the greater their popularity" (Porter 285). The changing landscape of how and why people sought treatment contributed to the change in the practice of medicine, the professionalization of medical practice, and cultural perceptions of medicine. But patients' consumer behavior on the market was not simply a response to the availability or affordability of services; rather, those behaviors were influenced by the rise in print media representations of medicine.

\section{Media's Impact on the Consumption and Practice of Medicine}

Changes in the type and availability of print materials, both written and visual, contributed greatly to shifts in cultural perceptions of medicine, illness, treatment, and practitioners. Eighteenth-century scholars such as Jennie Batchelor, Jeremy Black, Michael Caines, Sandro Jung, Gillian Perry, and Shearer West have traced the proliferation and impact of pamphlets, newspapers, magazines, tracts, novels, plays, memoirs, caricatures, miniatures, portraits, prints, and all sorts of other ephemera on an increasingly literate public. The shift in the amount of print material and the type of content from the early modern period to the eighteenth century was gradual, but it was incredibly significant due to developments in print manufacturing, circulation, and publishing. This increase in the amount of media consumed in the eighteenth century is not dissimilar to the dramatic shift in media that occurred with the development of the Internet in the late twentieth century. The rise of print media impacted the depiction and representation of nearly every part of eighteenth-century life, from political figures and current events to representations of sex, love, and religion. The depiction of illness, treatment, and medicine did not escape the eye of artists, authors, and commentators; on the 
contrary, it was one of the most frequently represented topics in both written and visual print culture.

Porter and others have discussed how the rise in medical texts changed the ways that patients perceived medicine and medical practice. Medical literature, advertisements for treatments, and reports of illness in newspapers, magazines, and pamphlets all contributed to the commercialization of medicine. Print media served as a way for medical practitioners to establish their reputations within their field through professional publication and to the public. Moreover, print media afforded patients and consumers information about medicine and spotlighted certain treatments and illnesses. But medical literature was just one form of print media that influenced cultural perceptions of medicine.

Literary representations of medicine, medical practitioners, illness, and treatment abounded, and the increase in availability of literature and the amount of literature produced impacted cultural perceptions of medicine as well. From the doctor in The Country Wife to Dr. Slop in Tristram Shandy, to Victor Frankenstein, eighteenth-century authors frequently represented, and typically satirized, medicine and illness. Often depicting quack physicians and practices, literary representations helped cultivate a skeptical consumer/patient who was apt to shop around for various treatments and practitioners. At the same time, literary representations also served as a way for patients to acquire medical knowledge, whether sound or unsound.

While nonfiction and literary representations of medicine were incredibly important to the development of cultural perceptions of medicine, the biggest shift in the type of content consumed in the eighteenth century was visual print culture. Developments in manufacturing made the mass production of visual prints possible, and visual depictions that used to be reserved for the wealthy who could afford sculptures, paintings, and portraits were now available to the 
middling classes. The mass consumption of visual media we are so accustomed to now began in the eighteenth century, and visual depictions of every aspect of life, including medical culture, illness, and treatment, flooded the market. Engravers and illustrators such as William Hogarth, James Gillray, and Thomas Rowlandson frequently depicted medical practitioners, treatments, patients, and illness in numerous caricatures and prints. Two of Hogarth's most famous print series, A Rake's Progress and A Harlot's Progress, depict the experiences and ultimately the demise of the two main characters as they move through eighteenth-century urban life. In each, several scenes feature the medical treatment that the characters experience. In A Harlot's Progress, as Moll lays dying from venereal disease, her physicians are shown arguing and ignoring their patient. Similarly, in A Rake's Progress, Hogarth portrays Tom in Bethlehem "Bedlam" Hospital, signifying his descent into madness while shedding light on the mistreatment of patients at the well-known asylum. Visual depictions such as these criticized medical practice but drew attention to medical culture in general.

Many scholars have investigated the cultural impact of the rise in visual culture, and works like Fiona Haslam's Hogarth to Rowlandson: Medicine in Art in Eighteenth-Century Britain (1996) examine the impact of visual depictions of medicine in particular. For Haslam, these illustrations and caricatures possessed a great potential to influence eighteenth-century perceptions of medical knowledge and practice. She argues that while they provide a window into eighteenth-century medicine, they should be read primarily for what they signified and represented to eighteenth-century consumers (13). These artists did not merely represent and satirize medicine within a vacuum, rather their works had direct impact on cultural perceptions of medicine, which often translated into what patients were willing to tolerate or interested in pursuing and, economically speaking, which treatments and services they would purchase from 
practitioners. For example, in Thomas Rowlandson's Transplanting of Teeth (1787) he "drew attention to the practice of transplantation of teeth, whereby the poor, in return for a small fee, could be persuaded to relinquish their teeth for the benefit of the rich. This practice fell into disrepute partly because of the publicity resulting from Rowlandson's print" (Haslam 6). As such, media, both written and visual, played a significant role in the development of medical knowledge and practice in the eighteenth century and on the medical market. Media, therefore, emerges as one of the cultural mechanisms capable of influencing the kind of cultural attention paid to disease, illness, and treatment, and ultimately the role of medicine within the culture.

Interestingly, because medicine was portrayed by popular media that circulated within a consumer market, these representations had the ability to create trends and fashions within the market. Indeed, the eighteenth century is often attributed with our contemporary understanding of fashion or the idea that something could be fashionable. Moreover, fashion, a term associated with eighteenth-century consumerism, sensibility, taste, luxury, and elitism, also became associated with certain types of illness and disease. Eighteenth-century scholars and medical historians have identified this phenomenon as the fashionable disease and illness, which was constructed primarily through representations of illness in literature. In his work on the development of fashionable diseases, David E. Shuttleton tells us that "Literature, in the broadest sense, disseminated notions of fashionable disease" and the "print explosion meant that academic medical terminology, traditionally the obfuscating preserve of the learned physician, readily precipitated out into other genres and broader communities of readers" $(273,274-275)$.

Scholars agree that these trends in disease and treatment were primarily the result of representations of disease and access to those representations that had not previously existed. As Shuttleton says, "This medico-literary convergence was enabled by specific material practices: a 
commercial landscape in which accessible medical books were being marketed and consumed alongside the emergent novel and other popular literary forms" (278). But they also agree that in order for something like disease to become fashionable, a phenomenon that seems to defy logic and reason, the diseases had to be associated with more than just wealth, class, or a certain lifestyle, and indeed eighteenth-century conceptions of sensibility contributed heavily to rise of fashionable diseases. Shuttleton tells us, "for a disease to be fashionable there must be at least some symptoms that can be presented in a positive light for bestowing heightened creativity, greater emotional sensibility, or finer social discrimination" (271-272). Certain diseases, particularly towards the latter part of the century, became linked to sensibility — what a person can feel and experience because of his or her emotional capacity versus simply their external environment.

Scholarship on fashionable illness credits George Cheyne's The English Malady; or a Treatise of Nervous Disorders (1733) with helping to establish the connection between disease and sensibility. Cheyne's text drew the connection between nervous disorders and those privileged enough to live a life of leisure, "claim[ing] that nervous complaints [were] the prerogative of the upper and middling ranks possessed of delicate constitutions" and as such, nervous disorders became known "under the one potentially flattering, patriotic label 'The English Malady"' (Shuttleton 274, 275). His text along with others depicted certain conditions as symptoms of wealth, position, and constitutions susceptible to sensibility and feeling. Thus, disease, illness, and treatments became not only a means of maintaining one's wealth, position, and status, but also a means of demonstrating a disposition of sensibility and potentially acquiring a more favorable position in society as a result. As a result, the reasons behind a patient's complaint of a fashionable disease were often called into question. 
The threat and potential for patients to fake illnesses in order to maintain or acquire an association with the wealthy and with a certain type of disposition became a concern for practitioners and medical commentators. Scholars of fashionable disease have explored this question as well. As Jessica Monaghan demonstrates in her study of fashionable disease and authenticity, the symptoms and experiences of patients were consistently questioned and scrutinized, lest they be faking for the sake of status (402). An incredibly insulting and problematic assumption as that may be, it was nonetheless a common reality in a culture when possession of a disease signified cultural position as well as symptom.

These medical and literary representations of these diseases had the potential to create fashions, or trends, in illness and treatment because they circulated within an increasingly commercialized, consumer-oriented medical market. The increase in treatments, types of maladies, medical practitioners, recipe books, self-help treatments, and a patient-doctor relationship rooted in consumerism contributed to the rise of fashionable diseases. In his work on the development of fashionable diseases, Clark Lawlor writes, "Fashionable disease was, and is, partly a product of the medical market, which itself is a subset of capitalism in general" (380). The medico-literary market helped to establish fashionable disease as a cultural phenomenon which then increased demand on the medical market for certain treatments, and as we have established, potentially certain diagnoses. Moreover, the market influenced how patients and practitioners interpreted symptoms, understood disease and treatment, diagnosed disease, and prescribed treatment. This, the degree to which fashionable disease had the potential to influence the patient's experience of disease and treatment and to influence the development of medical knowledge is what scholars on the subject are ultimately most interested in. Their work establishes one of the major premises taken by this dissertation: that cultural forces such as 
fashion and print culture had the ability to impact individual and cultural perceptions and experiences of illness, treatment, and medical practice. Fashionable disease, I would argue, is one product of a culture of medical celebrity. But their work contributes to the validity of this dissertation's central argument that cultural mechanisms shaped medical culture.

\section{Medical Celebrity Culture}

The work of scholars on fashionable diseases and treatment is foundational to the claims made in this dissertation, because they demonstrate one of the most profound examples of how the eighteenth-century medical market operated along the lines of celebrity culture. Scholars have also done extensive work on the commercialization of eighteenth-century medicine, the rise of fashionable diseases, and the rise of celebrity culture, and many common threads emerge within the literature: the formation of eighteenth-century consumer and commercial culture, the relationship between the consumer and the marketplace, the influence of literary and visual representation on cultural perceptions, the rise of print and visual culture, and the creation and role of reputation on the market. But despite these numerous overlaps in the research, there has been no study arguing that the culture of medicine and the culture of celebrity impacted on another or that they developed because of similar cultural mechanisms. This dissertation seeks to remedy this gap in the literature by proposing a new theoretical framework to analyze the rise of modern commercialized medicine and the rise of, what I call, modern medical celebrity culture.

Medical celebrity culture refers to the ways in which the medical industry uses celebrity culture and individual celebrities to increase the cultural, economic, and social cachet of certain practitioners, illnesses, and treatments. In contemporary culture, examples of this abound, such as celebrity promotions of medicines or endorsements of medical facilities, the commodification of illnesses like breast cancer, and marketing campaigns capitalizing on cultural trends to 
promote treatments or medical knowledge. Medical celebrity culture also refers to the cultural attention placed on celebrities' experiences with illness, health, and treatment and the impact those experiences can have on their celebrity. Examples include Julia Louis Dreyfus's representation of her recent breast cancer diagnosis on Instagram, Lance Armstrong's public battle with testicular cancer, or the many celebrity deaths that spark cultural conversations about the medical causes of those deaths.

Medical celebrity culture is ubiquitous in contemporary culture for many reasons, including the proliferation of information about celebrities via technology and social media, but also because of the popularization of medicine as a form of entertainment. Non-fiction television shows like "The Doctors," "Life in the ER," or "My Strange Addiction" exist in the same cultural moment as popular TV dramas like "Grey’s Anatomy," "ER,” or "The Good Doctor." Medical culture and knowledge as content for entertainment has contributed to the role celebrity plays in the contemporary medical profession wherein medical practitioners can become famous on social media as stars in their own right or through their association with celebrity culture. As such, in contemporary British and American culture, it is impossible to draw a distinct line between medical and celebrity culture, but this line has not existed for a long time.

This dissertation argues it is in the eighteenth century that we find the roots of medical celebrity culture. The scholarly work on fashionable disease and illness demonstrates the existence of one byproduct of medical celebrity culture: the ability for media representations of disease, illness, and treatment to create trends in interest and consumption. However, there are many other examples such as the way medical practitioners used marketing and advertising to promote their services; the numerous plays and novels that satirize medical practice and treatment; the publicity of the illnesses and treatments of famous individuals; the marketing and 
advertising of certain medications; and the fame and celebrity achieved by medical practitioners. These are all byproducts and examples of a medical celebrity culture wherein the culture's relationship to, perception of, and experience with medicine is inextricably linked with the culture's relationship to, perception of, and experience with celebrity. This dissertation examines the cultural mechanisms that created a medical celebrity culture in the eighteenth century in order establish a new theoretical framework whereby we may understand the lived experience of medicine of eighteenth-century and contemporary medical practitioners and patients. Ultimately, this theoretical framework for analyzing medical celebrity culture stems from the sociocultural phenomenon I have identified in eighteenth-century Britain: medical celebrity.

\section{What is Medical Celebrity?}

Medical celebrity is a sociocultural phenomenon wherein the cultural mechanisms that create celebrity (media, consumers, desire, fans, publicity, prioritization of the individual, etc.) help create cultural representations and perceptions of medicine, the medical market, and the medical profession. When this sociocultural phenomenon occurs, a medical celebrity culture is created, whereby the development of medical knowledge, the practice of medicine, and the role of medicine in the culture are inextricably, and often imperceptibly, linked to and dependent upon celebrity and its role within the culture. Medical Celebrity in Eighteenth-Century Britain argues that this sociocultural phenomenon began in eighteenth-century Britain, and in order to understand our contemporary medical celebrity, we must first examine the roots of the sociocultural phenomenon in the eighteenth century. The dissertation also operates under the basic premise that in order to understand the development and cultural significance of both medicine and celebrity in the eighteenth century, we must first eliminate the implicit assumption in the scholarship and in our contemporary cultural awareness that these two cultures are not 
linked. Ultimately, identifying and analyzing medical celebrity as a sociocultural phenomenon allows us to see how it constructs practitioners' and patients' every day experience with, relationship to, and perception of medicine. The case studies that follow examine how medical celebrity impacted four specific aspects of medical culture: the medical profession, the consumer medical market, cultural perceptions of illness versus health, and representations of medical treatment. Moreover, my work on medical celebrity is ultimately concerned with how practitioners and patients experience medicine within a culture of medical celebrity, and the chapters examine how medical celebrity exists at the intersection of the patient, the medical practitioner, and the public.

Many famous patients, diseases, cases, practitioners, and medical developments could have served as the content for the case studies in this dissertation. Examples include George III's madness, Mary Toft's litter of rabbits, Alexander Pope's poor health, Edward Jenner's smallpox vaccination, the fashionable treatments at Bath, and many more. Additionally, I could have chosen to pick a specific fashionable disease and establish that medical celebrity was at the root of its fashionability. Admittedly, the cases that follow are certainly not the most well known medical cases in the eighteenth century from the perspective of contemporary scholars. However, each chapter presents a case study that would have been incredibly famous and well known during its time, and by choosing cases that some scholars may be less familiar with today, I mean to imply that medical celebrity existed to such a great extent in the eighteenth century that we need not look for it just in the most famous cases. Rather, we can find medical celebrity at work at all levels of fame. Future studies should examine the ways in which medical celebrity changes based on the level of fame achieved by the individual. 
Gender also informs the selection of cases presented in this dissertation. The predominant work done by scholars on medicine in the eighteenth century focuses on the experiences and representations of male practitioners and patients. When women are discussed in the scholarship, it is typically within the realm of fashionable diseases or in discussions of mental health. I have chosen to focus on the experience of illness and treatment of three famous female subjects in order to add their narratives to our picture of women's experience of illness, diagnosis, and treatment in the eighteenth century. Future studies should be conducted to recover the work of female medical practitioners and interrogate how medical celebrity impacted their experiences outside of the medical profession. The selection of case studies that follows serves merely as the beginning of a typology of medical celebrity.

The first chapter examines how celebrity influenced the development of the medical profession of surgeons in eighteenth-century London through a case study of different types of fame acquired by John and William Hunter. Both brothers were incredibly successful anatomists and surgeons who achieved recognition during the second half of the century when surgeons, as a whole, were vying for professional prestige, social mobility, and cultural recognition. This case study of the Hunter brothers demonstrates how John managed to acquire celebrity status, while William only managed to achieve an extensive level of fame and both brothers' legacies were shaped by the cultural mechanisms of reputation, public persona, and public interest. By applying contemporary celebrity theory, such as Joseph Roach's theory of "It," to define and distinguish between celebrity and fame, I argue that John Hunter's persona and how he crafted that persona influenced perceptions of him within the scientific community, patients, and the general public. His persona, as opposed to William Hunter's, capitalized on the "It" quality that enables celebrities to captivate audiences and influence their perceptions. I create a case study of 
each brother's fame through close readings of their memoirs, biographies, and portraits. These case studies reveal that John's celebrity status enabled him to influence cultural perceptions and representations of surgeons and scientists in general. Ultimately, this chapter argues that the cultural mechanisms of reputation, public persona, and public interest affected how the profession of surgery developed to favor the persona of surgeons like John Hunter and impacted the cultural perception of surgery in the eighteenth century.

The second chapter continues the focus on medical practitioners but turns to establish how medical celebrity impacted the medical market. In this case study, the surgeon John Ranby published a pamphlet that exploited the fame of his patient, the Earl of Orford, that led to a pamphlet war as an attempt to shape the viability of a specific drug on the medical market. While pamphlet wars between medical practitioners were common in the eighteenth century, I argue that Ranby was not merely criticizing the physicians involved, but he also attempted to exploit the public recognition and cultural cachet of Walpole in order to influence public perception of the new drug, lithontripic lixivium. I provide a close reading of Ranby's Narrative and the other pamphlets to demonstrate both how Ranby positions the Narrative as a document intended for public consumption and how the other pamphlets discuss his appeal to the public. I conduct this close reading within the context of the eighteenth-century medical market and the purchasing power patients possessed as consumers of medical treatments and services. Finally, I apply contemporary celebrity theory to my interpretation of the potential impact of the Narrative on the medical market and Ranby's exploitation of Walpole's fame. The pamphlets when read in this context and when conceptualized along the lines of Turner's theory of celebrity as a cultural process, reveal that Ranby's Narrative used rhetoric and print culture to harness Walpole's public recognition in order to denigrate the reputation of the lixivium and ultimately impact its 
viability on the medical market. Ultimately, this chapter demonstrates how medical practitioners used the cultural mechanisms that create and sustain celebrity culture - specifically print media, reputation, and public recognition or fame. Thus Ranby's Narrative, and potentially other works published by medical practitioners, interact with celebrity culture to produce a medical-celebrity print culture wherein doctors influence public perceptions of medical treatments through appeals to public recognition, reputation, desire, etc. rather than just empirical evidence. As a result, I argue that this case study demonstrates the existence of the sociocultural phenomenon of medical celebrity as an influence on the medical market.

While the first two chapters establish some of the ways that medical celebrity impacted medical practitioners, the third and fourth chapters establishes how medical celebrity impacted patients' experiences of illness and medical treatment. The third chapter examines how celebrity impacted cultural perceptions of illness versus health in a case study of two actresses, Susannah Cibber and Peg Woffington, whose celebrity personas, relationships to audience, and reputations were inextricably linked to their experiences of illness and health. Susannah Cibber achieved celebrity as a dramatic actress and singer despite a stomach illness that plagued her for most of her life. I analyze the impact of this illness and the public discourse surrounding it on her career and her relationship with audiences. By examining memoirs, biographies, and letters about Cibber in conjunction with medical texts, I reconstruct her illness and treatment to establish her experience as a patient. I then argue that the theater, as a cultural mechanism of celebrity, allowed her experience as a patient to influence the audience's perception of her as an actress, fueling their loyalty and impacting her celebrity status. I argue that Cibber's success as a celebrity was connected to her reputation for being ill, whereas Peg Woffington's celebrity was connected to her reputation for being well. While Cibber was known for a chronic stomach 
illness that often made her unavailable for performances, Woffington self-fashioned a persona connected to her devotion to her audiences and her insistence to appear on stage despite illness. That insistence resulted in an on-stage stroke, the spectacle of which I analyze as the moment when Woffington's celebrity persona was impacted by illness. As such, this case study demonstrates how celebrities' experience of illness and health, status as patients, and the public perceptions of them impacted their relationship to audiences and their celebrity status.

Ultimately, I argue that the cultural mechanisms of fans, fashion, reputation, and self-fashioning impacted public perceptions of illness versus health.

The final chapter establishes how medical celebrity impacts a patient's experience of medical practitioners, diagnosis, and treatment and their representation of that experience. Whereas the first three chapters each focused on how medical celebrity impacted medical practitioners, print culture, and patients, this chapter presents a case study of Frances Burney's mastectomy, where all three are present. I argue that the letter Burney wrote detailing her mastectomy reveals the social network, relationship to medical practitioners, and access to medical treatment that her celebrity afforded her. Moreover, I establish the fame and celebrity of her two primary physicians and argue that both their fame and her fame influenced Burney's experience of diagnosis and treatment. Finally, I provide a close reading of Burney's description of the operation itself to argue that her procedure was likely informed by a popular textbook on surgery. As such, this chapter establishes how medical celebrity enabled both the operation itself and the posterity of her letter about the event. Ultimately, I argue that Burney's letter is an example of the intersectionality of medical celebrity culture wherein media, representation, access, reputation, fame, and other cultural mechanisms that create celebrity dramatically impact 
how patients experience the process of being treated for an illness medicine and how it is represented.

The consequences of medical celebrity in these case studies are both positive and negative. They demonstrate how medical celebrity allows medical practitioners to self-fashion their reputations but also enables bias in the medical profession: how it enables the exploitation of the fame of patients but also helps inform public audiences of certain medical treatments; how it gives audiences access to celebrities' experience with illness and medical treatment which can destroy their career or bolster their fan base; and how it fuels the social and production networks along which significant medical interventions occur but also enables access to medicine and experiences of treatment that prioritize fame. As such, it behooves us to conduct future analysis on the impact of medical celebrity on our contemporary culture in order to identify areas where medical celebrity both negatively and positively impacts the practitioner and patient experience of medicine. These negative and positive impacts might include the ways medical celebrity enables access to those with fame and wealth but limits it to those without, how medical industries manipulate consumers through marketing and advertising, how celebrity experiences with illness and treatment impact audiences' understanding of illness and treatment, proliferation of medical knowledge through online platforms like social media and news outlets, celebrities' ability to spread awareness of illnesses and treatment, or the influence celebrities have over the medical decisions patients make. If we begin to analyze how celebrity impacts our everyday lived experiences of medicine, the medical profession, and the commercialized industry of medicine, we will be in a better position to train practitioners, inform patients, and create policy to regulate the industry. 


\section{Chapter 1}

Blood Brothers: The Medical Celebrity and Fame of John and William Hunter

Every other year on Valentine's Day, the Royal College of Surgeons commemorates the birth of John Hunter (1728-1793), a celebrated surgeon and anatomist. Eight months later, in mid-October, the members of the Hunterian Society attend a service at Westminster Abbey and gather around his grave to commemorate his death. The two organizations have been practicing this ritual for almost a combined 400 years. The Royal College of Surgeons began their birthday celebrations in 1813 after the government purchased Hunter's anatomy collection from his two heirs, his nephew Matthew Baillie and his student Everard Home. The Hunterian Society was a little late to the party and only began commemorating his death in 1819 , when it was founded in order to "honour John Hunter, the Father of Scientific Surgery, to whose lifetime of teaching and innovative experimentation the Society was then, and is yet now, dedicated to celebrate" ("Beginnings"). Their website currently displays a picture of the wreath laid at Hunter's grave at the last meeting in October 2016. A distinct feature of both societies' ceremonies is the oration given every year that celebrates surgery and John Hunter's life and work. The speeches given biannually at both ceremonies are among the many narratives of Hunter's life which contribute to his reputation as "the Father of Scientific Surgery." But how do medical practitioners from the past acquire such grandiose titles and manage to make their legacies extend beyond their time period? More importantly, how does that process impact the way medical history gets recorded? These are two of the main questions at the center of this chapter.

\section{Part I: The Celebrity of Medical Practitioners}

Eighteenth-century medical practitioners did not possess the social status they do in contemporary culture, but the rise of print and consumer culture enabled medical practitioners to 
reshape their reputation. As physicians were able to advertise to patients and more patients acquired the means to be treated by someone outside of midwives and apothecaries, a market for medical practitioners grew. With little regulation of the profession, quacks with their poisonous tinctures and faulty treatments quickly flooded the market. Physicians and surgeons - the latter of whom were mistrusted more than their university-educated colleagues — worked to regulate their profession as they advertised to an increasingly discerning market. The professionalization of surgery officially began when they formed the Company of Surgeons in 1745, and continued into the nineteenth century. A physician or surgeon needed to establish credibility within the medical community through publication, lectures, and demonstrated skill, while also establishing visibility to a large portion of the population capable of choosing their own medical practitioner. ${ }^{2}$

As eighteenth-century medicine became increasingly commercialized, the role of practitioners changed as well. Roy Porter discusses how market forces impacted the degree to which practitioners needed to make themselves more appealing to patients as the increase in print culture publicized medical practitioners, patient experiences, and treatments. ${ }^{3}$ While he and others have discussed the processes and results of the commercialization of medicine as it impacted the medical profession, heretofore, no one has claimed that these processes were related to the development of celebrity culture in the eighteenth century. This, in spite of the fact that the cultural mechanisms that enabled celebrity culture are the same cultural mechanisms that enabled commercialization of medicine: reputation, marketing, public appeal, advertising, fame,

\footnotetext{
${ }^{2}$ I use the phrase "large portion" loosely here to imply that there was an increase in the number of patients financially able to be treated by physicians, but this portion of the population clearly refers to those in the upper and merchant classes residing in urban areas. Patients living below a certain income and those of any class living in rural areas would have still had little access to physicians, let alone a market in which they could choose a physician and course of treatment.

${ }^{3}$ See Health for Sale: Quackery in England 1660-1850 (1989), The Greatest Benefit to Mankind, and The Greatest Benefit to Mankind (1997), and Bodies Politic: Disease, Death, and Doctors in Britain, 1650-1900 (2001).
} 
etc. As such, we cannot understand the development of the medical profession in terms of how the role of medical practitioners evolved in the eighteenth century without first interrogating how the careers of medical practitioners interacted with and were influenced by celebrity.

This chapter examines how the cultural mechanisms that enabled celebrity impacted the development of the medical profession as a whole and of medical practitioners in particular. I identify the cultural mechanisms of fame, reputation, public persona, and public appeal in the lives of two surgeons and argue that these mechanisms contributed to their success, both in life and afterwards. I present the case study of the Hunter brothers to demonstrate how celebrity impacted the careers and legacies of two incredibly similar practitioners in very different ways. I argue that while John achieved celebrity, William (1718-1783) only achieved a high level of fame. ${ }^{4}$ By establishing and proving this distinction, I demonstrate how celebrity impacted their lives and legacies differently, which impacted how their lives and their work were recorded in medical history. Scholars such as Laura Engel, Fred Inglis, Joseph Roach, and Cheryl Wanko have argued that individuals became famous in the eighteenth century by self-fashioning through portraits, memoirs and autobiographies, newspapers and press, and public appearances in order to craft a public persona, and by extension, a public interest in that persona. ${ }^{5}$ Similarly, I examine

\footnotetext{
${ }^{4}$ The edited collection, William Hunter and the Eighteenth-Century Medical World (2002), presents an argument about William's place in medical history that runs adjacent to my argument about his fame. The collection seeks to rectify the neglect William Hunter has endured from historians. The editors state that it is not their intention to "debunk John" but rather to "spotlight his elder brother William" (Bynum and Porter 1). The collection addresses three reasons to explain why William has been forgotten: "first, there has been a simple lack of information about his life and works...second, Hunter, does not really fit into stereotypes of the medical men and medical scientists with which medical historians commonly work...[and] the third reason...is that so much of the background fine texture of eighteenth-century medicine remains to be explored" (Bynum and Porter 3). Certainly, these explanations are all true, but the collection fails to give due diligence to the difference in celebrity that William and John experienced. The editors give nod to the importance of celebrity in their initial explanation, claiming that William "failed to capture the imagination of succeeding generations of surgeons and obstetricians, or provide them with a serviceable icon to worship and ideal to emulate" (Bynum and Porter 1). But they do not conceptualize celebrity beyond this statement. The collection serves as a recovery of William's cultural significance from the shadows of medical history, and informs the presentation of William's biography and cultural significance presented here.

${ }^{5}$ See Laura Engel, Fashioning Celebrity: Eighteenth-Century British Actresses and Strategies for Image Making (Ohio State University Press, 2011); Fred Inglis, A Short History of Celebrity (Princeton University Press, 2010);
} 
how William and John's public personae, portraits, and posthumous narratives contribute to the degree to which they captivated public interest during their lives and after.

In this chapter, I refer to fame and celebrity as two distinct categories wherein fame is merely one attribute of celebrity. My definition of fame refers to renown within one's profession and certain portions of society, and builds on the distinction between renown and celebrity as made by Fred Inglis in The Short History of Celebrity. Inglis claims, along with Joseph Roach, that in the sixteenth and seventeenth centuries, cultural idolization shifted from religion and the monarchy to the emerging cultural conception of the individual. Fame and renown as cultural signifiers of social capital and power could be associated with individuals who became, or made themselves, public figures. Inglis claims that fame and renown of the individual are the precursors to contemporary celebrity. I interpret his definition of fame to be a subset or quality of celebrity. Fame, as it is used in this chapter, is the degree to which a physician becomes well known within the eighteenth-century medical community and among other public figures because of their work and social networking. Fame should be distinguished from reputation insofar as reputation depends upon one's merit or lack thereof, whereas a physician can be famous regardless of their reputation.

I define the celebrity of medical practitioners by adapting theoretical approaches of contemporary celebrity scholars Graeme Turner, Chris Rojek, and Joseph Roach for eighteenthcentury celebrity culture. ${ }^{6}$ According to celebrity theorist Graeme Turner, celebrity is "a media process that is coordinated by an industry, and as a commodity or text which is productively

\footnotetext{
Joseph Roach, It (University of Michigan Press, 2007); and Cheryl Wanko, Roles of Authority: Thespian Biography and Celebrity in Eighteenth-Century Britain (Texas Tech University Press, 2003).

${ }^{6}$ This methodology of applying certain tenets of contemporary celebrity studies to analyses of eighteenth-century celebrity comes from the work of scholars in celebrity studies like Joseph Roach, Laura Engel, and Cheryl Wanko. One of the premises of early celebrity studies is that celebrity of the eighteenth century serves as antecedents to contemporary celebrity. As such, theoretical approaches are often adapted across time periods in order to analyze how celebrity functions in a culture and how it develops.
} 
consumed by audiences and fans" (23). I, and others, interpret this for the eighteenth century to mean that celebrity functions as an industry of image making and fame which influences cultural conceptions of the individual and the self. As such, in order for medical practitioners to be famous, their images must be produced and replicated during their lifetime and afterwards. Contemporary celebrity also requires public interest in an individual. Chris Rojek claims that perception of a split between the public and veridical (private) selves fuels public interest (Rojek 11). Celebrity arises when the viewer desires to see both the public and the private selves, and to work around the split (Rojek 11). When we are not interested in a person, we do not really perceive this split because there is no curiosity about what someone is really like or what they are like at home. In order for celebrity to occur, that interest must exist. Turner interprets Rojek's theory to declare that, "we can map the precise moment a public figure becomes a celebrity. It occurs at the point at which media interest in their activities is transferred from reporting on their public role (such as their specific achievement in politics or sport) to investigating the details of their private lives" (8). In adapting this concept to theorize eighteenth-century medical celebrity, I argue that the same must be true for medical practitioners to be celebrities - there must be a representation of a public and private self that captured people's interest. But what initially sparks this interest? It can be many things. For the other celebrities in the dissertation, it is often their artistic contribution, such as with the actresses presented in Chapter 3 and the author studied in Chapter 4. Public interest might also arise because someone is in a position of power and their actions impact the lives of others, such as the prime minister studied in the next chapter. Typically, public interest arises from a mix of two things: the person contributes something that speaks to the cultural zeitgeist, and the person possessing some form of what Joseph Roach calls the "It" factor. Later in the chapter we will examine It more thoroughly, but it 
essentially refers to a "strange magnetism" that draws people in so that they are interested in someone enough that the person almost transcends their humanity (Roach 4). So, for medical practitioners to capture public interest, they would need to contribute something that speaks to cultural interests and possess some form of the It factor.

In short, the celebrity of eighteenth-century medical practitioners requires fame but also requires three things: 1 . representations that are produced and replicated during and after their lifetime, 2. public interest in the physician's public and private selves, and 3. capturing public interest because of their contributions to cultural interest and their It factor. I argue that while both Hunter brothers achieved the first requirement, only John achieved the second two. The result of that difference is that while John's life, work, and legacy is revered and almost worshipped after his death, William's life, work, and legacy remained in the shadows. Reconstructing their fame and celebrity, as such, reveals how the cultural mechanisms of celebrity shape both the success and lives of medical practitioners in the eighteenth century —and how they shape the process by which we record medical history, and how we codify the cultural definition of a successful medical practitioner.

Ultimately, I argue that while merit and impact on the field were certainly major influences on the success of medical practitioners in the eighteenth century, so too was celebrity. Moreover, the power of celebrity to impact public perception influenced how medical practitioners were memorialized, and how they exist in medical history. As such, in order to understand medical knowledge and history as epistemological categories, we must understand the ways in which celebrity influenced the narratives by which they are constructed. To put it simply, William and John Hunter both contributed greatly to the study of anatomy, surgery, and medicine. But we remember John and forget William because John makes a more compelling 
and interesting figure, which lends itself more easily to celebrity. This chapter will analyze how exactly John was made into a more compelling and interesting figure, by examining William and John's dispositions, public personae, visual representations, and the narratives written about each posthumously.

\section{Part II: The Brothers' Biographies}

\section{Background}

William and John Hunter were born "on a small estate in [the] parish of Long

Calderwood" in Lenark County, Scotland (Simmons 1). ${ }^{7}$ Their father sent William to the College of Glasgow at the age of fourteen to join the church. However, William met Dr. William Cullen, a country doctor who would go on to achieve great fame and success in his career, and he decided to "devote himself to the profession of physic" (Simmons 1). After working with Cullen, William decided to leave Scotland for the promise of greater success in London, where he first resided with Dr. Smellie, the well-known obstetrician, and then had an apprenticeship with Dr. James Douglas, a wealthy, reputable, and established physician with many social connections. Smellie inspired William's interest in obstetrics, while Douglas influenced his decision to stay in London and establish his own practice instead of returning home to work with Dr. Cullen. While working for Douglas, William attended Saint George’s Hospital as a surgeon's pupil and “soon became [an] expert in dissection" (Simmons 3). After writing his first essay for the Royal Society, he decided to become a lecturer of anatomy, the specialization for which he became widely respected by his contemporaries.

\footnotetext{
${ }^{7}$ William was the seventh and John the youngest of ten children, most of whom did not survive into adulthood. Their two older brothers died as young children and their brother James died in his late twenties; only William, John, and their sister Dorothea survived past their thirties. Dorothea (1721-1806), married Rev. James Baillie and was mother to the physician Matthew Baillie (1761-1823), the famous author Joanna Baillie (1762-1851), and their sister Agnes (1760-1861).
} 
He was employed in 1746 by "a society of Navy surgeons" to provide lectures on "operations of surgery," and he was so successful that they asked him to lecture on anatomy as well (Simmons 5). This was the start of William's impact on the education of anatomists in London, which he professionalized by offering more frequent and rigorous courses. William was popular as a lecturer because of his delivery and knowledge, and his courses provided him a healthy income. His success led to his appointment as the Professor of Anatomy at the Royal Academy of Art in 1767. He petitioned the government for land in order to start the first public anatomy school, but was denied. Instead, he built a residence at Great Windmill Street to house the school in 1768 . He practiced both surgery and midwifery in addition to his work as a lecturer and anatomist, and he became a popular obstetrician (man-midwife) with women of the aristocracy. His success in this area culminated in his appointment as Physician Extraordinary to Queen Charlotte, which gave him access to the most important and fashionable members of society. He associated with public figures such as "Joshua Reynolds, Hester Thrale, Charles Burney, and David Hume" (Gruber n.p). As the first professor of anatomy for the Royal Academy of Art, William associated with the best and most famous artists. Not only was he successful, but he was well-liked and respected by his students, pupils, patients, and acquaintances.

William died in 1783, after exhausting himself giving a lecture while ill. He provided for his sister and her children: his nephew Matthew Baillie, whose education and career he had taken charge of, and his nieces, Joanna and Agnes. He died possessing financial wealth and a remarkably extensive museum, which was housed at Great Windmill Street. He left his collection and library to Glasgow University, which formed the foundation of the current Hunterian Museum at the University. 
His younger brother, John, achieved an equal and in some cases greater degree of success as a surgeon, anatomist, and collector, but his path to success was not quite as linear as William's. While William went to school and then college as a young boy, John hated school and was barely literate as a teenager. Instead, he spent time studying plants, animals, and insects in their natural habitats. John worked as a carpenter with his brother-in-law until he was twenty, when he went to London to work for William, who was thirty and already running successful anatomy courses out of Douglas's house. Under William's teaching and employment, John learned how to make preparations, dissect specimens, and master anatomy, and he began lecturing. He worked for William for twelve years, and during that time he tried to gain the professional training and credentials to join the Company of Surgeons, but did not fare well in the various schools that he attended. Presumably he loathed formal education as much as an adult as he had as a young boy. As a result, in 1760, he enlisted in the "army as a staff surgeon" to serve during the Seven Years' War (Gruber n.p). His service allowed him to achieve the credentials he needed to join the Company, and when he returned to London in 1763, he "found rooms in Golden Square only a few streets from his brother's now successful Jermyn Street establishment" and began working for James Spence as a dentist-surgeon until he could establish his own practice (Gruber n.p.).

Dentists were usually associated with quacks, and surgeons made great efforts to separate from them, so John made the best of his less financially and professionally fruitful position. He took on students to help pay for his expenses and began studying and conducting experiments related to human teeth. His time working for Spence culminated in his first substantial publication, A Treatise on the Natural History of Human Teeth (volume 1 appeared in 1771 and volume 2 in 1778). His work enabled him to purchase a house at Earl's Court, a rural area just 
outside of London, where he could keep the numerous animals he observed and used for experiments. In 1771, John took over the rest of the lease on William's practice at Jermyn Street when his brother moved to Great Windmill Street. The location allowed him to establish a surgical practice and provide more regular lectures. In that same year, he married his wife Anne Home, who had a greater and more reputable social network than John. Anne was a poet who associated with people such as Hester Thrale and Samuel Johnson, and she was an amiable and charming host. With Anne's help, John prospered both domestically and professionally.

By 1783 , he needed to move to a larger location to house his family, students, and growing anatomical collection. Only a few blocks away from his brother's well-known Great Windmill Street school, John leased 28 Leicester Square, which would contain his private residence, anatomy theatre, dissection room, housing for students, and the greatest anatomical and natural philosophy collection in London. John continued to prosper in his practice, research, and collection, and he was extremely dedicated to his work despite his chronic angina. He died as a result of the heart disease in 1793; after the excitement of an argument with his colleagues forced him to leave the room, he collapsed and died. Contemporaries would have considered this a fitting end to the life of their eccentric and irascible colleague--who was a terrible lecturer and public speaker, lacked social manners and decorum, and was prone to outbursts and argument. During his illustrious career, John produced several important publications in addition to the Natural History of Human Teeth, one of the most crucial being his posthumous Treatise on Blood, Inflammation, and Gunshot Wounds (1794).

But John Hunter became equally well known for the specimens he prepared for his anatomical collection and for his "systemic" approach to surgery and anatomy (Gruber n.p). John worked to prove the vital-principle hypothesis, which stipulates that all life originates and 
functions because of something within the anatomy of organisms. As such, "his research led him to define...structures [such] as the cerebrally centered nervous system, the circulatory system whose fluids both fed the organism and cleansed it of wastes, the musculoskeletal system which moved it, and the process which propagated the species. His was a holistic view of the organism, each part playing its own role in a constantly interacting systemic whole that was the living organism" (Gruber n.p.). As a result, John is one of the key anatomists and scientists to be credited with our modern conceptualization of anatomy, physiology, and biology. Biographers dub him the "father of surgery" because of his scientific approach to surgery, which prior to the late eighteenth century was considered a rudimentary and crude approach to the human body. While William shared his brother's views, John immortalized this scientific approach through his anatomical collection. Though popular as a collection of oddities, the collection was not valued by medical professionals; John's heirs eventually sold it to the Royal College of Surgeons, where it resides today in London as the Hunterian Museum (Gruber n.p). Contemporary surgeons and anatomists recognized the value of the collection, but nineteenth-century scientists, along with John's biographers, helped identify the dramatic contributions to the study of science and anatomy the collection made.

\section{Publications and Contributions}

Both brothers established anatomical collections and both became well known as a result, in addition to William's fame as a lecturer and John's fame as a surgeon. And while neither published extensively, their written work did make significant contributions to the fields of obstetrics, surgery, and anatomy. William's most important published work, The Human Gravid Uterus (1774), was the first publication to describe and illustrate the entire female reproductive anatomy, including the uterus during gestation. He worked with illustrators and engravers to 
ensure the depictions were as life-like and accurate as possible, requiring they draw only from anatomical specimens rather than from memory (Andrews 279). Published less than a decade before his death, William's magnum opus took over twenty years to complete, and it cemented his legacy as an obstetrician and anatomist. The work was lauded in its day, but its significance grew in the decades after its publication as a work of medical and artistic importance.

While William published one major work, John published three: Treatise on the Natural History of Human Teeth (1771-78), Treatise on Venereal Disease (1786), and Treatise on the Blood, Inflammation, and Gunshot Wounds (1794). These treatises demonstrate not only the breadth of John's studies, but the methodology as well. Whereas many surgeons and physicians during the mid-late eighteenth century still relied on the practice of applying a set of ideas and presuppositions about how the body worked to individual cases, John did the opposite. As one biographer says, "Hunter shared the skepticism of his fellow Scotsman David Hume about the generally assumed precedence of ideas over experience, together with his emphasis on the need to separate matters of meaning from essential matters of fact from which the former are always inferred. Hunter's world was that of matters of fact; he was very cautious in moving to the level of generalization occupied by matters of meaning" (Gruber n.p.). Within this evidence-based model, treatment of the human body, particularly in surgery, was meant to correct a malfunction within a piece of the body that normally worked as a cohesive and connected whole (Gruber n.p.). He was not alone in this approach, but his publications, and more importantly his lectures, codified his scientific approach to surgery, which greatly influenced modern medicine.

In the developing eighteenth-century medical community, publication was the primary means by which one substantiated one's work and reputation, along with belonging to the appropriate Colleges and Societies. As print culture became more easily accessible and 
affordable, attribution became a hotly contested topic amongst doctors and anatomists who were keen to plant their flag on their claims and theories, so as to receive credit in their lives and legacies for their work. In the next chapter, I will analyze the role print culture played in the development of a culture of medical celebrity, but in this chapter I would like to focus on the other means by which a medical practitioner could achieve celebrity. The following case study examines how the Hunter brothers' public personae, their portraits, their collections and the posthumous narratives about them contributed to William's fame and John's celebrity. Ultimately, these forms of representation reveal how the cultural mechanisms of fame, reputation, and public interest impacted the perception of these two medical practitioners during their lives and after.

\section{Part III: Personae in Public, Portrait, and Pieces}

\section{William's Public and Professional Personae}

William tried to cultivate the public persona of a gentleman who could move between many influential spheres, but unfortunately, his professional ambition and pride contradicted that persona. He socialized with his peers in medicine and his patients and acquaintances in the aristocracy, arts, and the royal family. He was known as an entertaining conversationalist sometimes willing to share stories of his patients, and he became the confidant and sole obstetrician of several women of influence, including Queen Charlotte. William frequented the "British Coffee-House" where he was said to be "gay and lively to the last degree, and often came in to us at nine o'clock fatigued and jaded. He had no dinner, but supped on a couple of eggs, and drank his glass of claret; for though we were a punch club, we allowed him a bottle of what he liked best. He repaid us with the brilliancy of his conversation" (qtd. in Oppenheimer 124). Such a description speaks volumes about Hunter's persona because while he is "gay and 
lively," his choice of a modest supper and a glass of claret, as opposed to the punch everyone else was drinking, signify his rigidity and reserve. He gained a reputation, as aforementioned, for his lecture style, which was charming and charismatic, while informative. As such, the public persona he created allowed him to be comfortable with a variety of people who were beneficial to his reputation and career.

Professionally, William was known for getting into disputes with his colleagues about the credit and attribution of certain discoveries or scientific claims. William may have been the picture of amiability in society, but in his disputes with colleagues, which occurred primarily in print, he could seem jealous and petty. One of the most notable controversies was between William and the Monroes. The dispute was over who discovered the absorbent function of the lymphatic system first, William or Alexander Monro, Jr., a young doctor in Edinburgh and the son of a prominent physician there. Monro published the discovery in his thesis in 1755 , which William claimed to have been teaching for years in his anatomy lectures. A bitter dispute between William and Monro ensued and lasted for five years, ultimately consisting of a review of Monro's thesis in The Critical Review, and letters between William and Monro featured in the same publication (Ambrose 7-8). By 1758, Monro, hoping to establish a reputation within his field, felt compelled to write Observations anatomical and physiological, wherein Dr. Hunter's claim to some discoveries is examined, in which he stood by his claim that he and not Hunter had made the discovery (Ambrose 11). This was the last response on this dispute until 1762, when William published Medical Commentaries, in which he constructed a case against Monro to prove once and for all that he had made the discovery about the lymphatic system, and that it was by attending his lectures that Monro was able to write the portion of his thesis in question. William proved his claim in the publication, which addresses much more than the Monro dispute 
and which Porter has claimed to be part of William's miserly attitude towards credit and attribution. ${ }^{8}$ He describes William's disposition in this regard as follows: "Hunter fiercely defended his rights to his findings as private property like everything else in his anatomy theatre...launch[ing] into print, asserting his own intellectual property in his savagely sarcastic Medical Commentaries" (Porter, "William” 25-26). As Porter sees it, William's attitude aligns with his general philosophy that the anatomy profession was "dog eats dog" (Porter, "William" 26). And he claims that this philosophy extended beyond disputes about his own work and included "all investigations undertaken within his patrimony" (Porter, "William" 26). For example, "his relations with his underlings [assistants] generally plunged into cantankerous wrangling, with their claims to property in preparations or research done under his employ being dismissed by him as embezzlement" (Porter, "William" 26-27). These descriptions demonstrate William's fierce and often unforgiving ambition. While William was cordial and friendly with his patients and people in power, his professional persona was incredibly pragmatic and prideful. His public persona contributed to his success during his life, particularly his ability to make advantageous social connections. He had a wonderful reputation with his upper-class female patients for keeping secrets and as an entertaining companion, which, because he was a man-midwife, maintained his supply of lucrative patients. Moreover, his reputation as a lecturer inspired students from all over Britain to study under him. However, after his death, his professional persona negatively impacted how he was remembered by those in his field. For

\footnotetext{
8 Ironically, neither William or Monro deserve credit for the findings, as they were originally published by Francis Glisson in 1654, which both anatomists missed during their research but which William includes in Medical Commentaries (Ambrose 12-14). As Charles Ambrose states, "Glisson was correct in asserting that lymph is collected from the tissues but was in error or wanting on other details. By contrast, in all particulars, Hunter's...represents the modern view of the lymphatic system and one of its basic functions" (Ambrose 13). Thus, neither deserve the credit they claimed, but William, out of the two, deserves recognition for clarifying a principle Glisson found years earlier.
} 
example, biographer R. Hingston Fox, writing in 1901, considers William's attitude towards his colleagues and intellectual property to be his fatal flaw. Fox writes, "It is right to mark the failings even of the great, and this jealousy for the fame of a discoverer is one" and compares William's attitude toward one of his contemporaries: "Far better was the reply of Watt, when a friend regretted that another should have carried off the honour of discovering the composition of water: 'It matters not whether Cavendish discovered this or I: it is discovered" (Fox 13). William's persona, as a result, is undercut by his focus on ambition or fame, rather than the work itself. It is common for his biographers and those writing after his death to criticize him for the kind of self-fashioning that made him successful in life. It seems that while William made many helpful social connections, his efforts to make a name for himself as a scholar of medicine were a detriment to his status within his profession. That lack of interest from his colleagues ultimately influenced the interest in his life and his work after his death. John's persona, on the other hand, was almost completely opposite to that of his younger brother and seems to have enhanced his success in life and death.

\section{John's Public and Professional Personae}

John was not as adept or interested in forming socially advantageous acquaintances, and most of his closest companions were either students who went on to become colleagues or his wife's friends. Anne Hunter was a poet and part of London's literary and artistic circles, which included Hester Thrale, Samuel Johnson, Joseph Haydn, Lady Mary Wortley Montagu, Horace Walpole, and others (Handley 316). She enabled John to interact with parts of London society that his singular interests in anatomy and surgery would have normally excluded him. Biographer W. Sampson Handley states that "people were known to have consulted Mr. Hunter professionally in the hope of an invitation from Mrs. Hunter" (316). Anne was a generous host 
and filled her half of the house at Leicester Square with dinner parties and "was in the habit of receiving at her table, and sharing in the conversation of, the chief literary persons of her time" (qtd. in Slagle 102). Although John did not have the social acumen or interest of his older brother, his marriage to Anne compensated for this lack. In her biography of John, Moore portrays the couple as opposite yet complementary forces wherein both parties made attempts to support the interests of the other:

Although Hunter rarely participated in his wife's gatherings-literary debates were decidedly not his idea of fun — he usually took time out from his studies to greet her guests as they arrived. But they were not always made welcome. Arriving home one evening, only to find his drawing room filled with dancing guests, he stormed into the room and announced, 'I knew nothing of this kick-up, and I ought to have been informed beforehand; but as I am now returned home to study, I hope the present company will retire.' Sheepishly, Anne's friends shuffled out. Yet though he was certainly more comfortable in the company of his male, scientifically minded Royal Society chums, he did accompany Anne to the theatre, concerts, and house-parties. (Moore 168) The anecdote illustrates the dynamic between the pair and how John's personality could sometimes clash with her social life. Moore goes on to quote Lord Holland, an acquaintance of the Hunters', to show how John compensated for his sometimes cantankerous disposition: "John Hunter was neither polished in his manner nor refined in his expression, but from originality of thought and earnestness of mind he was extremely agreeable in conversation" (qtd. in Moore 168). What he lacked in social decorum and grace, he made up for with his knowledge of the odd, obscure, and inventive. 
However, John's reputation as a surgeon widened Anne's social network. One of Anne's closest and well-known collaborations was with Joseph Haydn on Dr. Haydn's VI Original Canzonettas. She wrote "the words for all six songs in the first set," and Haydn dedicated the work to Mrs. John Hunter (Grigson 50). But before Haydn was Anne's collaborator, he was John's patient. The Austrian composer, "on [his] first visit [to London]...consulted the man whom he described as 'the greatest and most celebrated chyrurgus in London" for nasal polyps, a common ailment due to sinus problems (Grigson 50). John wanted to remove the polyps, but Haydn refused. On a second visit to the surgeon, John would not be put off. Haydn's own retelling, a story often referenced by biographers, demonstrates the degree to which John prioritized treatment over the social status and even wishes of his famous patients. The composer related the following account:

Shortly before my departure $\mathrm{Mr} \mathrm{H}$. asked me to come and see him about some urgent matters. I went there. After the first exchange of greetings a few brawny fellows entered the room, grabbed me, and wanted to force me into a chair. I yelled, kicked until I had freed myself, and made it clear to Mr H., who already had his instruments ready for the operations, that I did not want to undergo the operation. He was very astonished at my obstinacy, and it seemed to me that he pitied me for not wanting to undergo the happy experience of enjoying his skill. (qtd. in Grigson 150)

This account demonstrates how singularly focused John was on the practice of surgery and on Haydn as a patient. While his reputation as a brilliant surgeon made it common practice for him to treat important or famous figures, he was not particularly interested in socializing with them or making social connections. In Haydn's story of his treatment, John lacks not just social decorum, but also social awareness as both a surgeon and a person. That seems to be his persona in social 
settings: someone who prioritized his work over his social life, the perceptions of others, or his reputation.

John's professional persona was similar to the ill-mannered but brilliant man his wife's friends knew. Biographer George R. Mather says of John’s demeanor, “Although full of energy, he was not a man to make friends, or to inspire public confidence rapidly. His manner was abrupt, and at times even course and repellent" and that his "brother medicals" referred to him as “Jack Hunter” (Mather 134-135, 127). Unlike his brother, John's quarrels were attributed to his temper and disposition rather than his professional pride. While at St. George's Hospital as a "member of the Company of Surgeons and a member of the surgical staff," a position he held from 1768 to his death in 1793 , he got into many arguments with his colleagues and was generally not very well liked (Gruber n.p.). This is not surprising considering John's distaste for the establishment and traditional education. Despite his cantankerous personality, he was well respected and his expertise as a surgeon was considered to be unparalleled. He received several prestigious appointments as a result, including: "surgeon-extraordinary to the king in 1776, surgeon-general of the army, and inspector of its hospitals in 1790" (Gruber n.p.). While William engaged in public quarrels over credit because of his pride, ambition, and jealous disposition, John argued with his peers day-to-day about the practice of medicine and surgery because of his deep knowledge paired with an ungentlemanly way of engaging with people. William's public persona reflected his ambition, while John's persona was associated with his genius and eccentricity.

Perhaps no other example more clearly illustrates the difference in their personae than the stories of their deaths. William suffered from gout and kidney stones for some time, and after recovering from a particularly difficult period of illness, he "determined to give the introductory 
lecture to the operations of surgery...He was determined to make the experiment, and accordingly delivered the lecture, but towards the conclusion his strength was so exhausted that he fainted away, and was obliged to be carried to bed by two servants" (Simmons 27). He died a few days later on March 30, 1783. A more dramatic exit from his professional role of lecturer could not be imagined, and William's insistence to appear in public and teach his pupils exemplifies not only the determination he exhibited in life, but also his determination to be in the public eye. Lecturing was what William did best and the part of his profession he most valued. Like a dedicated actor needing to appear on stage, William did not want to disappoint his audience. The lecture theatre was a platform by which he was perceived by others and on which he presented himself to the people of his profession. Rather than compromise that position, he persevered and then fainted onstage, never to return again.

A similar stubbornness hangs over John's death, which was brought on by his chronic angina. John was ill for most of his adult life, going to Bath and seeking other remedies for his heart problems for decades. Mostly, his angina was manageable, but he knew it worsened when he became angry or too excited. So, the generally cantankerous and irascible surgeon had to try to maintain a good temper. But on October 16, 1793, he went to St. George's Hospital with the specific purpose to advocate on behalf of a few students from Scotland who were hoping to be admitted. Naturally, he got into a dispute with his colleagues and "in the middle of a personal attack by an opponent, Hunter fell ill and went off to a neighboring room where he soon collapsed and died" (Gruber n.p.). As with his brother, John's death exemplifies his public persona as someone who consistently prioritized his work over any social graces or how others perceived him. Indeed, his ill-mannered temper and passion for his profession and subject were the very things that killed him. Both brothers died during their efforts to serve their students, but 
even the strikingly similar final moments of their lives, a difference in their priorities is clear. While William risked his health and life to be in front of his students, leading and teaching them, John risked his health and life to argue on behalf of the principles of his profession. One brother valued society's standards and public perception, while the other valued the science above all else. The portraits and collections of the Hunter brothers further reflect that difference in their personae.

\section{Persona in Portraits}

Portraits of medical practitioners were not uncommon in the eighteenth century. They, along with many other individuals, participated in the genre that became an incredibly popular art form in the 1780s. As Marcia Pointon has discussed, by the end of the eighteenth century, portraits were produced and purchased more than any other original, as opposed to reproduced, visual art form (79-80). Members of the royal family and upper class utilized the genre to decorate their homes and reproduce images of themselves, but so too did an increasing number of other individuals hoping to reproduce their likeness. Portraiture in the eighteenth century functioned both as a way for artists to uphold social order and to destabilize it and to do so within a genre that seemed to be fairly conventional. Pointon, as such, argues that we think of portraiture not merely as a means of representation or a commodity but as an "ideological mechanism" (4). As an ideological mechanism, portraits played a vital role in the development of eighteenth-century society, politics, and culture because of their ability to influence what and how people thought, which could vary depending on the genre, context, sitter, and painter. Subsequently, sitters and painters belonging to various groups within the social hierarchy had access to an influential form of media. For medical practitioners in particular, portraits served as a way for them to represent themselves as men of science and learning, as Ludmilla Jordanova 
points out in her discussion of the development of scientific and medical portraits from 16602000. She claims that "medical practitioners, whose occupational activities were particularly problematic in being (especially in the case of surgeons) both manual and potentially transgressive, were quite keen to be seen as possessing mastery of non-manual-that is to say, intellectual—skills" (42). Portraits of medical practitioners as a result often portray someone who is alone with books or in a scholarly type of atmosphere (Jordanova 41-42). Thus, their portraits evoke men of learning, "a recognized social type...[which] did not connote social dominance or power, [but] it did evoke a certain respect (Jordanova 42). This is true for one of the Hunter brothers' portraits, but not the other.

William's portraits present a professional and a gentleman, and, as we will see, they existed to convey that message to polite society and to his colleagues. John's portraits portray an anatomist who prioritized experimentation; they emphasize the potentially transgressive nature of his work, and only one of his portraits was meant for public consumption. The differences in the context of their portraits and in their content impacted the portraits' impact on fame and celebrity. I will analyze the context and content of their portraits by applying one of Chris Rojek's theories about the split between the public and private self that is necessary for audiences to be interested in a famous figure. Using that theory, I argue that William's portraits contribute to his reputation and fame, but they do not create the circumstances necessary for public interest, and consequently, celebrity. In this section, I argue that the public personae presented in the portraits mirrors the personae they portrayed to their colleagues and social acquaintances. When we apply Rojek's theory to our interpretation of the discursive effect of John's portraits, we can account for the public interest that surrounded the only one of his portraits meant for public consumption. 
The first portrait of William was painted by Allan Ramsay in 1762 (Figure 1.1), followed by Mason Chamberlin in 1769 (Figure 1.2), Robert Edge Pine in 1770 (Figure 1.3), James Barry in 1777-1784 (Figure 1.4), and Sir Joshua Reynolds's posthumous portrait of William in 1787 (Figure 1.5). The most famous of these portraits were by Ramsay and Reynolds, the most famous portraitists of the period. William's first portrait celebrated his appointment as Physician Extraordinary to Queen Charlotte in 1762. This portrait has not received much attention by scholars, but a few have written about it, both noting how purposefully blank it is. Joanna Woodall calls the piece a "masterpiece of denial," which Jordanova claims explains the portrait's “cleverness" $(110,159)$. Both argue that because William's positions as a man-midwife and as an anatomist were so controversial, the portrait deemphasizes his occupations and presents William as a "member of polite society" who is devoid of "medical or scientific accoutrements... [or]marks of occupation" (Jordanova 161, Woodall 110). The colors and textures in the painting stand out to emphasize the richness of his attire and suggest the brilliance that led to his appointment to the Queen, while it is utterly devoid of visual references to his work as an anatomist or obstetrician. Jordanova suggests that this was purposeful on Ramsay's part, and his ability to create a beautiful and striking portrait that is also completely blank suggests he was aware of the social context in which the portrait would operate. She argues this demonstrates his skill as a portraitist who understood the genre (Jordanova 158-159). She interprets Ramsay's artistic choices as a "brilliant solution to the problem of depicting a controversial and upwardly mobile medical man" (Jordanova 161, 163). Even the pages William holds and points to are blank, which suggests a learned man who relies on texts, but the portrait does not reveal what those texts are. The portrait celebrates William's appointment to the Queen 
without celebrating the parts of his work that would make viewers recoil or sneer and, as such, echoes the gentlemanly persona William presented to society.

In Fashioning Celebrity: Eighteenth-Century British Actresses and Strategies for Image

Making, Laura Engel argues that celebrities, specifically actresses, used portraiture as a way to self-fashion their personas, fame, reputation, and celebrity. Portraiture, as such, emerges in eighteenth-century celebrity studies as one of the cultural mechanisms that created celebrity culture. I would argue Ramsay's portrait of William is an example of a similar kind of selffashioning wherein the details of the portrait participate in and contribute to the sitter's persona and reputation. The Ramsay portrait, as such, helps to position William as a gentleman in the eyes of the viewer, thereby increasing his social and cultural cache. Other portraits of William perform a similar function. 


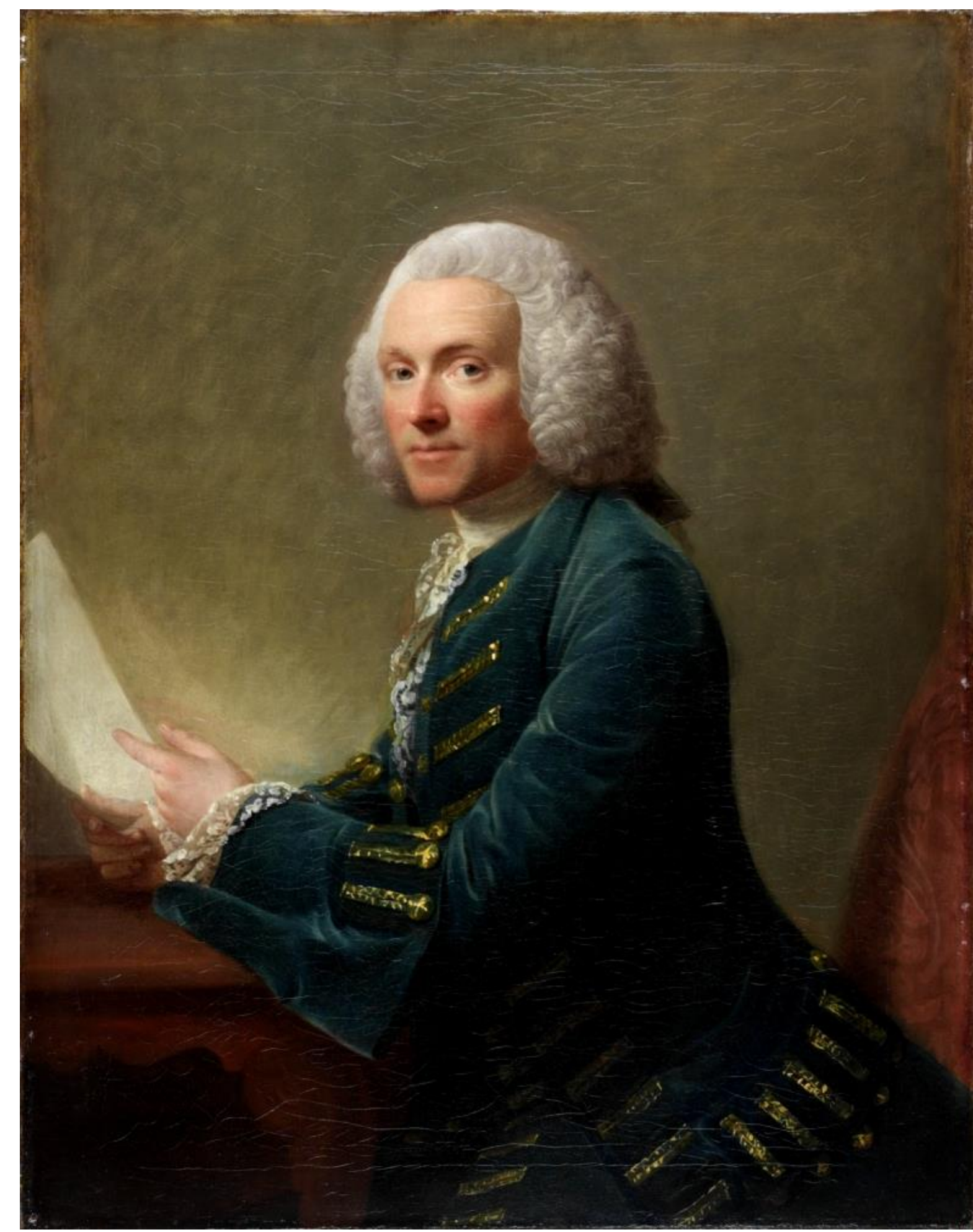

Figure 1.1, William Hunter, Allan Ramsay, 1763-66, The Hunterian Art Gallery, The University of Glasgow. 


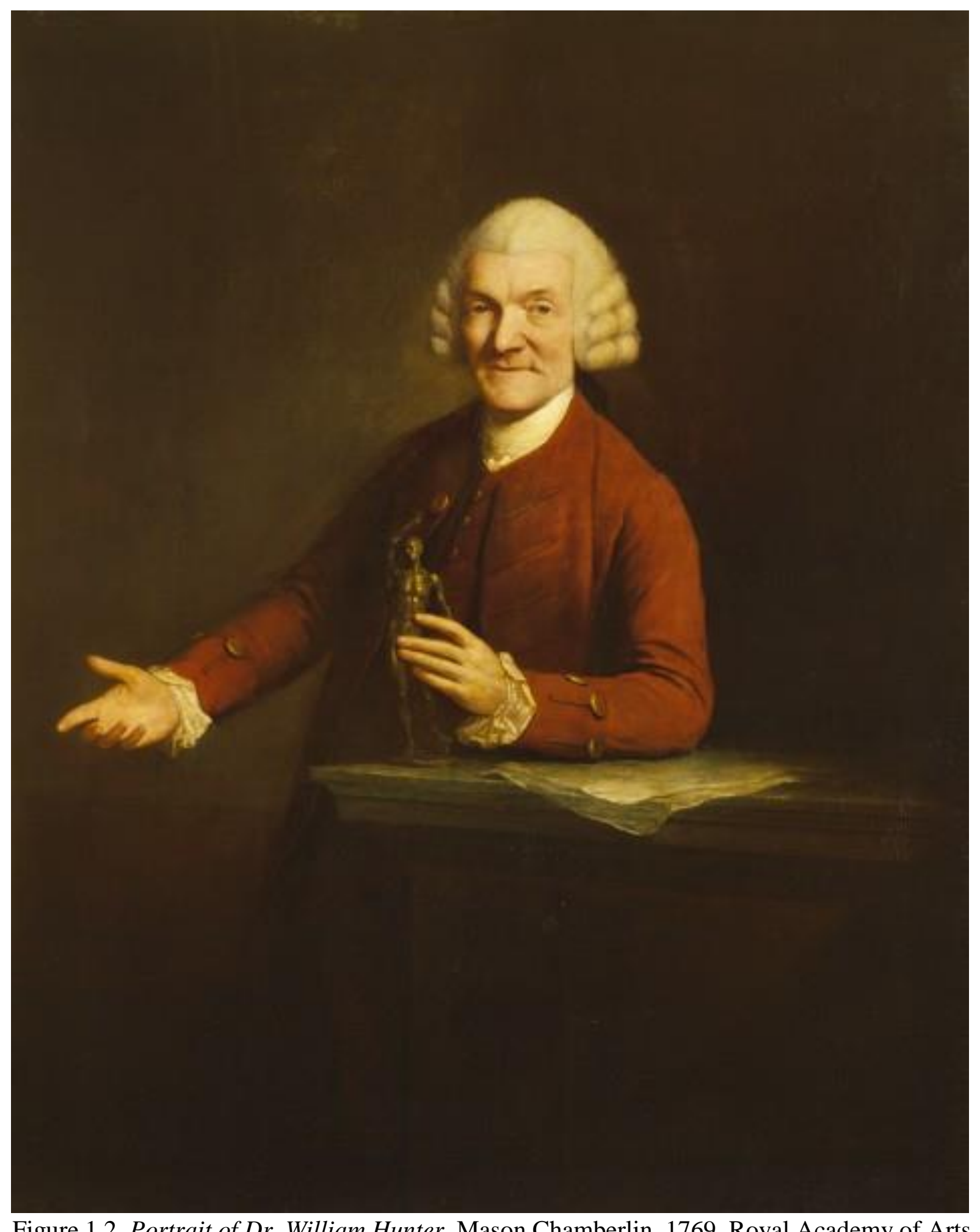

Figure 1.2, Portrait of Dr. William Hunter, Mason Chamberlin, 1769, Royal Academy of Arts. 


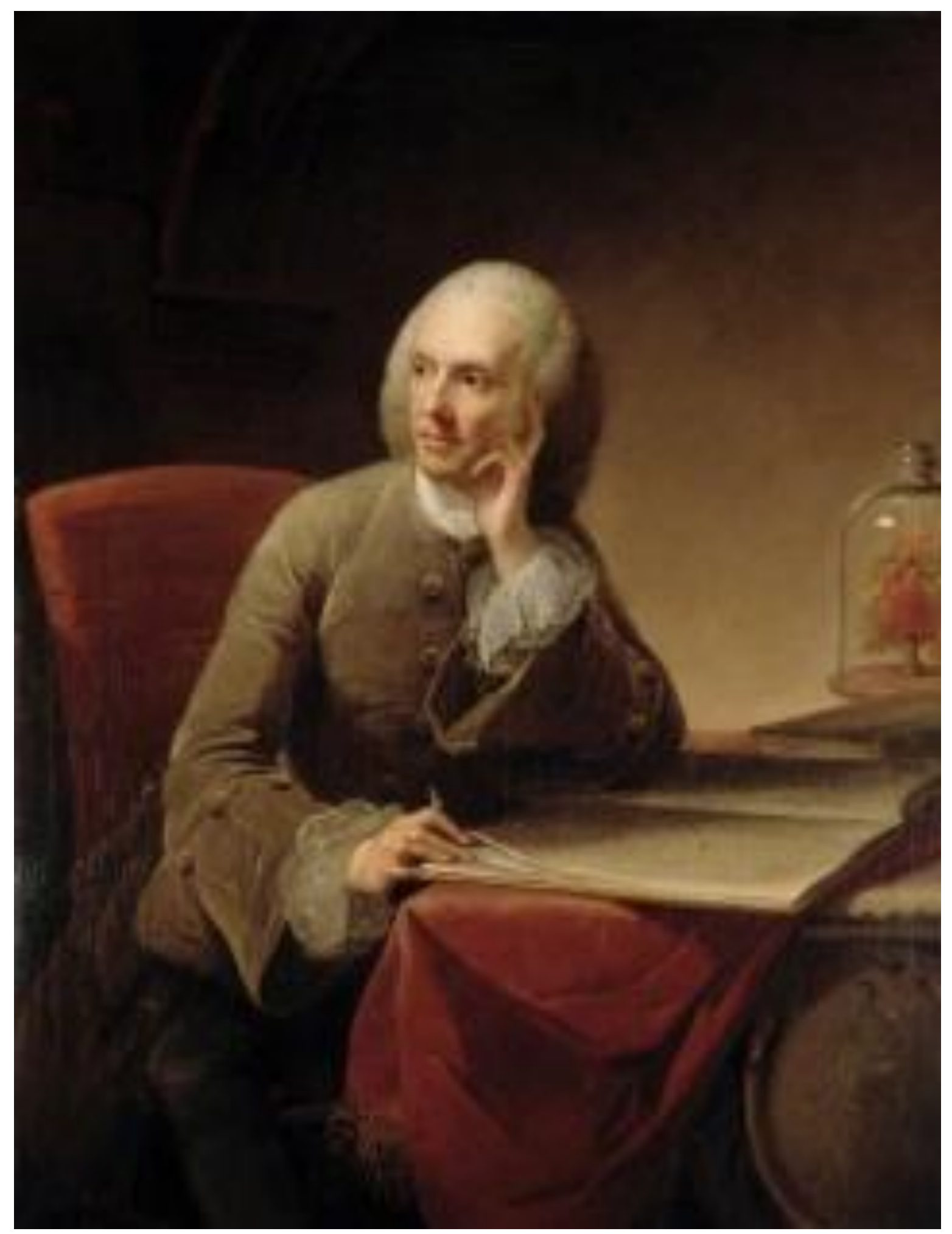

Figure 1.3, William Hunter, Robert Edge Pine, Hunterian Museum, Royal College of Surgeons. 


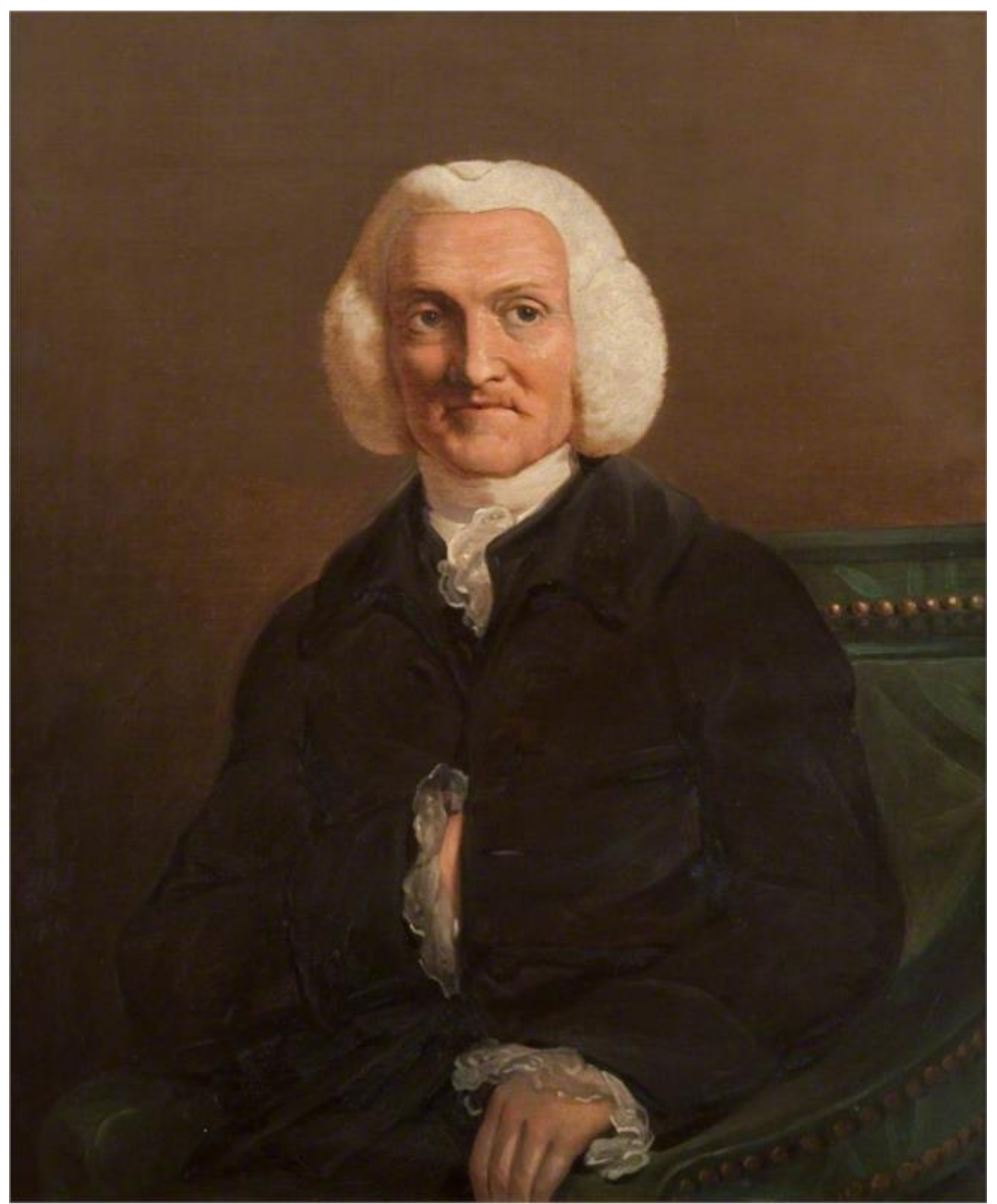

Figure 1.4, William Hunter, 1784, James Barry, Royal College of Physicians of London. 


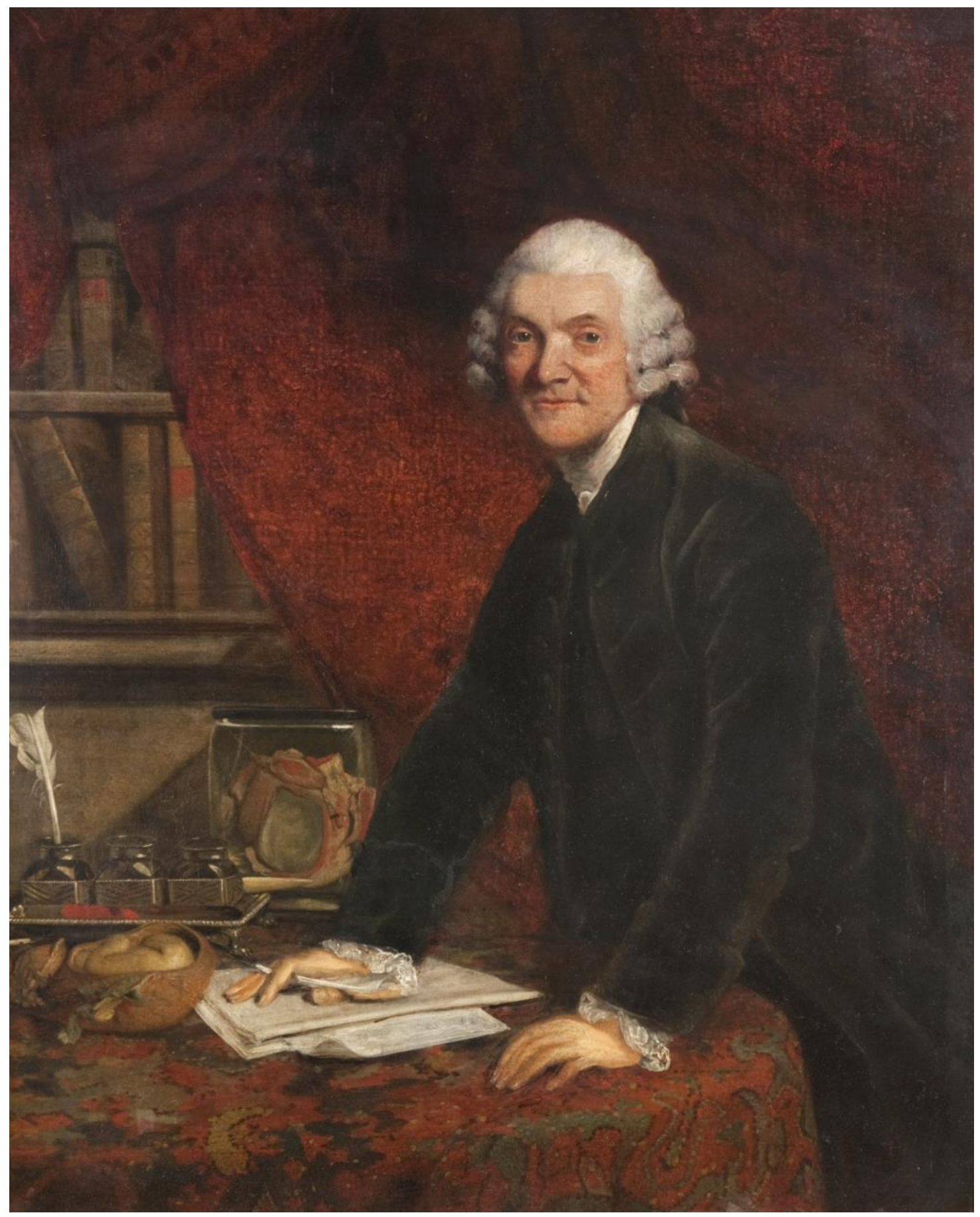

Figure 1.5, William Hunter, Sir Joshua Reynolds, 1787, The Hunterian Art Gallery, The University of Glasgow. 
Except for Reynolds's portrait, William's other portraits depict similar images to Ramsay's, presenting a professional to polite society in order to deemphasize the controversial parts of his work. In fact, the portraits are practically reincarnations of each other. In every portrait, William wears a formal waistcoat with large lace cuffs and a perfectly coiffed wig in front of a blank background with almost nothing else in the portrait. In three out of the four portraits, there are blank sheets of paper and in two of them there is a small, singular object. Otherwise, the portraits feature William and a chair or a table. In a genre that relied heavily on iconography and cultural context to convey complicated and nuanced visual representations, William's portraits seem almost Spartan. Stephen Paget describes him in the portraits as "a gentleman, well-dressed, [and] carefully posed" (45). The element of the portraits that most consistently projects that persona are the wigs. Pointon discusses the cultural significance of wigs worn by men and their representation in portraits specifically in terms of how they contributed to portrayals of masculinity, social order, and individuality. One of her arguments is that the depiction of wigs in portraits operated within a tradition of artistry related to the color, size, and appearance of the wig (Pointon 129-130). The depiction of wigs within that tradition was a way of upholding the social order, whereas departures from the predominant fashion signified individuality and disruption (Pointon 130-131). In William's portraits, he is depicted wearing a white, perfectly coiffed wig in every portrait. They are neither emphasized nor deemphasized, and this aligns with Pointon's descriptions of traditional depictions of wigs (Pointon 131). As one of the most predominant signifiers to an eighteenth-century audience, William's wigs would have portrayed someone who is not trying to disrupt the social order. This, similarly to the blankness found in his portraits, would seem to be an attempt to deemphasize how forward-thinking and upwardly mobile William's work was. Rather, the portraits attempt to 
insert him into a tradition of men of learning and gentlemen. Here is not a cutting-edge anatomist or obstetrician, but instead a member of polite society.

The only two portraits that include a direct reference to William's work as an anatomist or obstetrician are those by Chamberlin and Pine. In the first, William holds an écorché, ${ }^{9}$ which Woodall states was "the acceptable cultural face of medicine, since it evokes the study of art as well as well as of anatomy, not everyday medical practice" (110). Pine was William's friend, and he commissioned the portrait seen here in addition to one of his sister Dorothea (McCormack 77). It is unclear what the model on the table is in direct reference to, but as Helen McCormack notes, it "is one of the few images of Hunter that includes a direct reference to anatomy" (McCormack 78). This portion of the portrait was removed from both engraved reproductions of the portrait and an oil painting reproduction. William's other portraits would suggest that it was taken out of the portrait because it was too direct of a reference to his work, but I would argue that based on William's other portraits, it was most likely removed from the portrait in order to make the image seem more stately and less medical. The original, after all, hung in William's anatomy school at Great Windmill Street, whereas the engraving and oil painting reproductions were meant to exist for the public (McCormack, "Great Windmill," 7). In Chamberlin's portrait, William holds the écorché on a table, while his other hand is open and points ever so slightly out of frame, seemingly inviting the viewer to view the écorché. The portrait is not timid in its presentation of its sitter as someone holding a piece of medical accoutrement, but it is incredibly controlled and cautious.

Within this gallery of portraits, there is one outlier that does not depict the same image of William as the others. The Reynolds portrait, which was painted posthumously at the request of

\footnotetext{
${ }^{9}$ A painting or sculpture of a human figure with the skin removed to display the musculature (Oxford Dictionaries)
} 
the University of Glasgow, presents the image of a man in the midst of his work (Figure 1.5). Whereas the other portraits are static, implying the sitter was a respectable figure within society, Reynolds's evokes movement. William's posture and position are distinctly different, but so too is the background, which overflows with anatomical object and books. Next to the papers under his hands, there is a wax model of a uterus and a fetus, and just beyond to the right, we find a large jar containing what could be a specimen of a uterus. The wax model and specimen clearly allude to William's most significant printed work, The Human Gravid Uterus. Reynolds's use of these objects direct refers to William's work as an anatomist and obstetrician, by evoking the major contribution William made to both fields with his publication. Unlike the other portraits, however, this one does not contribute to William's public persona during his lifetime because it was painted posthumously, and without his prior knowledge.

The portrait was commissioned by the people of Glasgow to accompany the collection William bequeathed to the University of Glasgow. They hoped the portrait would serve as a remembrance and memorial to him. The label on the painting reveals the circumstances under which the portrait was commissioned:

In 1787 it was reported that 'The Glasgow people, well impressed with the extraordinary merit of Dr. Hunter, are anxious to perpetuate his resemblance; his memory can never want of any other aid than that of his professional excellence. They have therefore applied to Sir Joshua [Reynolds] for a portrait, for the ornament of their University. Their offer, with becoming munificence, is $£ 100$ for a head. And thus accompanied the great painter was asked 'If he thought he could do it?' The Scottish professors were much pleased with his answer which was literally in a single word 'Possum [I can]'. The resulting full-length portrait shows William at a table, pen in hand, and surrounded by a 
preparation and a cast hinting at the publication that established his medical reputation, 'The Gravid Uterus.' (“William Hunter”)

The description of the portrait makes it clear that the portrait serves to memorialize his reputation and professional success. To meet that demand, Reynolds evokes William's contributions to obstetrics and anatomy, which seems to have been the exact opposite intention of the other portraits. Here his work as an anatomist and obstetrician are directly referenced because that is the only way to depict his significance to viewers in perpetuity. As opposed to the professional member of polite society, here we see a man who looks determined and preoccupied--interrupted even--as though we have disturbed him during his work. Here, his controversial work is not erased but is instead the focus of the portrait--but this portrayal only happens after William's death. As such, it does not contribute to his public persona in life or the public appeal he might have possessed.

In terms of how these portraits contribute to William's fame and potential celebrity with, they fashion the public persona he established with his upper-class patients: that of a professional and a gentleman who deemphasized the revolutionary and potentially transgressive nature of his work. The foundation of the public persona that he created and that is depicted in his portraits rests on a certain amount of anonymity and aloofness. Except for the Reynolds portrait, the rest could be depictions of almost anyone because of the amount of personal detail they withhold. As a result, the portraits do not seem to have captured much public interest, which can be explained by Rojek's theory of how celebrities cultivate public interest. Subsequently, the portraits helped fashion a culturally valuable public persona; however, they did not help fashion William's celebrity. 
Rojek argues that in order for public interest to exist, there must be perceived split between the veridical (private) and public self (11). The perception of the split is key because everyone has a public and private self, or many versions of those two; however, if a public audience is aware of that split in the persona of a public figure, they are more likely to be interested. That public interest is essential for celebrity to occur, because it arises when the viewer desires to see both selves and to work around the split— to discover or learn more about the veridical self despite the barrier that has been put up between it and the public self (11). In other words, when a public figure sparks our interest, it is partially because they have managed to present a version of themselves that makes us want to know more than what they have presented. In the case of William Hunter, he does not represent the split; he merely presents one static image to the public. The representation, in person and in portrait, does not suggest to people that there is more beneath the surface, which is essential in order for public interest and celebrity to occur. His portraits, as such, did contribute to his reputation and persona but they do not fashion the intrigue necessary for celebrity to occur.

John's portraits do the exact opposite: they create a narrative that there is a public version of John who is a learned man and a professional, but there is also a private John who is a surgeon, anatomist, and someone who does not seem to care that his work is transgressive or potentially threatening to the social order. His portraits, as we will see, both fashion and contribute to his celebrity.

There are only three portraits where John is the sole sitter, two of which were painted by his brother-in-law Robert Home, while Sir Joshua Reynolds painted the third. In each of the portraits, the artist incorporates objects and iconography that emphasize John's work, specifically his more controversial work. The most conservative and stately of the portraits is 
Home's depiction of John circa 1770 (Figure 1.6), which shows John dressed in "black tri-corner hat, dark blue coat and white neck-cloth with a red waistcoat embroidered in gold and buckled knee-breeches over white stockings" (“Portrait of John Hunter”). At first glance, the portrait seems rather ordinary and typical, and like William's portraits, the viewer might not know the sitter was a surgeon and anatomist if they did not know John Hunter's occupation. However, there is a second sitter in the portrait, a dog who rests his head on John's knee and who is closer to the viewer in the foreground. Again, at first glance this is a typical feature of portraits, but the dog's 


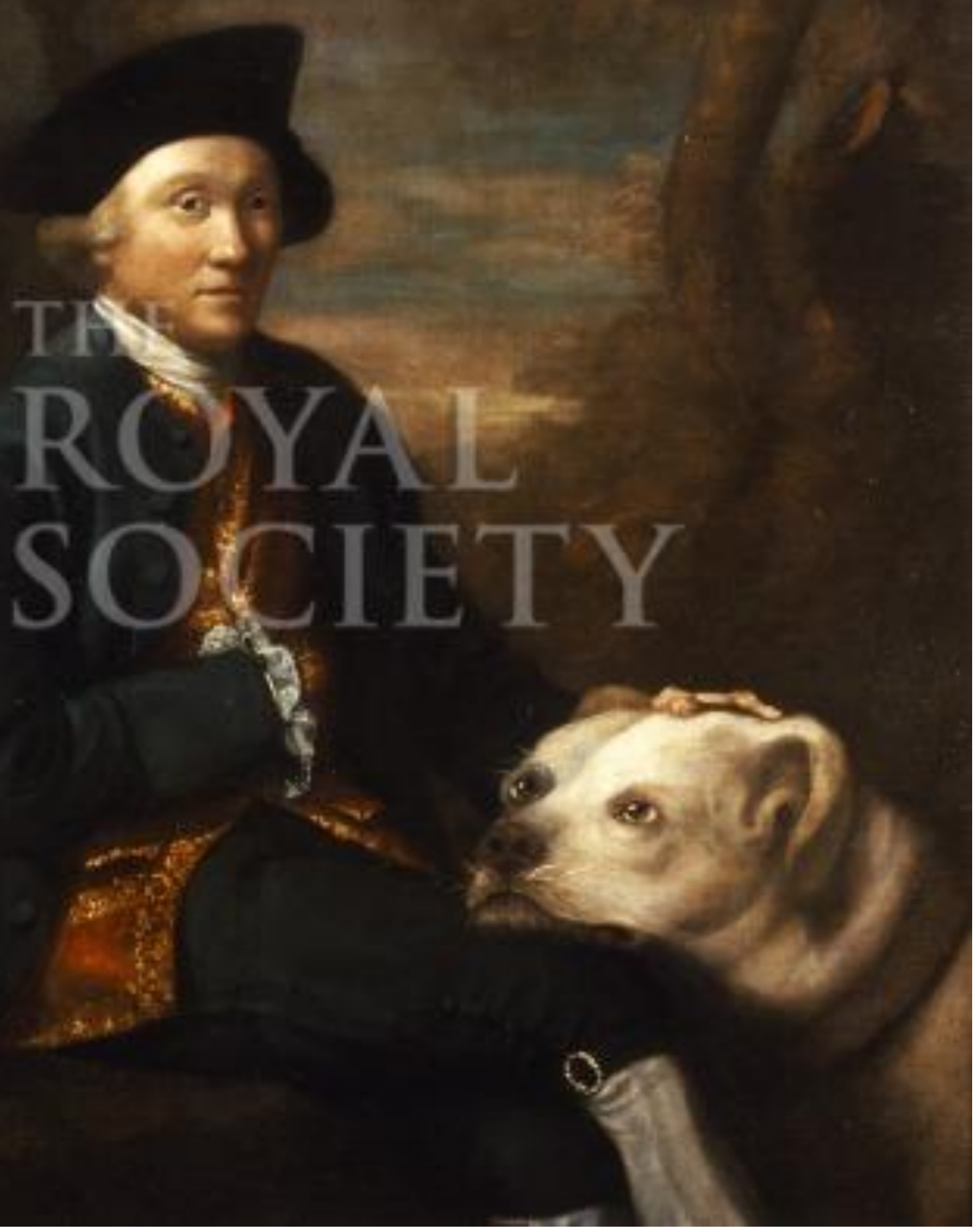

Figure 1.6, John Hunter, Robert Home, 1770, The Royal Society. 
eyes are askew and the body oddly proportioned and uncommonly large. It looks almost as if the artist did not get the proportions of the dog and sitter quite right, but that seems unlikely since the rest of the portrait is perfectly in proportion. More than likely, the dog in the portrait was “one of John Hunter's wolf-dog hybrids" ("Portrait of John"), particularly when we consider the date of the portrait. This dog would have been one of many animal hybrids John created at his large house at Earl's Court, where the lawn was usually occupied by ostriches, buffalo, "strangely altered fowl, some with human teeth or their own spurs grafted to their combs," and where he housed a large kennel for lions and leopards, and where "wolves, jackals, and dogs had been penned together" (Kobler 244). While Earl's Court was more rural than downtown London, neighbors and visitors could not help but notice the menagerie of animals, some rather odd, that grazed the surgeon's lawn. In fact, John's reputation for allowing so many animals to wander around his property is said to have been part of the inspiration for the character of Dr. Doolittle. While the portrait is reserved, even the most reserved portrait of John showcases his work, often controversial, as an anatomist and scientist, while also capitalizing on his reputation and attention-grabbing antics. The portrait prompts the viewer to look closer: "Is that a dog? What's wrong with that dog? Isn't John Hunter the one who has all of those animals?' By drawing the viewer in, the portrait sparks interest and conversation, and as such, the portrait creates a narrative of the sitter that exists beyond the viewing and the objects inside the frame.

Home's other portrait (1775-1779) (Figure 1.7) shows John at a desk, pen in hand, as he looks at the viewer, but his dress and the objects in the portrait draw the viewer's notice. As 


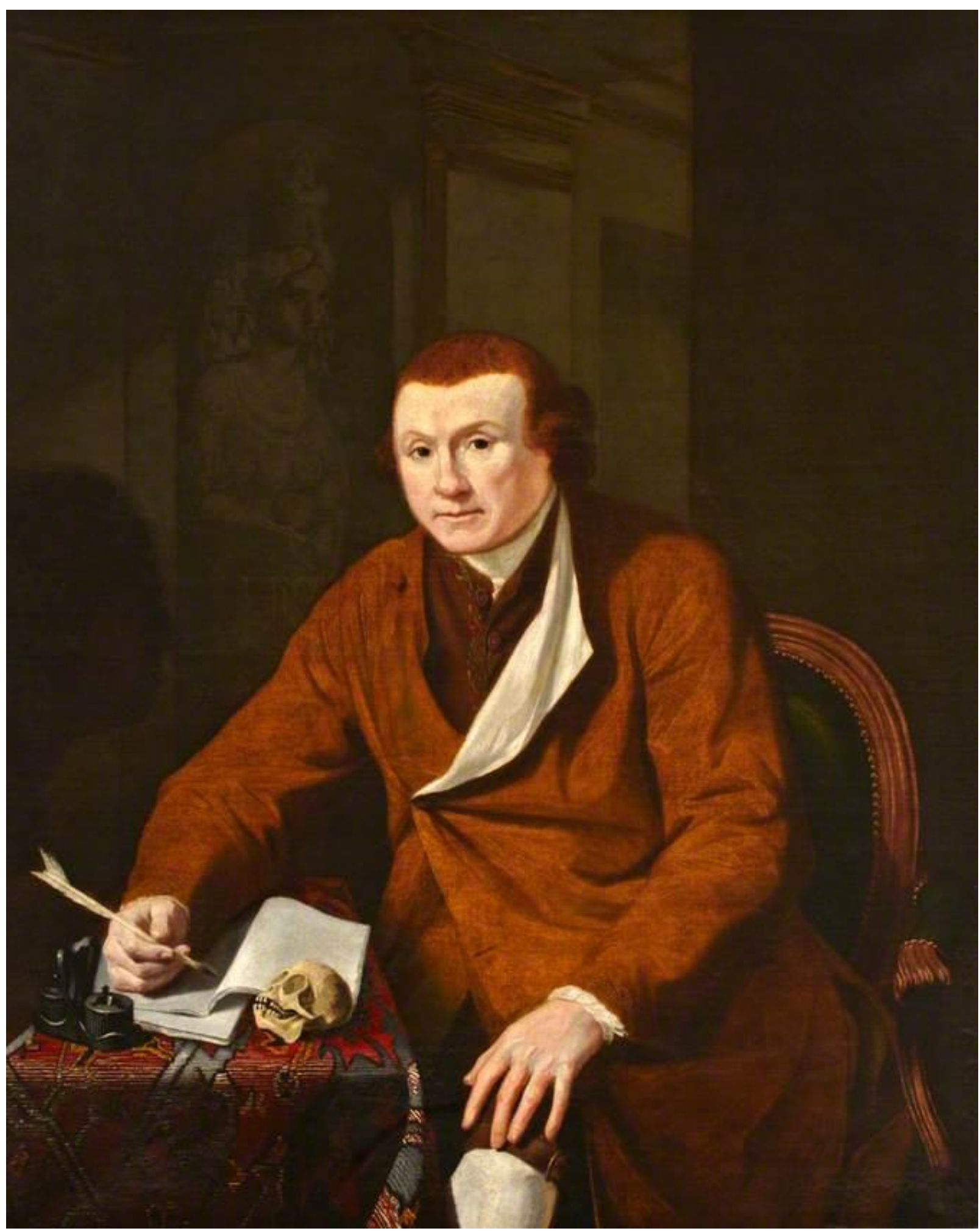

Figure 1.7, John Hunter, Robert Home, 1775-1779, Hunterian Museum, Royal College of Surgeons of England. 
Paget describes, "Home has painted him in his working dress, a loose dissecting-apron with long sleeves; the cuffs are turned back, the garment is caught round him anyhow with a single button; his attitude is clumsy, and he seems to be in a hurry to be gone; his features have none of his brother's good looks, they want firmness; but the whole face and figure are full of indomitable strength" (Paget 45). Home positions John in a typical and standard pose--pen in hand, legs crossed, looking at the viewer--but he chooses to show John in his dissecting apron, which was certainly not typical. The gown, as Paget notes, seems as though it has been buttoned hastily as John rushed to the table to write something down. The askew button and cloth and the dissecting apron beckon the viewer to notice his wardrobe and contemplate both what it is and what it was used for. The button, then, might be closing the gown over stains of blood and gore, and John might have just finished a dissection. Paget notes that John does not appear particularly attractive in the portrait, unlike his brother's portraits, nor does he have William's fixed and strong jaw. His soft face makes him both less attractive and less imposing. The other reason why John is not particularly striking or attractive is Home's color palette in the portrait. The sitter is almost entirely monochromatic, with his hair even matching his shirt; because there is no singular color to fix our eyes on, John and the table he leans on do not seem particularly beautiful or entrancing. Certainly, there is not the contrast of colors found in the Ramsay portrait of William. And yet, this portrait still creates intrigue for the viewer.

If the dissecting gown were not interesting enough for the viewer, a conspicuous animal skull resting on the table captures the viewer's attention. Presumably, this is what John is writing about. The skull in and of itself would be enough to spark interest in the viewer and signal that the sitter is an anatomist, but when we see the skull next to a sitter wearing a hastily buttoned 
dissecting gown, the object and the wardrobe cannot help but seem connected. Again, a narrative for the viewer is made possible: "What was he dissecting? Is that skull from the dissection he was just performing or a previous one? What kind of animal is it, and what is he writing about it?" Once again, the viewer is invited to look closer and imagine John out of the frame, busily slicing and boiling animals to be made into preparations. This, of course, would connote the human bodies John would have been doing the same things to, and the viewer would be looking at someone who regularly dissected human bodies and lived in the world of resurrection men and body snatching.

Unlike his brother's portraits, this one of John allows us to see and imagine both the public and private John Hunter. The public version is the one who sat for portraits like other successful and wealthy members of society, wrote scientific treatises for publication, and received fame and recognition for his surgical and anatomical work. The private version is the one who wears dissecting gowns instead of waistcoats, boils the skulls of animals, and dissects human bodies possibly (and probably) acquired through unsavory means. William did the same thing, but his portraits erase any indication of such a life and of his private self. John's portraits reveal the split between the public and veridical self, and allow the viewer to glimpse both-the precondition for celebrity, as noted by Rojek.

The portrait that shows this split most overtly is the portrait of John by Sir Joshua Reynolds (1789) (Figure 1.8). John was not keen on sitting for the renowned artist who lived just down the block from him, and he resented having to sit still when he could be working. 


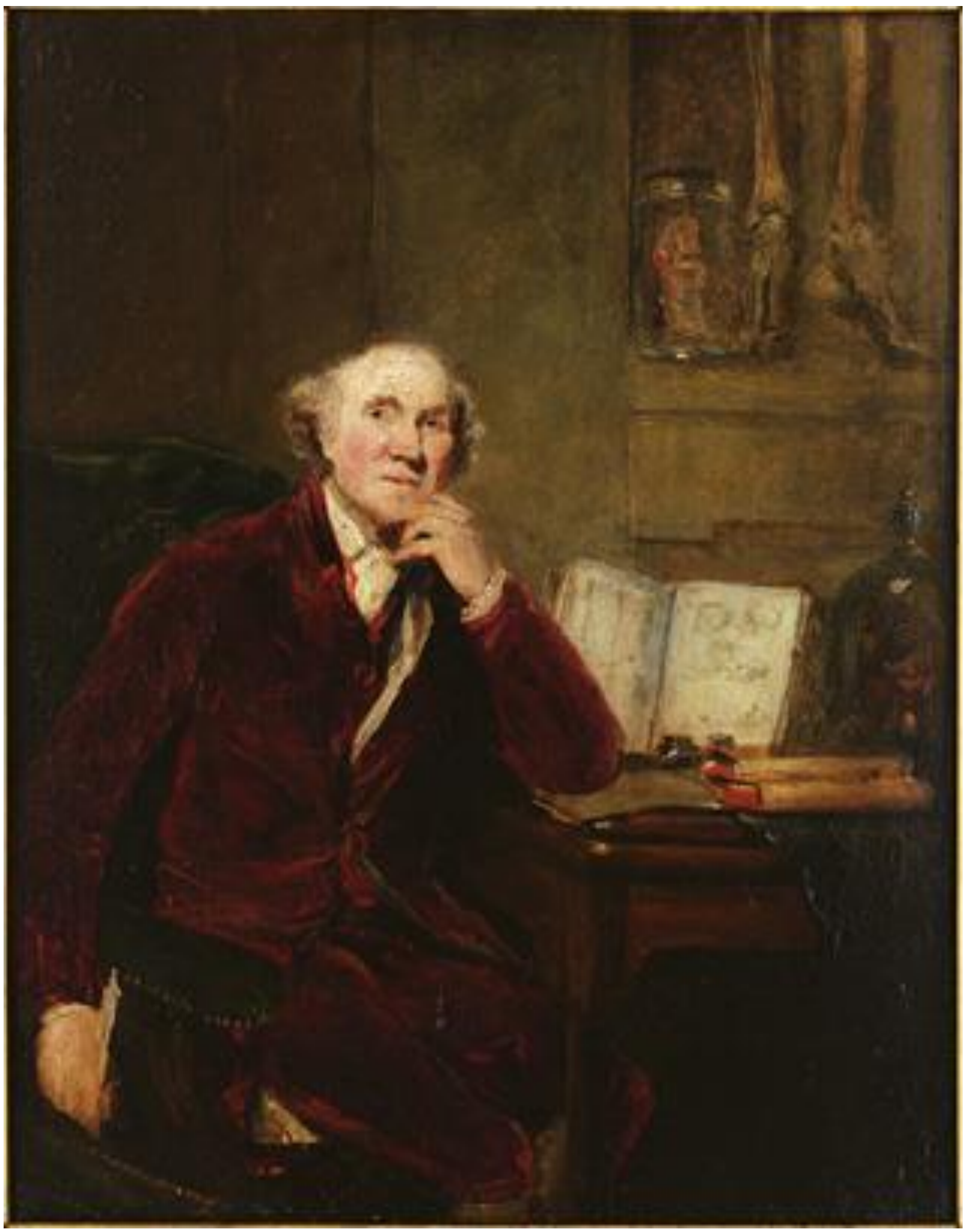

Figure 1.8, John Hunter, Sir Joshua Reynolds, 1789, Hunterian Museum, Royal College of Surgeons of England. 
Biographers claim that the expression on John's face happened when he suddenly became lost in thought, and Reynolds managed to capture the moment of stillness and reflection from the otherwise restless sitter. It is this expression that immediately draws viewers into the portrait because of the lighting Reynolds used, a soft white glow in a relatively dark and shadowy portrait. The surgeon, famous and respected at this point in his career, seems unaware that he is in a portrait at all, and the viewer is allowed to see his open face and faraway look unencumbered by any awareness that he is being looked at. Despite the intimacy that might be created between viewer and sitter because of his expression, his clothes are suitable for a public appearance. The red velvet waistcoat and trousers are more suitable than the dissecting gowns he was shown in a decade earlier. This is a portrait of John Hunter, the established surgeon and anatomist, and as such, the portrait feels more professional. However, the sitter is not wearing a wig, something John refused to do, which makes the portrait seem more intimate, and so at first glance, the portrait presents a professional and public persona.

However, once the viewer moves beyond John himself, we see anatomical objects and specimens that take up an equal, if not greater, amount of the frame as John. These objects, and what they symbolize, give viewers a look at John's private self and his behind-the-scenes work. Moreover, I would argue that by analyzing the objects in the portrait, we can see how the portrait emphasizes, capitalizes on, and perpetuates John's controversial work. Similarly to Home’s second portrait and Reynolds's posthumous portrait of William, several anatomical objects fill the table: a book of Hunter's drawings depicting the head and hand of humans as part of his theories of evolution, two books on natural history, and a specimen of "desiccated and dissected lungs of a man who had an osteosarcoma" (Keith 205-207). These objects not only establish John as a scientist but also assert his position as an innovative and progressive anatomist. Rather 
than objects that could be used by any anatomist or surgeon, these emphasize the most

controversial and intriguing parts of John's reputation and work. Rather than hide his reputation, the portrait emphasizes it, in the hopes of capitalizing on the public interest surrounding John.

Arguably, one of the most prominent images, and the one that most obviously capitalizes on and perpetuates John's celebrity, is the set of bones hanging in the upper-right corner. The bones belong to Charles Byrne, the Irish giant who cultivated his own celebrity by appearing in public exhibitions and curiosity shows before dying in 1783, just six years before this portrait was completed. Before his death, the 7'7" man who had been stared at and ostracized most of his life arranged for his body to be buried at sea. John, undeterred by the last wishes of Byrne, paid for someone to steal the corpse of the rare skeletal specimen before it was lost at sea. He prepared the bones, waited a few years so as to avoid public ridicule and accusations of indecency, and then displayed Byrne in his collection, where he still stands today in the Hunterian Museum. No doubt it received similar remarks from visitors of the Hunterian in the eighteenth century as it does today. The bones in the portrait represent a few things: Byrne's celebrity, the controversy and interest around John's body-snatching activities, John's utter lack of respect for Byrne and his desire to show off his acquisition, and the ways that the portrait overtly capitalizes on and perpetuates celebrity. ${ }^{10}$

\footnotetext{
10 As Wendy Moore has illustrated, John Hunter was well known for his interactions with body-snatching and resurrection men. As cultural attitudes shifted away from considering surgeons and anatomists to be unskilled or even nefarious defilers of the sacred human body, there was a growing fascination with dissection and anatomy. Negative cultural perceptions persisted in the eighteenth century, but those began to dissipate as anatomy schools grew in number and as surgeons separated themselves from barbers. Whereas dissections in the sixteenth and seventeenth centuries were still rather infrequent, by the mid-eighteenth century, demand for cadavers to be used in dissection increased exponentially. In the early to mid-eighteenth century, cadavers were only provided to the Royal College of Physicians and the Company of Barber-Surgeons, and at a limit of ten per year. An underground industry of body snatching by resurrection men (those men willing to dig up recently buried bodies and sell them to anatomists) grew to meet the increasing demands. The demand for cadavers became so high and the body-snatching industry so great that it was necessary to pass the Murder Act in 1752, which required that the corpses of all executed murderers be dissected (Cheung 37). The act was meant to satisfy demands of anatomy schools and deter people from committing murder because they would be refused a Christian burial (Cheung 37). However, anatomists like John benefited from the resurrection men willing to sneak into dark cemeteries to unearth recently
} 
Featuring Byrne's skeleton in his collection overtly capitalizes on the fame that Byrne acquired before death. However, the giant bones dangling behind John's head in his most famous portrait also demonstrate the surgeon's utter lack of social decorum and, to an extent, his lack of connection with other people. Viewers of the portrait would have recognized the skeleton to be Charles Byrne's, and they would have been keenly aware of the scandal surrounding his death. The portrait capitalizes on their grotesque fascination and disregards any disapproval viewers may have had. Not only does the portrait disregard public opinion in favor of showcasing this latest, most-prized acquisition, but it also disregards the wishes of Byrne. Viewers, used to gawking at Byrne who was not only a giant but an Irish giant, would more than likely not have found John's actions as repellent as modern readers do. John may have held those anti-Irish biases against Byrne, thus making the removal of the man from the bones all the easier. But the scandal and the fact that John waited a few years before he displayed the skeleton, demonstrate some acknowledgment of the cultural disapproval regarding how Byrne was treated in death. Yet John's portrait dismisses both this cultural disapproval and Byrne's personal wishes in favor of showing off his anatomical acquisition, thereby reinforcing his persona as a medical practitioner and scientist who prioritized the science over the patient.

While William's portraits do not seem to have captured public interest, we have evidence that John's portrait was commissioned with that outcome in mind. According to George Mather and other biographers, it was only because of William Sharp, the engraver and friend of both Reynolds and John Hunter, that the surgeon agreed to sit for the portrait at all. Mather writes,

buried men, women, and children before and after the act was passed. The industry was an open secret that did not significantly wane until the Anatomy Act of 1832, which placed heavier regulations on anatomy schools and permitted any person in legal possession of a body to use it for the purpose of dissection (Cheung 38). As a result, cadavers, dissection, and anatomy were necessary and culturally sanctioned activities, but also existed in a liminal space of legality, ethics, and respectability. 
"Sharp was exceedingly anxious to get John Hunter to sit for Sir Joshua, that he might engrave the portrait, and never let the great surgeon rest till he agreed to do so. The engraver seemed to be possessed with the idea that there was that character in Hunter's head and face which would be a fortune to him if he could only have it engraved" (217). Sharp recognizes the potential market value of John's portrait as a commodity, and this instance represents how media production and marketing enable celebrity, as Wanko, Luckhurst, Moody, and Turner describe. Not only was John's portrait completed because someone else thought it would be profitable, but the reason it would be profitable was due to something in John's disposition and look. What Sharp refers to as "that character in Hunter's head and face" goes beyond just looks. Sharp is trying to name something beyond appearance and beyond just a rendering of the surgeon's face, something that will draw viewers in and make people want to purchase the engraving. He seems to be referring to the "It" quality that Joseph Roach identifies in contemporary culture and traces back to the eighteenth century.

In his theorization of "It," he quotes Elinor Glyn, a "Hollywood tastemaker" and author whom Roach attributes with coining the popular usage of the term, defining "It" as that strange magnetism that attracts both sexes. He or she must be entirely unselfconscious and full of self-confidence, indifferent to the effect he or she is producing, and uninfluenced by others. There must be physical attraction, but beauty is unnecessary. Conceit or self-consciousness destroys 'It' immediately. In the animal world 'It' demonstrates [itself] in tigers and cats--both animals being fascinating and mysterious, and quite unbiddable." (Roach 4)

Certainly, Sharp's comments seem to be reaching for what Glyn and Roach term "that strange magnetism" in which desire and intrigue are vital but "beauty is unnecessary." Moreover, it was 
Sharp who wanted the portrait done, not John, who resented spending his time idly posing for Reynolds and was said to be a fidgety and restless sitter. John was wholly "indifferent" to having his portrait done and the popularity and profit its engraving might gain. What Sharp alludes to here is the reason why William achieved fame and John achieved celebrity; one brother had It, while the other did not, but wanted It. ${ }^{11}$ Moreover, because John's portraits highlight the split between his public and private selves, they capitalize on the appeal of his It quality. His portraits demonstrate how Rojek and Roach's theories can work in tandem to enable celebrity. Subsequently, William's portraits lack the public/private split and they do not help cultivate or demonstrate any It quality. Moreover, their portraits mirror the public personae they each cultivated. John's portraits mirror his public persona as someone who prioritized the science and the accoutrements of his experiments. On the other hand, the portraits of William, the more sociable and socially accepted brother, mirror his public persona as a successful gentleman. Thus, portraiture emerges as a mechanism that contributed to the celebrity of these two medical practitioners. Their anatomical collections participate in their creation of the celebrity as well. William's Pieces: the Collection and Museum at Great Windmill Street

As was the fashion with doctors in eighteenth-century London, both Hunter brothers created museums to show off their elaborate collections of anatomical specimens, fossils, books, art, and other items that filled curiosity cabinets around the city. Expanding trade routes and a growing merchant class fueled Enlightenment scholars' systems of collecting, categorizing, and curating. Curiosity cabinets, particularly from men of science, became popular and some collectors, like the Hunters, opened their collections to the public. In this way, their museums

\footnotetext{
${ }^{11}$ As one critic says, "Engravers have not been particularly kind to the memory of William Hunter, and there is no great engraved portrait to enable us to carry his likeness in our minds. In the case of his brother John, it is not so, for the magnificent engraving in line by William Sharp of Sir Joshua Reynolds's portrait of the great surgeon must remain as one of the finest engraved portraits ever executed" ("Portraits of William Hunter" 247).
} 
were typical of their profession and their time period. Both Hunter brothers housed their collections in the same location as their domestic homes and their anatomy theatres. And both museums exist today: William's at the University of Glasgow and John's at the Royal College of Surgeons in London. On the surface, their collections would seem to have had the same impact on their fame and their legacies. However, while William's museum and collection were impressive and worth curating for years after his death due to the sheer breadth of items, John's collection had an organizational principle that his brother's lacked, and it appealed to an eighteenth-century curiosity for oddities. When we examine the contents of the collections, it becomes clear that while William collected what was important professionally and what he thought was important to have socially, John collected for the purpose of articulating the vital principle of life, an eighteenth-century theory about the source of animation in living organisms. William's collection reflects someone who is interested in positioning himself socially and professionally, while John's reflects someone who is focused on proving a scientific thesis. Moreover, not only did John's collection have a clearer focus and appeal, but he added drama and intrigue to his collection in his presentation of it. As such, I argue that William's collection, while impressive and certainly a contributor to his fame, lacked the "It" quality of John's, which contributed to his celebrity.

First, let us examine the circumstances under which William opened his museum and anatomy school. As an anatomy teacher who helped professionalize surgical and anatomical education, William's legacy should have been the first public anatomy school in London, but unfortunately, his most ambitious goal never came to fruition. Despite his connections at court, his request for "the grant of a piece of ground in the Mews for the scite [sic] of an anatomical theatre" was denied (Simmons 24). Even with William's proposed personal contribution of seven 
thousand pounds for an endowment, his proposal fell on deaf ears. Not one to have his ambitions thwarted, William purchased a plot of land at Great Windmill Street in 1770, where he opened his own private anatomy school, one much larger than his rooms at Jermyn Street, where John took over lecturing. Great Windmill Street contained a "handsome amphitheatre and other convenient apartments for his lectures and dissections and one magnificent room fitted up with great elegance and propriety as a museum" in addition to his living quarters (Simmons 24). The location became well-known as an anatomy school and continued to function as the Hunterian School of Medicine until 1839, over fifty years after William's death.

As for the collection, it consisted of anatomical preparations primarily used in the study of anatomy by students unable to see the dissections themselves or unable to afford to be dissecting pupils (Brock, "William," 67). Minerals and fossils could be found in the museum, but they were not catalogued properly until “George Fordyce used Hunter's collections for his work on the chemical composition of minerals. He worked out a rational system of mineral classification, a system he applied in arranging and cataloguing Hunter's minerals for him" (Brock, "William," 67). Shells, insects, paintings, and books filled the museum in addition to William's extensive coin collection, but the vast collection was often curated by others. In some cases, as with the books about which Brock claims "it is difficult to see... anything more than his desire to 'possess a copy of every curious book on the face of the earth"', there seems to be no clear method or reason behind the collection (Brock, "William," 69). As such, it is difficult to disagree with Brock when she states that William's collection “was extraordinary only in the extent and variety of his collection. Nor was his museum in any sense a collection of curiosities, but had direct relevance to current interests and was organized in a rational manner" (Brock, “William," 67). In other words, while William's collection was impressive and useful for 
students, colleagues, and scholars at the time, it did not necessarily contribute to the degree to which William captivated public interest. ${ }^{12}$ As such, I would argue that while the museum as it exists now contributes to the propagation of William's professional legacy, the museum only reified the public persona as established by his public persona and portraits. The museum presents one consistent representation of William as someone who collects what was expected of an eighteenth-century man of learning. There is no suggestion that there is more than meets the eye-there is no suggestion of a split between his public self and his private self. As such, the museum contributed to his fame, but it did not add to his celebrity.

\section{John's Pieces: the Collection and Museum at Leicester Square}

John's collection, which now forms the Hunterian Museum in London, was not constructed with the development of an altruistic public anatomy school in mind. Rather, when he leased 28 Leicester Square, it was because Earl's Court was not large enough to house his family, collection, and animals. To remedy this, John leased 28 Leicester Square and the house behind it, 13 Castle Street, before constructing a large glass structure to house the largest specimens in his collection and to connect both houses. In examining his collection in terms of its appeal to the general public as well as the metaphorical significance of its structure, it becomes clear that while William's collection established his reputation as a lecturer and anatomist, John's collection helped solidify and amplify his celebrity.

Leicester Square was a popular place of residence and attraction for artists, performers, and writers. The square seems to have been a meeting place for the creative and eccentric, of

\footnotetext{
${ }^{12}$ It is unclear the degree to which the public had access to William's museum, but based on Helen McCormack's work, specifically "The Great Windmill Street Anatomy School and Museum," the museum was intended primarily for students with opportunities for people to attend public lectures. Moreover, Brock discusses the formality and ceremony that accompanied William's lectures and the "strict hierarchy" that dictated seating in the anatomy theater (McCormack 19). As such, for my purposes, it appears that William's collection would have been interesting to a general public but perhaps not intended for them.
} 
which John was both. John's biographer John Kobler provides a fascinating list of tenants and visitors: actors, playwrights, painters, sculptors, and men of science all frequented the pubs and coffee houses in the square (228). Meanwhile, Hogarth's widow lived on the same side [as Hunter] at No. 29, Sir Joshua Reynolds lived at no. 47, and "William Woollett, an engraver, [who] resided at No. 11 Green Street where a cannon projected from the roof and at frequent intervals the tenant... would climb up to fire the [cannon to celebrate] the completion of a new plate" (228). As a famous surgeon and anatomist with a growing anatomical collection, John Hunter was a fitting addition to the cast of characters at Leicester Square. And he used the location of the two houses he connected to his advantage. The front of the house, where one would enter from Leicester Square, held the public and respectable family quarters, Anne's entertaining rooms, and John's surgical practice. The back of the house, the Castle Street entrance, contained the dissecting rooms, quarters for a few of John's pupils, an anatomy theatre, and entrances (most notoriously a drawbridge) for his hired resurrection men to deliver corpses. The middle portion of the house(s) held the majority of John's anatomical collection--his most prized possession and achievement. By connecting the two houses together, John managed to connect two separate worlds: the world of civil homes and medical practices with the world of dissecting rooms, anatomical specimens, and body snatching. For John, this was ideal on a practical level because he now had room for his collection, his family and surgical practice all under one--or three--roofs. And if it had remained only for his private use, the house would be interesting and we still might interpret it as a metaphor for the man himself, but it would have had very little impact on his reputation and fame. As it was, the prospect of showing off his collection was too great to resist. 
After three years of construction, John opened his collection to visitors, and it was open for the whole year except in October, when he only allowed scientists to visit, and in May, the month he reserved for the "noblemen and gentlemen...in town during the spring" (Kobler 233). Visitors would have beheld a collection unlike any other, as they walked under skeletons of bottlenose dolphins suspended from the ceiling (the only ones in England at the time); preparations of bones and muscles of insects, fish, birds, and other animals; teeth of all kinds (170 to be exact); stomachs, sensory organs, diseased human organs, spinal cords, nerves, eyes, teeth, lungs--basically all pieces of organic life necessary for him to "display throughout the chain of organized beings the various structures in which the functions of life are carried on" (qtd. in Kobler 234). Needless to say, the spectacle of the visitors, students, and patients coming in and out of 28 Leicester Square would have greatly surpassed William Woollett's occasional celebratory cannon fire.

If we think of the house as a metaphor for John's public persona, it is easy to focus on how the two sides of the house (the domestic and the public, the civil and the grotesque) are opposed to one another, and to interpret this as true for John as well. In her popular work The Knife Man, biographer Wendy Moore equates John's relationship to the house and his presence in the neighborhood to that of Jekyll and Hyde. However, to view John as two dichotomous forces existing next to one another is to oversimplify his identity and his success. The key difference between the Jekyll/Hyde character and John—and between John and his brother William, for that matter-is that he is not hiding his "dirty work," but rather, he is making it available to a curious public. After all, even in the fiction of Stevenson's novel, Jekyll creates Hyde specifically because he feels he must hide the more sinister parts of his character. The difference speaks to the kind of person eighteenth-century Londoners found fascinating, and as 
with Reynolds's portrait of John, allowing the public to see both the respectable surgeon and the body-snatching anatomist capitalized on that fascination.

\section{$\underline{\text { Part IV: Codifying the Celebrity of Medical Practitioners }}$}

The result of William's inability to achieve celebrity in life was that he was

overshadowed by his brother's celebrity in death. The fascination that John managed to cultivate and that fueled his celebrity in his lifetime performs a similar function after his death. Whereas William's biographers consistently try to recover his work and justify his fame, John's life and work inspire a fan base that exists today. Examining the predominant narrative in the posthumous writings about their lives reveals how posthumous narratives both codify and perpetuate the cultural value of one brother versus the other. Biographers consistently position the fame of one brother in relation to the other, and when we compare how their legacy is positioned, two clear patterns emerge. The first is that most biographers assert John's celebrity without question, whereas biographers write William's life and career from the perspective of recovery, as if William has been forgotten and erased. Second, William's biographers typically attribute his erasure to the fact that John's posthumous reputation and fame has overshadowed him. I argue those narratives operate along the lines of fame, reputation, public interest, and ultimately celebrity. As such, these cultural mechanisms influence the representation of the work and lives of medical practitioners in medical history and cultural memory.

The first publication detailing William's life, An Account of the Life and Writings of the Late William Hunter (1783), written by Samuel Foart Simmons and annotated later by John Hunter, does not undercut William's fame because his reputation and fame would not yet have been forgotten so soon after his death. Instead, the memoir starts the narrative of William as an ambitious, fame-hungry figure. The memoir honors William's life and contributions to medicine 
and science, but the tone at the end of the memoir takes a defensive turn. Simmons, claiming that William should be remembered for his contributions to science as well as medicine and midwifery, says,

The munificence he displayed in the cause of science has likewise a claim to our applause.--Persons of an insidious turn of mind who seek to depreciate his merit in this respect, may perhaps endeavour to trace the motive by which he was actuated and ascribe to vanity what deserves rather to be considered as a commendable love of fame...He seems to have been animated with a desire of distinguishing himself in those things which are in their nature laudable; and being a batchelor, and without views for establishing a family, he was at liberty to indulge his inclination. Let us therefore, not with-hold the praise that is due to him; and at the same time let it be observed, that his temperance, his prudence, his persevering and eager pursuit of knowledge constitute an example which we may advantage to ourselves, and to society, endeavour to imitate.

(Simmons 69-70)

Rhetorically, this ending simultaneously allows for the reader to question William's "claim to our applause" while also defending it. Simmons, by writing about the doubts some people of "an insidious turn of mind" had about William, reinscribes that doubt and then traces it to William's supposed vanity, which he then reframes and defends as William's “commendable love of fame." Perhaps Simmons was anticipating negative responses by those who might hold grudges against William, which would have been likely, but rhetorically this defense of his “commendable love of fame" sets a precedent for other biographers to defend William's ambition and desire to be famous. The ending seems to indicate some insecurity about William's 
reputation and fame on the part of the author, and future authors reiterate this need to defend William's desire for fame and social status.

The next significant biography of William, Two Great Scotsmen, the brothers William and John Hunter by George R. Mather, does not appear until 1893. The memoir attempts to reclaim the nationality and cultural significance of both brothers as Scotsmen. In the introduction, Mather discusses the efforts made to preserve John's legacy, to which he concludes, “...is it matter for wonder that posterity should be entranced with the genius of this man? But why should his brother William be forgotten?...He was the pioneer; if it had not been for William we never could have had John..." (5). He claims that John's legacy has not overshadowed William's, but that in order to fully appreciate John, posterity must also recognize the merits of his brother. In other words, while John's legacy and fame after death has “entranced" people, William's must be recovered and understood in relation to his younger brother's legacy. Not only have William's legacy and fame been neglected, but the author implies that his fame and legacy arise out of the impact William had on John.

Similarly, R. Hingston Fox's biography, William Hunter, anatomist, physician, obstetrician (1901), attempts to recover the forgotten merits of the older Hunter brother. The work stems from a talk given at the Hunterian Society Oration, in which Fox presents the life of William to the society in order to demonstrate how he is "one worthy of [their] honour" (1). The Hunterian Society, named after and devoted to John, had heretofore paid little recognition to his older brother, and the author seeks to rectify this. In his introductory note to the biography, Fox writes that his aim "has been to give a complete outline of the life, works and place in Medical Science, of one whose fame has been too often eclipsed by that of his younger brother, the great John Hunter" (n.p.). As with Mather, Fox writes from the position of a biographer attempting to 
bring William out from the shadows behind John, and to reiterate how much William deserves fame and legacy. He concludes his address and biography by saying, "May we not rightly speak of "the era of the Hunters," and associate the two brothers together in the great work they did for natural science?" (33). Like Mather, Fox appeals to the society to remember and celebrate not just John, but also William, and he too makes the case for their joint fame and legacy.

The next book-length biography of William is published in 1946: New Aspects of John and William Hunter, by Jane Oppenheimer. The biography focuses on not just William, but also on Everard Home, John's brother-in-law. According to the author's preface, the purpose of the work is to shed light on these two men because of their relation to John Hunter. She writes,

John Hunter has been brought alive to our generation as a dominant figure in the history of scientific medicine. The chronicles of his activities, the nature of his person and the worth of his intellectual contributions have been analyzed for us in frequent Hunterian orations and in countless other descriptive and critical studies. William Hunter, his brother, and Sir Everard Home, his brother-in-law, are less often encountered...The present studies, therefore, seek to supplement what is published of these men by interpreting their characters in the light of their relationships with their contemporaries. (vii)

Once again, the author presents William's biography as it relates to John and because of his relation to him. In the foreword, Oppenheimer begins her discussion of the works written on John and William in the following appeal to the reader: "Although John Hunter became the greater of the two brothers, through making science the handmaiden to medicine as well as surgery, we may ask, should not William be given credit for influencing and training this unusual mind of his brother during its formative years? It would certainly seem so" (xiv). As with Mather 
and Fox, Oppenheimer makes an appeal to the reader to acknowledge and remember William even as she places him in relation to John. It is clear in her writing which surgeon she considers to be more important. The work, though about William Hunter and Everard Home, is not for surgeons in general, medical students, scholars of anatomy, or the successors of Home and the Hunters, but "For John Hunter's Successors" (n.p.). Oppenheimer, along with the other biographers, writes about William but still manages to position him as crawling towards the spotlight held by his younger brother.

Simmons, Mather, Fox, and Oppenheimer write the most significant biographies of William until the late twentieth century, when modern scholars such as Helen Brock and Roy Porter once again revive his fame and legacy. ${ }^{13}$ Authors consistently write William's biographies from the position of recovery, and more importantly, position him in relation to his more famous brother John; his fame cannot exist on its own merit after his death. Framing William in relation to John's fame, reputation, and public appeal, reveals how celebrity impacts the record of William's biography, life, and works. William is memorialized not just as an accomplished anatomist, obstetrician, and teacher but also as the less famous Hunter brother. The legacy of his work is dictated by his success or failure as a celebrity.

John's biographers make the exact opposite rhetorical decision in framing his celebrity. Rather than try to make a case for his fame, they simply state that he was and is famous. End of story. Whereas William's biographers attempt to make case after case for why we should remember him and why he was famous, John's biographers create a consistent narrative of celebrity that existed in his life and which exists today. Moreover, they contribute to and perpetuate his "It" factor by writing from the position of a fan looking up to someone who is

\footnotetext{
${ }^{13}$ Two other biographers, G.C. Peachey and Sir Charles Illingworth exist as well, but these biographies are referenced less often in modern scholarship.
} 
separate from the rest of the world, mysterious and unbiddable. When describing his work routine and its regimented rigor, one person writes, "What a life to live! Which of us would accept it, even to be, as Hunter is, immortal?" (Owen 343). The assertion of John's celebrity and his immortality is overt in other biographies as well. Writing in 1817 with the hope of filling in the gaps in John's previous biographies, Joseph Adams tells the reader that since John's death instead of being forgotten, we find his fame gradually increasing...To what do we owe this increasing posthumous fame?...His reputation has grown like that of other original geniuses. In proportion as we have since improved our knowledge of Nature, we see the force of, because we understand, what he taught. In other words, when we make a discovery in pathology, we only learn what we have overlooked in his writings, or forgotten in his lectures. (3-4)

According to Adams, John's posthumous fame increased because the value of his work, which was not understood at the time, becomes more apparent as more work is done and new discoveries are made. It is important to note that Adams assumes here that everyone, even twenty years after John's death, is so familiar with his work that they continue to understand it in new and developing ways, and as a result, think more highly of him. Adams depicts John's fame as ubiquitous and continually growing. There is no room in Adams's description to question or doubt John's fame - his fame is an unquestioned fact. By reiterating that posthumous fame in his biography, Adams is one of many biographers and writers who codify the existence and perpetuity of John's celebrity.

The most significant contributions to John's celebrity are the biannual celebrations of his life and death. These celebrations are examples of the media and marketing necessary for celebrity to exist according to Turner and Wanko. As mentioned at the beginning of the chapter, 
members of the Royal College of Surgeons and the medical community gather every other year to commemorate John's life and give an oration in his honor. One writer describes the event in 1854, over fifty years after John's death, as follows: "Every year there is a grand day at Lincoln's-inn-fields. Warriors and statesmen--poets and artists--men of celebrity in every walk of life, are found among the audience. The president is the orator...[and] he proceeds in a notice of his life, to show what the college and the world owe to this illustrious man" (Montgomery 3: 211). As he suggests, the entire purpose of the event is to celebrate the life of John Hunter, but the event also creates, replicates, and then expands on a narrative of John as a medical celebrity. The speakers often describe John in not just laudatory terms, but in terms of a celebrity who is immortal. In 1911, he is described as existing "forever in a niche in the Temple of Fame" (Owen 344). In 1815, the speaker implores listeners to follow in John's footsteps: "Pupils of Science! Seek the paths illumined by HUNTER: study the works of his talent, and labour: receive the Light of his truths; multiply its useful rays, and reflect them to the world around!" (Blizard 81). He is said to be one of "Such Luminaries in the murky atmosphere of a gainful Profession, whose humble glory is to do good...like the Lamps of Heaven; they cheer and enlighten us through those dark and fearful duties, which touch the springs of human life" (Carlisle 48).

The claim that John was the father of scientific surgery also appears throughout the orations. He is said to "[have] made surgery a science" (Abernethy 57), and is praised for focusing on science above all else: "His was that true and lofty spirit of science, which will not condescend to seek for eminence or wealth, by arrogating a degree of skill and dexterity that no other can attain...but which rests for its reward on the fair fame and merit of its acts; which is ever intent on the discovery of truth and is then most of all delighted, when it can most effectually assist others in the common labour and duty of us all--the advancement of human 
knowledge, and the alleviation of human distress" (Chevalier 76). The speakers are using terms of admiration and at times exaggeration for rhetorical purposes, in the hopes of adding reverence and inspiration to their speeches and to the event. But that performance and the repetition of that performance is exactly what has codified John's celebrity in London's medical community for the last two hundred years. Any celebrity he achieved during his lifetime has only been amplified by the ritualized celebration of his birth and death. The orations are published and then archived, so that they become part of the printed works that provide biographical details of his life. Thus, these celebrations perpetuate a cycle of media production, marketing, and consumption that enable the production of John's celebrity. As a result, if one begins to do research on the younger Hunter brother, it is impossible not to encounter this narrative of celebrity established by his biographers.

The narrative of John's celebrity codifies him in the annals of medical history as a largerthan-life figure that future surgeons should revere, and this, more than the empirical value of his work, contribute to why he has served as a source of inspiration for works of fiction and popular biographies. While William and John are both remembered by scholars, the younger Hunter brother inspired two (technically three) of the most famous literary characters: Dr. Jekyll/Mr. Hyde and Dr. Doolittle. As mentioned earlier, John's house at Leicester Square and his persona are said to have inspired the home in Stevenson's novel and the dual character of the polite doctor with the grotesque Mr. Hyde. ${ }^{14}$ It is difficult to imagine Stevenson being similarly inspired by the controlled and sociable William. John's residence, crowded with animals both domestic and exotic and equipped with a bona fide lion's den, is also said to have inspired Hugh Lofting's Dr. Doolittle, who was capable of speaking to animals. John Hunter appears in a recent

\footnotetext{
${ }^{14}$ For more on this see John Kobler's The Reluctant Surgeon, pgs. 229-230.
} 
mystery novel, The Dead Shall Not Rest (2013) by Tessa Harris, and a recent play, Mr. Foote's Other Leg (2015) by Ian Kelly.

In addition to fictional representations, he inspired three biographies intended for a general audience. The first, The Reluctant Surgeon: A Biography of John Hunter (1960), written by John Kobler, was described by a reviewer as "a vivid depiction of an extraordinary life" in which John "makes a record for indefatigable diligence, responsiveness to human needs, and brilliant scientific achievements that makes all mankind his debtor" (Goode 546). The second, Master Surgeon: John Hunter (1971) was written by Iris Noble, an author known for her biographies of famous figures such as Cleopatra, Shakespeare, Sarah Bernhardt, and Joseph Pulitzer, written for young adult audiences. The third and most recent, The Knife Man: Blood, Body Snatching, and the Birth of Modern Surgery (2007), by Wendy Moore, is described by Publisher's Weekly as a book about the "brilliant anatomist, foul-mouthed and well met, avid empiricist, and grave robber, John Hunter [who] cut an astonishing figure in Georgian England" (Publisher's Weekly). The next logical step on that trajectory is a movie or HBO series that adapts the biography for contemporary audiences. Unlike John, William's life and career remains in academic texts and at his museum in Glasgow, despite his desire for fame.

John's public appeal influenced how biographers, scholars, and scientists remembered and memorialized him. As such, his status as a celebrity when compared to his brother's lack of celebrity reveals a potential area for us to examine the development of the cultural interests, prioritization, and ultimately stereotypes of medical practitioners and scientists. The biographies romanticize John's eccentricities and personality in order to emphasize his genius and individuality. As a result, the "father of surgery" is immortalized as a man who preferred to work alone - he did not get along well with people in his professional community, was misunderstood 
by his profession, felt stifled by traditional education and means of success, was willing to throw away decency and decorum for the sake of scientific discovery, and made an unparalleled contribution to the field of surgery and anatomy. It is no coincidence that many of these biographers were writing during the height of the Romanticism and that John's qualities exemplify the Romantic individual driven by imagination and a desire to understand and connect with nature. William's prioritization of society and the perception of others seems much less appealing from the Romanticist's point of view. While it would be too far-reaching to claim that these biographers valued Romantic ideals that caused them to fanboy out over John, I would argue that more than just his scientific work influenced their opinions of him. With this in mind, we can better understand the development of cultural interest in certain medical practitioners and certain tropes of medical practitioners as well.

The depiction of John as the mad scientist locked away in his lab or a medical doctor incapable of connecting with patients is similar to tropes of characters in the medical profession that we find in literature, TV, and film. Classic works such as Mary Shelley's Frankenstein and Stevenson's Jekyll and Hyde depict men who will not only ignore social decorum but the rules that make up the fabric of society as a whole for the sake of their scientific discoveries. Modern depictions of doctors and scientists portray similar characters who focus on the medicine and science while lacking interpersonal skills. Dr. House in House, Dr. Brennan in Bones, and Dr. Yang in Grey's Anatomy are just a few examples from recent television shows. To fully understand the development of that trope and the cultural perception of medical practitioners it influences, we must first recognize that narratives of medical practitioners' lives and contributions to science are greatly influenced by cultural mechanisms like fame, reputation, and interest. Failing to make that distinction forces us to inherit cultural perceptions and value 
judgments of medical practitioners without the full theoretical framework necessary to analyze them.

Moreover, without recognizing that celebrity deeply impacts not only how we perceive medical practitioners but how we remember them within medical history, we are more likely to continue to privilege the work and lives of medical practitioners who achieved celebrity over those who did not. Future work should examine how medical celebrity intersects with race, gender, and class to create a certain narrative of medical history and development. 


\section{Chapter 2}

“that Mankind might reap the proper benefit”: John Ranby's Narrative of Sir Robert Walpole's

Final Illness, Celebrity, and the Medical Market

When Sir Robert Walpole, the First Earl of Orford (1676-1745), died of complications

related to a bladder stone on March 18, 1745, the eighteenth-century version of a high-profile exposé ensued. ${ }^{15}$ Walpole's surgeon John Ranby published A Narrative of the Last Illness of the Right Honourable: The Earl of Orford, which attributed the Earl's death to a combination of a misdiagnosis and a new medicine called the "lithontripic lixivium" (Ranby 13). Published less than a month after his death, the pamphlet detailed the illness, symptoms, and treatment the Earl experienced from May 1744 until he died. According to Ranby's account, Walpole suffered from a bladder stone, which his physicians misdiagnosed as a kidney stone, and the lixivium, a nostrum meant to dissolve stones in the urinary system, ultimately worsened Walpole's condition and led to his death. Ranby primarily criticized two of Walpole's physicians: Sir Edward Hulse (first physician to King George II) and Dr. James Jurin, the creator of the lixivium. By modern standards, the narrative was not an outright accusation of malpractice, but by the standards of the burgeoning eighteenth-century medical profession, the account implied that these physicians were quacks and that the lixivium was quack medicine. ${ }^{16}$

15 According to Ranby's autopsy, the stones which plagued Walpole up until his death originated in the bladder. Bladder stones and kidney stones are distinguished as separate but related disorders in contemporary medicine and they warrant different treatments. Kidney stones originate in the kidney and pass through the ureters into the bladder and through the urethra, whereas bladder stones originate in the bladder and then pass through the urethra. While kidney stones might be caused by concentrated urine, bladder stones can be caused by an inability to empty the bladder, causing minerals in the urine to crystallize ("What are Kidney Stones," "What are Bladder Stones"). The difference between the two matters to Ranby because, according to the appendix of his second edition, it made no sense to treat Walpole with a lixivium intended for the bladder if the physicians thought he was suffering from kidney stones (Ranby 8).

16 The term "quack" in the eighteenth century was used to stigmatize a few different types of practitioners 1 . those who practiced either ineffective, even dangerous medicine knowingly, 2. those practitioners whose practices and treatments turned out to be ineffective over time, 3. those practitioners who provided treatments or services 
Anonymous authors published five tracts in response to the Narrative between April until September 1745. Some of these authors defended the physicians and the lixivium, while others added to the controversy around the drug. After months of heated exchange, Ranby published another version of his account, which firmly reasserted his initial criticisms along with the claim that Walpole ordered him to write the narrative to reveal to the public the danger of the lixivium. ${ }^{17}$ I argue that Ranby's appeal to the public via his invocation of Walpole increased the narrative's potential influence on the drug's viability on the medical market and public perception of the physicians involved. I situate the pamphlet war within the eighteenth-century medical market as theorized by Roy Porter, which emphasizes the power that patients possessed both as consumers and as participants in the practice of medicine. He argues that the commercialized medical culture of eighteenth-century Britain encouraged medical practitioners to appeal to patients via advertisements and marketing techniques. I argue that Ranby's narrative should be read within this context of commercialized medical culture. As such, when the narrative claims to depict Walpole's experience as a patient, it exploits Walpole's celebrity to add cultural cachet to the narrative. Ultimately, this case study investigates how a surgeon exploited the fame of his patient in order to change public opinion about a particular drug and his profession. While the previous case study demonstrated how medical celebrity impacted the success of medical practitioners, during their lives and posthumously, this case study demonstrates how medical practitioners could use the mechanisms that produce celebrity as

condemned by the predominant medical profession. Here I am using it not as a definitive category that was fixed but instead as a category that was used to denigrate practitioners and negatively influence their reputation. Quack, in the eighteenth century, evolved as a category by which practitioners could claim superiority over their colleagues often because of legitimate claims, as was the case with Ranby's accusation, but also through evidence meant to damage reputation more so than protect patients.

17 It is unclear whether or not Ranby's account of Walpole's final wishes for the publication is accurate. The only evidence that exists in reference to this is Horace Walpole's description of his father's last words, which include Horace telling us, "When Sir Robert Walpole was dying, he told Ranby his chirurgeon that he desired his body might be opened" (Walpole 26: 12) 
identified by Turner, Wanko, and others to impact medical culture. In this chapter, I examine how print media, reputation, and public recognition or fame function as mechanisms that produced medical celebrity. As such, medical celebrity emerges from my analysis as the sociocultural phenomenon that enabled medical practitioners to use celebrity and the famemaking industries that produce it to shape cultural perceptions of medicine and to influence the medical market.

Medical historians refer to Walpole's death and the ensuing controversy as a notorious example of how medical treatments developed in the eighteenth century, and most do not spend much time discussing the cultural implications of the event. ${ }^{18}$ The study which informs my reading most thoroughly is a chapter devoted to Ranby in Sophie Vasset's edited collection Medicine and Narration in the Eighteenth Century. Vasset examines the pamphlet war as a process by which medical practitioners developed a "proper style for medical debate" and the genre of case histories (44). She synthesizes the primary arguments presented in each pamphlet in order to argue that the pamphleteers criticize Ranby primarily for two things: his inability to follow "writing conventions of case histories" and his literary style (33). Vasset analyzes the debate to demonstrate the development of the genre of medical narrative within the eighteenthcentury British medical community. Vasset claims, "The methodological debate here between Ranby and the pamphleteers concerns the status of the patient, and the manipulation that can stem from such an example. On the one hand, the patient's fame added undeserved scientific authority to the case, the pamphleteers argue, and on the other hand, the public account of the private opening of Walpole's 'venerable' body is deemed disrespectful..." (35). She claims, in

\footnotetext{
${ }^{18}$ For example, in "The Last Illnesses of Robert and Horace Walpole," Arthur J. Viseltear provides detailed medical context for Walpole's illness and treatment. Adreas-Holger Maehle's Drugs on Trial: Experimental Pharmacology and Therapeutic Innovation in the Eighteenth Century provides the most in-depth examination of the lixivium, its history within the treatment of bladder stones, and the context in which it was produced.
} 
other words, the other physicians criticize Ranby for how he handles the case of a famous patient. Vasset's summary of the debate and her rhetorical analysis of the eighteenth-century medical community's efforts to establish professional genres lay the foundation for my analysis. Just as Vasset establishes the rhetorical significance of the debate in the medical community, this chapter establishes the cultural significance of the debate to the general public, specifically patients at that time, who would have been quite familiar with the former prime minister.

Sir Robert Walpole possessed an incredible degree of fame and public recognition in Georgian England. As the first minister of the king with the title of "prime minister," Walpole maintained a position of power in the eyes of the public for over two decades. His entry in the Oxford Dictionary of National Biography states that "he dominated the public consciousness in a manner that no politician had ever done before... a consequence of the rapid development of the press during the early eighteenth century... as a result of which visual representations of the prime minister became familiar to a large part of the population" (Taylor n.p.). Depictions of the prime minister were commonplace, and were also the subject for some of the most popular satirists, including "John Gay, Samuel Johnson, Alexander Pope and Jonathan Swift" who "attacked Walpole, alleging that he governed through corruption and that his attitudes were debasing British public life and society" (Black 66). The most notorious satirical representation of Walpole can be found in Gay's The Beggar's Opera, arguably the most successful play of the eighteenth-century stage, which "draw[s] parallels between both the highwayman Macheath and the thief-taker Peachum on the one hand and Walpole on the other" (Taylor n.p.). As a polarizing figure in Georgian society, his degree of public recognition cannot be understated. Shortly after his resignation in 1743, Walpole became seriously ill in May of the following year due to bladder stones, and the complications from this illness killed him on March 18, 1745. 
Ranby's narrative details Walpole's symptoms, which we will use to create a picture of his illness and to provide a more comprehensive understanding of what the lixivium was supposed to treat. According to the narrative, Walpole's illness began in the spring of 1744 when he was "attack'd by an Intermitting Fever" (1). But the fever was soon accompanied by "great Pain in the Head, and Giddiness, violent Sickness at the Stomach, a frequent Inclination to Vomit, intense Pain in his Back, and [he] made Coffee-colour'd Water" (2). This first episode lasted "about ten Days" after which Walpole remained at home for about a month (4). During this time and after, the Earl experienced similar symptoms intermittently and passed bloody urine frequently, often brought on by motion (5-6). All of this was accompanied by a frequent need to urinate (6-7). As his disorder worsened, Walpole started passing urine that was almost entirely blood and experienced frequent pain at the "End of the Penis" (9). By January 1745, he managed to "void as much gritty Matter, as would cover a Shilling" (14). Ranby describes the symptoms that Walpole experienced, as well as the various treatments he received from the spring of 1744 until January 1745, for about fifteen pages. Following this portion of the narrative, Ranby provides entries from a journal that he and "one of [Walpole's] own sons" kept starting February 3, about a month and a half before Walpole died (15).

By February, Walpole passed a stone "exceeding the size of a Kidney Bean," which was removed from the urethra (15). His condition deteriorated as he passed more broken stones and continued to pass bloody urine of varying degrees. Ranby concludes the narrative by describing Walpole's final symptom: “About a Week before he expired, he was seized with a colliquative Diarrhea; which, being beyond the Power of Astringents, or Opiates, to remedy, contributed, no doubt, to put a more immediate Period to his tedious, and at Times, most intense Pains" (37). 
This final symptom, as Ranby points out, reminds the reader of the great pain Walpole experienced throughout the illness, which he succumbed to on March 18.

As Walpole's surgeon, Ranby would have been responsible for performing the procedure to remove the stones from the urethra and inserting the catheter. Surgeons could perform a range of procedures, but typically (and according to Ranby's narrative), prescribing nostrums, tinctures, herbs, dietary regimen, etc. was the duty of physicians. As a highly skilled surgeon, Ranby rose to prominence when he was appointed "sergeant-surgeon to George II," a position he obtained in 1740, and later as principal sergeant-surgeon, to which he was promoted in 1743 (Power n.p.). ${ }^{19} \mathrm{He}$ was instrumental in helping found the Company of Surgeons, the first formal organization wherein surgeons distinguished themselves from barbers, and was nominated as its first master as a result (Power n.p.). Ranby's surgical skill and his most significant publication, The Method of Treating Gunshot Wounds (1744), helped bring respect to his profession (Power n.p.). His reputation and renown were well established throughout the medical community and at court. He is remembered today for his treatment and narrative of the Earl, and his contributions to surgery as a professional field. His position as a surgeon within Walpole's group of physicians placed him in a unique position to criticize their treatments, which he was not involved in, and, as we shall see, his narrative serves as a public indictment against the lixivium prescribed to Walpole. ${ }^{20}$

\footnotetext{
${ }^{19}$ Ranby's role as surgeon within the group of the Earl's illustrious physicians illustrates the hierarchy in the medical profession at the time. Physicians possessed more credibility socially, economically, and politically, particularly in the early eighteenth century, than surgeons who had petitioned to have their own company separate from barbers. Ranby makes his appointment at court and membership of the Royal Society clear on the title page of the narrative, which reads: "By John Ranby, Principal Serjeant Surgeon to His Majesty, and F.R.S."

${ }^{20}$ Walpole's physicians provided him with numerous treatments, which include but are not limited to: ingesting bark, bloodletting, a plain diet with little wine, rest and limited movement, an emulsion of gum arabic, an undisclosed "soft, diluting method," clysters, suppositories, a draught of herbs, spirit of mint, opiates, and Jurin's lithontriptic lixivium. The only surgical procedures were the stone extraction that Ranby performed and the insertion of a catheter. Ranby overtly condoned the use of a several of the treatments such as the bark, which he says was a
} 


\section{Part I: The Lithontriptic Lixivium}

Let us first examine how Ranby and the other pamphleteers discuss the lixivium, which sets the stage for Ranby's appeal to a public audience. Ranby criticizes the lixivium in the narrative by strongly suggesting that it worsened Walpole's condition. According to Ranby, at some point in December 1744, Walpole and his physicians decided not to perform surgery to find and extract the stone, and instead he was prescribed a draught

of six Ounces of Pectoral Decoction without the Herbs, an Ounce of Syrup of MarshMallows, two Drachms of Spirit of Mint, and a Drachm of Dr. Jurin's Lixivium

Lithontripticum. This was directed to be given three times a Day; and the Dose of the Lithontriptic Lixivium gradually encreased to almost a triple Quantity. After some Time he took the Lixivium at his Meals in small Beer, in which was a Glass of Sack. So that from the fifteenth of December, to the fourth of February following, my Lord had taken six and thirty Ounces of this Lixivium. (13)

Immediately after informing the reader of the amount of lixivium Walpole consumed, Ranby says, "Bloddy Urine during this Period renewed the Alarm several times. On the ninth of January particularly he had a more than ordinary Flux of Blood, attended with greater Pain, than he had ever yet felt, at the End of the Penis. Clysters were frequently injected; but these proved of very little Advantage..." (13-14). Ranby implies that Jurin's medicine is to blame for this "more than ordinary" period of pain and blood. While his opinion of the lixivium is strongly hinted at in this first edition, we shall see that after the pamphleteers challenged his criticism, he responded with an outright condemnation of the drug in his second edition. But what exactly was this lixivium?

\footnotetext{
"judicious" decision (1). He also approved of the plain diet and rest, while not taking issue with the bloodletting, which he implies helped alleviate one of Walpole's fevers (2).
} 
Jurin's medicine was one of many attempts to dissolve bladder stones, a common illness in the eighteenth century, most likely due to a lack of "fresh water and vitamins" (Withey 22). Physicians knew that the stone needed to be dissolved and that there were certain substances, lithontriptics, proven to do this. The key was to avoid damaging any organs in the process, as well as to create a remedy that would consistently dissolve stones. Joanna Stephens, an apothecary in the mid-eighteenth century, created a recipe which through a small clinical trial was thought to be successful enough for Parliament to purchase the recipe for $£ 5,000$ and "in June 1739 her recipe was published in the London Gazette" (Maehle 68). Subsequently, other physicians and apothecaries could recreate "Mrs. Stephens' medicine," as it was called. Debate about the efficacy and safety of Mrs. Stephens' medicine arose after the publication of her recipe. While many "respectable practitioners" performed their own trials with patients to determine its efficacy and then "condoned" its usage, others claimed that rather than dissolving the stone, the medicine created sediments that when passed in the urine looked like pieces of stone from the bladder (Maehle 75, 76). After giving Mrs. Stephens' medicine to a patient not suffering from a bladder stone and then finding sediment in the urine of the patient, one physician concluded that the medicine was "not only useless but dangerous" (Maehle 76).

When Jurin attempted to cure his own bladder stone in 1740, he hesitated in taking Mrs. Stephens' medicine, choosing instead to create a "simplified and modified" version (Maehle 76). Mrs. Stephens' medicine "consisted of a powder, a decoction, and pills. The powder was made from calcined eggshells and snails; the decoction was produced by boiling in water some herbs together with soap, burned swines-cresses, and honey; and the pills consisted of calcined snails, wild carrot seeds, burdock seeds, ash, hips, and haws, all burnt to blackness, soap, and honey" 
(Maehle 68). Jurin eliminated some of the ingredients and chose instead to treat himself with soap-lye, which he found cured his bladder stone. Following his own successful treatment, he standardized his soap-lye, also trying to make it less nauseous. The exact mode of preparation was not revealed by him, however. Instead, patients were referred to the London apothecaries Beckington and Littlebury, who prepared the remedy, now known as 'Jurin's Lixivium lithontripticum,' according to his directions. Jurin justified this procedure by asserting that the quality of the remedy was guaranteed in this way. The price -- 1 shilling 6 pence per half pint bottle-- was, as he thought quite low anyhow, being an adequate compensation for the apothecary's efforts. (Maehle 77)

Rather than sell the recipe, Jurin decided to sell the drug exclusively through his apothecaries, who would prepare it for Jurin's patients or those willing to purchase the drug. By not releasing the recipe, he ensured that patients would have to buy from his apothecaries and that other physicians would not be able to copy it. Jurin, therefore, had a vested interest in the reputation of the lixivium because of its value on the medical market.

While the other pamphleteers respond to Ranby's criticism of the drug, their responses contradict one another, and they do not establish a clear vindication or condemnation of the drug. Vasset asserts that Jurin was the first to respond in An Epistle to John Ranby...on the Subject of his Narrative of the last Illness of the late Earl of Orford, as far as it relates to Sir Edward Hulse, Dr. Jurin, and Dr. Crowe (32). On April 22, just thirteen days after Ranby's account became available, The Daily Advertiser informed its readers the pamphlet could be purchased "at the Golden Lion in Ludgate-Street" for six pence (Daily Advertiser, April 22, Issue 4451). Jurin's text condemns Ranby for several things, including the lack of sophistication of the writing, Ranby's abuse of his relationship with Walpole, and Ranby's betrayal of the privacy of 
the physicians involved. But what Jurin most vehemently disputes is the "main battery of attack against Dr. Jurin's Lithontriptic Lixivium” (Jurin 20). He condemns Ranby for attributing Walpole's inability to pass the stone to the lixivium, and claims that this medicine has been unfairly portrayed to be ineffective or even harmful. He writes:

You tell us in Consequence of my Lord's taking it, that he voided a Stone, among others, 'compacted of three, very slightly cemented together; being unable, seemingly, to bear even the least Touch without danger of falling asunder.' Now, what should thus loosen this Cement, but the powerful Efficacy of the Medicine, he had been taking in so large a Quantity, as six and thirty Ounces and which would infallibly have clear'd His Lordship's Bladder of the few remaining Calculous Concretions, had there subsisted a competent Fund of Strength of Nature, to have supported him thro' a Scene or two more of that Tragedy, which, as you say, after ten Years' Intermission, began to be reacted the preceding May. From the unparallel'd Artifice, with which you tell the Story, an unwary Reader would be apt to conclude that the bloody Urine my Lord so frequently made, after Dr. Jurin had visited him, was altogether occasioned by this Lixivious Medicine. For, thro' the whole Series of your hopeful Journal, you do not so much as once remind us that this shocking Symptom had been almost a constant Complaint, long before the Earl of Orford entered on this dissolving Method. (22-24)

Jurin criticizes Ranby for misplacing blame for the symptoms onto the medicine without admitting that it may have helped dissolve the stone. He accuses Ranby, therefore, of misrepresenting the effects of the drug to readers. That criticism is bolstered by Jurin's overall tone of dismissal, which he uses to imply that Ranby exaggerated the circumstances of Walpole's death and betrayed the privacy amongst medical practitioners. He first accuses Ranby 
of blowing the case out of proportion: “The Earl of Orford was a long while labour'd under an incurable Distemper; took Medicines, prescribed him by Some of the most Eminent in their Profession, without any successful Effect; and consequently, finish'd the natural Course of his latterly tedious Mortality. What then?" (9) Jurin portrays Walpole's case as routine insofar as his illness, treatment, and cause of death are concerned. The lixivium, according to Jurin, did not contribute to his death because his death was caused by the illness and symptoms he suffered. Moreover, he claims that Ranby's accusations about the drug violate the privacy of the medical practitioners involved, relying on anecdotal evidence as opposed to facts. He writes, "Must the Chit-chat, and unguarded Expressions, dropt amongst intimate Acquaintance, and supposed Friends, in a Bedchamber, be immediately on such an Event published to the World, no ways interested in it; and formally set forth in an historical Tract as if they had been the grave Result of the most solemn Deliberations?" (10). Jurin accuses Ranby of violating the trust amongst medical practitioners deliberating about a patient's illness and then using those thoughts expressed in private against them in public - a fair criticism in an age in which there was very little regulation of how and when to diagnose a patient. According to Jurin, Ranby violates the conventions of medical practice, particularly those of physicians, under the premise that the public has a right to know because of the potential danger of the lixivium. And Jurin believes Ranby has misinterpreted the effects of the lixivium, which, if true, would deeply undermine Ranby's narrative and impetus for publishing it.

While Jurin defends the lixivium and undermines Ranby's criticism of it, the other pamphleteers are divided in their opinion of the lixivium, and only one author outright defends it. In A Letter from a Physician in Town to Another at Bath (May 13), the author defends the lixivium at length, and ultimately concludes: 
upon the whole, here was nothing to discourage either his Lordship, or his Physicians, from pursuing the Use of the Lixivium, but quite the contrary, that Medicine seeming to have had, in some degree, the very Effect it was intended to produce. Tho' I will not take upon me to be positive, that this Effect was produced by the Lixivium, since Dr. Hepburn informs us, that much the same had happen'd to his Lordship when he had taken no Lixivium. (18-19)

This is certainly not a ringing endorsement of the medicine, but the author essentially says that there was no reason to prevent the physicians from prescribing it, and he goes on to claim that the lixivium was not responsible for Walpole's death (33).

The author of An Epistle from a Physician at Bath to Dr. Rock, Occasion'd by The Letter from a Physician in Town to Another at Bath (June 5), responding to the author of A Letter, mocks the author's defense of the medicine and attributes it to the overzealous support of medicines, many of which are probably flawed, by his entire profession. In sarcastic support of the author's defense of Jurin, he upbraids the physician's involvement in the medical market: [I] am apt to think it Grounds for no mighty Astonishment, that a Man of his solemn Composure, and Hippocratic Countenance, should move in so conspicuous an Orb of Business: especially, as there are not wanting in his extensive Metropolis, numerous Examples of Those, who, tho' not endued with a Tithe of his Excellencies, are every Day stepping, even from behind Counters, into the glaring Eclat of far-resplendent Vehicles; and without Fear of Propriety, fall o' Prescribing your Drastics, Epispactics, your Hectic, Prophylactic, Sudorific, Prolific, Ortive, Abortive, Hysteric, Chimeric, Styptic (and why not Lithontriptic?), Pregoric, Emetic, Cathartic, Diuretic, Anodyne, Panodyne, Hypnotic, 
Narcotic, Exotic, and What-not-ic, Doses in greater Profusion, that one would wish any

Patient, one does not mortally hate, to be induced either to bear, or take. (15-16)

This author lumps Jurin's medicine in with the hundreds of other nostrums that fill apothecaries, and implies that Jurin is one of many physicians quick to overprescribe as they "move in so conspicuous an Orb of Business." He further critiques the author of A Letter for defending Jurin's medicine as if it is somehow beyond reproach. The author tells us that in order to let everyone know about the merits of the lixivium, what he calls the "unerring Remedy," he has posted an advertisement throughout town encouraging people to take the miraculous drug (13). This section is dripping with sarcasm, and the advertisement makes his rebuke abundantly clear: “To be had at Mr L-ttl-b-ry's, \&c. and no where else, the most powerful Lithontriptic in the World almost at prime Cost; the Profit being not above Two-pence, in what is sold for Eighteenpence: Prepared with all requisite Nicety, and hit off by Mr L-ttl-b-ry himself, according to Dr. Jr-n's essential Direction; as is more amply set forth in Pages Patent of a most delightful Letter, issued for that Purpose, from a Physician in Town to Another at Bath." (13-14) He is not just mocking the author of A Letter in this advertisement but also pointing out how absurd it is to support a medicine with so much gusto when its dangers may outweigh its benefits. Moreover, he is criticizing Jurin's refusal to publish the recipe of the medicine, requiring patients to purchase the lixivium from his apothecary.

The author of Advice to John Ranby, Esq., principal surgeon of His Majesty, and F.R.S. with some observations on his narrative of the last illness of the Right Honourable the Earl of Orford (April 25) offers a similar castigation of the physicians' proclivity towards overprescription. While highly critical of Ranby's narrative for its literary style, the author acknowledges that Ranby has a point when he claims that the physicians continued to use the 
medicine even after Walpole's symptoms worsened. He writes, "It is to me a Matter of Wonder...how Sir Edward Hulse and Doctor Jurin could go on to plye him [Walpole] with the Lixivium Lithontripticum, when they found the Bleeding not only not to stop, but to increase" which he attributes to their "Hopes of Relief [that] might encourage the trying a forcible dubious medicine" (12-13). Even Ranby's most severe critic admits that if the symptoms worsened, they should have stopped using the lixivium, and he reveals his doubt about the medicine's efficacy, deeming it dubious.

After these conflicting opinions written by anonymous pamphleteers appear in print, Ranby responds in September 1745 with a second edition of the Narrative, which includes an appendix in which he addresses the author of A Letter to a Physician. In it, he not only criticizes the drug but he condemns the use of it. Ranby tells us that the narrative was written so that "Physicians [would] be detter'd for the future from enterprising with such Edged-Tools, as...was the Lithontriptic Lixivium: which Dr. J had assured...was four times-stronger, than the strongest capital Soap-Lye" (Appendix 4). Whereas the first edition strongly implicated the lixivium, here it is an "Edged-Tool" much stronger than the other medicine commonly used to treat bladder stones. In other words, like an edged tool, the lixivium might be effective in its purpose, but only while causing a certain amount of damage. And, like an edged tool, it easily becomes dangerous. His final condemnation minces no words: "For my own part, I do firmly believe, that he died of the Lixivium" (Appendix 39). This accusation places all of the blame for Walpole's death on this one drug, claiming it is not simply dangerous but deadly. As such, future physicians should not use the lixivium, as it poses too great of a risk. Thus, Ranby accuses the drug of being too dangerous to prescribe to patients - a serious accusation in the unregulated, pre-clinical trial, 
eighteenth-century medical market, and one that had the potential to undermine Jurin's business and reputation.

Although Ranby and the pamphleteers do not use this term, they are debating about whether not the lixivium is quack medicine according to eighteenth-century medical standards-that is, medicine which has no useful effect on the patient's body and which might be harmful. Quack medicine, as Roy Porter has discussed at length, flooded the eighteenth-century medical market as manufacturing and advertising grew to meet the demands of an increasingly healthconscious consumer culture. Eighteenth-century newspapers were flooded with advertisements for all kinds of medicine to cure any sort of illness. In fact, it is at this time that "nostrums were far less likely to be panaceas"; instead, more advertisements appear for specific remedies targeting specific illnesses, of which the lixivium was just one of many (Porter 119). Presumably, Jurin wanted to heal people but also capitalize on the "advent of the standardized, brand-name commodity" which Porter argues "form[ed] the great growth of non-regular medicine in the Georgian era" (Porter 45). For Porter, regular medicine refers to physicians and treatments produced by university-educated physicians who possessed that title professionally (8-9). But as he argues, it was easy for new medicines to be stigmatized as non-regular or quack. The lixivium, created by a respected physician, would have been classified as regular medicine and would have possessed the credibility associated with that class of drugs. However, as Porter argues, the classification of quack versus regular medicine was hardly black and white. While some quack medicine may have been concocted for the purpose of profit rather than cure, others were produced and sold by physicians and apothecaries who believed in the efficacy of the product. Quack medicine did not exist as a binary but rather as a tenuous classification (Porter 10-11). That classification of quack versus regular medicine was determined through a combination of 
physician experience, unregulated experiments and trials of the drug, the experiences of patients, cultural perceptions, and rhetoric. As such, the pamphlets attempt to determine if the drug is quack or regular. Whether or not future physicians will consider the drug to be dangerous or quack partially relies on what these pamphleteers, Ranby and Jurin included, write about the medicine. The opinions they publish shape the reputation of the drug as perceived by practitioners. The processes by which medical efficacy is determined and the endorsement of a drug is granted, in this case, operate along the lines of reputation. As such, when the pamphleteers participate in the discussion of the drug, they utilize mechanisms of fame and celebrity to impact the reputation of the drug. This becomes more evident when we examine how the debate over the drug was intended not only to influence the perception of the medical community of practitioners and into the medical market of patients with purchasing power.

\section{Part II: Public Appeal}

Ranby's narrative was intended for a general audience, which he makes clear in the preface. In fact, the entire impetus behind the narrative is to inform the public about the questionable circumstances around Walpole's death. According to the preface, his account is a result of Walpole's final wishes to benefit greater mankind, a sentiment that would have raised a red flag for those familiar with Walpole's reputation. He writes,

Tis in Consequence of a solemn Injunction of his Nature, that I have penned the following Narrative; the illustrious Personage, who is the melancholy Subject of it, having, in his ebbing Moments, recommended to me in the most affecting Manner this peculiar Province of exploring, by Dissection, the Seat, and of course, the Cause of the Disorder, and of communicating to the World a faithful Relation of all the Circumstances: Desirous, from his innate Love to Mankind, when he could survive no 
longer to profit them, of being the Means of conveying what Good he could to them after his Death. (Ranby n.p.)

So Ranby performed an autopsy on Walpole because the Earl requested it before he died, and Walpole requested that he "communicat[e] to the World a faithful Relation of all the Circumstances" and his findings, which were intended to benefit a wide-reaching audience and the general public. Moreover, by telling the reader that the purpose of the autopsy and subsequent publication was to find the "Cause of the Disorder" and then communicate that to the public, Ranby implies that the circumstances around the Earl's death are questionable or suspicious. The preface makes it seem as though Walpole did not believe the cause of his death and the circumstances would be communicated correctly, or perhaps honestly, afterwards. It seems unlikely that this accurately depicts Walpole's feelings because, presumably, a man with his power would have dismissed his physicians if he was aware of their malpractice. Instead, Walpole's last wishes to Ranby serve the rhetorical purpose in the narrative of adding credibility to Ranby's claim and position Ranby as the only medical practitioner Walpole trusted. Walpole may or may not have said these things to Ranby, but the surgeon frames the entire narrative as an honest discovery of Walpole's cause of death, and as part of his duty to inform the public of what really happened. The narrative appeals to the public as an exposé, revealing the truth behind Walpole's death. As such, Ranby self-fashions himself as a narrator with access to Walpole's private self, capitalizing on public interest in the prime minister.

Additionally, Ranby's audience is not simply the medical community but the "World" and all of "Mankind"-in other words, everyone outside of medical professionals. Ranby reiterates this purpose more fervently in the appendix of his second edition, wherein the audience of his narrative cannot be misinterpreted. He not only restates who his intended audience is, but 
states that his purpose is to discourage people from using the lixivium. He writes, "I here repeat, that the Account I have given was in Obedience to the late Earl's Commands: who, in the Presence of his whole Family, directed me to open him, and communicate a History of his Case to the Publick; that Mankind might reap the proper benefit from a Relation of that nature, and Physicians be deterr'd for the future from enterprising with such Edged-Tools, as, in his Opinion, was the Lithontriptic Lixivium" (4). In the second edition he claims not only that he thinks the lixivium was dangerous, but Walpole did as well. Horace Walpole corroborates this claim in his written account of his father's last words: "Dear Horace, this lixivium has blown me up. It has tore me to pieces. The affair is over with me; that it may be short Dr Ranby, is all I desire" (Walpole 12). According to Horace, Walpole did fault the lixivium, and Ranby uses the Earl's opinion, uninformed as it may be, to bolster his accusations against the drug. Ranby hopes to deter physicians from using it while also revealing the danger of the drug to the public so that they might "reap the proper benefit."

Several of the pamphleteers address the impact that this kind of appeal might have on the general public. In Jurin's defense of the lixivium, he emphasizes the danger of appealing to readers unfamiliar with medical knowledge. He writes, "From the unparallel'd Artifice, with which you tell the Story, an unwary Reader would be apt to conclude that the bloody Urine my Lord so frequently made, after Dr. Jurin had visited him, was altogether occasioned by this Lixivious Medicine" (22-24). After first accusing Ranby of constructing a false narrative, Jurin says that "unwary Readers" could easily believe such falsehoods. Surely he is referring to a readership outside of the medical community, considering the deference and respect he uses in the rest of the letter when discussing members of his profession. "Unwary Readers" in this case refers to a public readership for whom the narrative was intended, and who would be duped by 
Ranby's criticism of the lixivium. If the "unwary Reader" believes Ranby, they are apt to think the medicine "occasioned" Walpole's "bloody Urine." According to Jurin, Ranby's narrative is capable of damaging the viability of the lixivium as a treatment for bladder stones in the eyes of the public. The other pamphleteers echo similar concerns about how the narrative might alter the public's perception of the lixivium, and medicine in general.

In his second pamphlet (September 9, 1745), the author of $A$ Letter accuses Ranby of trying to influence patients because he cannot convince his peers. He writes that Ranby "is resolved to do his utmost to deter...Patients from taking it" since he cannot convince the physicians "from giving so dangerous a Medicine" (8). While Ranby states in his appendix that the narrative is intended for both physicians and patients, the author of A Letter implies that patients will be most heavily influenced. He goes on to accuse Ranby of unnecessarily frightening patients by exaggerating the effects of the medicine, asking, "Why then such an Outcry, and so much Bombast, to frighten People from taking, perhaps, the only Medicine that has ever succeeded, in a Case hitherto thought insuperable by the Power of Physick? Does he think a Stone in the Bladder to be dissolved by taking whipp'd Cream?" (9). The author points out Ranby's appeal to the public and criticizes him for resorting to fear to influence patients after he is unable to influence those who might prescribe the medicine. His criticism echoes the concern that Jurin expresses about the potential of the narrative to damage the viability of the lixivium as a treatment for bladder stones.

But how important was the patient's opinion, or the perception of a treatment? Wouldn't patients rely primarily on their physicians to determine which drugs were safe and unsafe? According to Roy Porter's theorization of the eighteenth-century patient and physician relationships, patients contributed a great deal to their own diagnosis, and thus the patients' 
perceptions of their illnesses and treatments mattered a great deal to the types of treatment they sought and received. As Porter has argued, prior to modern diagnostic tools, which allow physicians more thorough access to the body, the patient's account of their symptoms and medical history "commanded a privileged status" in diagnosis and treatment (33). In addition to verbal accounts, it was common for patients to write to physicians who would diagnose their symptoms and prescribe treatment through correspondence with the patient. A patient's ability to understand, articulate, and then communicate their symptoms drastically influenced the type of treatment they would receive. Yet, Porter argues many physicians resented having to rely on patient narrative, and what resulted was a muddied negotiation between patient and physician. Both doctor and patient relied upon rhetorical strategies so that diagnosis and treatment could occur. It is the power that the patient holds in this relationship, and the fact that eighteenthcentury patients were quick to self-medicate, that leads to the proliferation of quackery, according to Porter. But quacks did not walk around with signs posted naming them as such, nor was there a standing body of power that distinguished quacks from professional doctors. Instead, as Porter argues, quack medicine filled the gaps in the growing medical market between empirical scientific data, a regulated system of training physicians, and patients' understanding of medicine. For instance, while some quacks knowingly sold useless medicines to people desperate to try anything, much of quack medicine resulted because of the circumstances under which eighteenth-century medicine operated. In the case of an affluent patient being treated for a fever, their doctor might have known, as many did, that to bleed the patient would only make matters worse, but the patient may have insisted on the treatment because of his or her past experiences and knowledge. The doctor had two options: refuse the patient treatment entirely, thereby losing a paying customer and leaving the patient in the hands of someone less capable, or 
take care of the patient themselves, which meant performing the treatment in order to, as Porter phrases it, "kowtow to patients' whims" while convincing the patient to take other more effective treatments as well (33). A circumstance like this one would have coerced or even forced professional, well-meaning, and educated physicians to practice, even if only for a moment, quack medicine.

Because patients played such a large role in diagnosis and treatment, they also contributed to the success and failure of a drug on the market. Unlike most modern medicines that receive approval through clinical trials or regulatory agencies like the FDA, eighteenthcentury medicine gained credibility through physicians' experiences and patients' opinions and perceptions. In other words, it gained credibility through reputation and the process of reputation formation. Because eighteenth-century medicine operated as a free market, those opinions and perceptions translated into purchasing power as consumers. Subsequently, appeals to the public about the efficacy of a drug had the potential to dramatically impact whether or not patients purchased and took certain medicine. As such, Ranby's narrative had the power to influence how patients perceived the lixivium, and by extension, to impact how patients perceived bladder-stone treatment in general.

Porter argues that increased advertising and manufacturing practices, combined with the disempowerment of the College of Physicians, led to an unregulated, consumer-driven market of medical practice and treatments (28-29). As a result, university-educated physicians, surgeons, apothecaries, and quacks all had to appeal to their patients as consumers. Porter describes the role that traditional credentials, like those of the physicians in Ranby's narrative, played in this market: "In the absence of legislation specifying minimum requirements for general practice, no hurdles stood in the way of setting up in medicine, and the notional divide between the regular 
and the quack might matter little to the public as contrasted to such factors as reputation, personality, and experience" (29). Patients, in other words, considered many factors before choosing which physicians and treatments to use. As Porter states, "a free market thus in effect became the norm, in which...even regular practitioners...often found themselves competing for custom with their colleagues... [and] pressed by the iron logic of the cash nexus, practitioners themselves would resort to such quackish practices as undercutting, price wars, gimmicks, nostrum-mongering, and client-poaching: over competition-induced quackery" (29). The commercialization of the medical market Porter describes takes place within the broader context of the rise of consumer culture in eighteenth-century Britain, which emphasized the greater cultural prioritization of the individual, fame, and celebrity.

In this type of free market wherein practitioners had to appeal to patients with unequal access to medical knowledge, fame and celebrity emerge as effective means of drawing public attention and establishing a relationship with the public. As a result, public perception of medical culture could be influenced by appeals to public opinion such as quack doctors who relied on their ability to acquire fame rather than credibility, nostrums and tinctures depicted in advertisements, and medical practitioners with amiable personalities and social connections could heavily influence patients. Fame-making industries, in such an economic climate, arose to satisfy the demands of patients who wanted treatment and to fill the gap in the organized discovery, recording, and dispersal of medical knowledge. With this as the economic backdrop of Ranby's narrative, his appeal to the public should be read as neither an altruistic exposé nor simply as a narrative that reflects conflict within professional medicine. For Ranby, the narrative has the potential to increase his reputation and fame by defaming his colleagues. However, when we consider the appeal he makes to the public within the context of the medical market, his 
narrative emerges as a marketing tool capable of deterring patients from purchasing and taking the lixivium and influencing their perceptions of medicine and treatment more generally. However, while Ranby addresses his narrative to the public, he does so under the pretense that he has been ordered by Walpole, and it is Walpole's fame that gives the marketing tool its power.

\section{Part III: Medical Celebrity on the Market}

As a prominent public figure, Walpole possessed greater public visibility and recognition than an anonymous patient, and the pamphlet war following his death echoes the tumultuous relationship between the prime minister and the press in life. As biographer Jeremy Black tell us, as the "first ministry [to hold] office for a long period after the lapsing of the [Licensing] Act," Walpole's efforts to "develop techniques of press management, manipulation and control" were of "particular importance" in light of the increased "development of the press" (100). Depictions of Walpole's ministry abounded in newspapers, and he made efforts to suppress oppositional writers while supporting ministerial writers and papers (Black 102-103). As the longest reigning minister and one who was depicted by both newspapers and literary writers, Walpole garnered a significant amount of public recognition.

When Ranby claims he is voicing the deceased Walpole's opinion, he invokes the cultural recognition and perceptions of Walpole. Regardless of public opinion related to Walpole, the recognition adds cultural cachet to the pamphlet. Several of the pamphleteers express concern over the public obtaining information about Walpole's illness and final moments. Most of them claim to be concerned with the optics of the narrative because of its lack of propriety and invasion of privacy, but one pamphleteer in particular directly mentions the way that Walpole's position as a famous public figure changes the narrative's impact on the public. 
The author of Advice, one of Ranby's most vicious critics, addresses his narrative to the surgeon and tells him:

when you go about to set up for a Writer, an Author of momentous Truths, and a fair impartial Relater of facts, it looks as if you intended to put in for Fame, and make your Name immortal; especially when we consider who have been the Occasion of your Writings...the great Earl of Orford. The scheme is well directed; for,... They had no other Way of going to heaven, but by taking fast hold of his Cloak, so it has been Custom, Time out of Mind, for Writers of all Sorts and Denominations (who can find no other Way to Fame) to have the Vanity of their Names being handed down to Posterity, together with those of the great Men of their Age. (2)

The author accuses Ranby of trying to become famous by associating himself in print with Walpole's fame and reputation. The implication here, too, is that this narrative would not have the same cultural cachet with only Ranby's fame and reputation to carry it "down to Posterity." The author makes a valid claim here because while Ranby garnered fame within the medical community for his other publications, his practice, and his work to establish the Company of Surgeons, he possessed very little cross-cultural appeal or fame. Educated, wealthy readers may have been aware of his appointment at court, but recognition of the narrative for his authorship alone paled in comparison to the public's awareness of Walpole's death and illness. In fact, the newspapers reported a great deal of information about Walpole's illness leading up to his death, which would have provided interested readers with some background about the case before reading Ranby’s narrative.

Beginning in early February, newspapers report Walpole's condition almost daily. On February 5, they reported that "the Earl of Orford, who has been very Ill for some Time, voided 
two Stones, each as big as Horse beans; which gave his Lordship so much Ease, that he afterwards went to Court" (Daily Gazetteer). Then, on February 4, "the Right Hon. the Earl of Orford lay at the Point of Death, at his House in Arlington-Street" (Daily Advertiser). On February 7, they corrected the optimism from the previous day: "It was thought Yesterday, that the Right Hon. the Earl of Orford was considerably better, but last Night his Lordship relapsed, and continues dangerously ill" (General Evening Post). Around this same time, it was reported that "the Earl of Orford has voided forty-five Stones of different Sizes, and a great Quantity of Blood, and that the Surgeons were afraid the Urethra would mortify, it having been miserably torn by extracting some of the large ones, and last Night 'twas thought his Lordship could not recover" (London Evening Post 7-9 February). ${ }^{21}$ These reports provide consistent and reasonably detailed information about Walpole's health. Reports such as these were not particularly unusual — details of the illnesses, deaths, marriages, and travel of public figures filled the newspapers. Eighteenth-century readers acquired significant access to the private lives of public figures as a result of the rise of newspaper culture. That industry of print media provided public access to information about the public and private lives of celebrities, a necessary precondition for celebrity according to Rojek. The newspaper, in this way, functioned as a mechanism of celebrity, which is after all a media production according to Wanko, Brock, and others.

\footnotetext{
${ }^{21}$ The subsequent reports inform readers that "the Earl of Orford was Yesterday so dangerously ill, that it was believ'd he could not recover" (Penny London Post 8-11 February). More hopeful reports followed: "The Physicians begin to have some Hopes of the Right Hon. the Lord Orford, tho' Yesterday his Lordship was very ill, and has rested but indifferently for this Week past" and his "Fever was thought much better" (Penny London Post 11-13 February; Daily Advertiser 13 February). By the February 13-15 issue of the Penny London Post, readers were informed that "We are assured that the Earl of Orford is much better, and gathers Strength daily." A few days later, the London Evening Post reported: "the Earl of Orford is thought to be much better, and drinks Asses Milk" (14-16 February). However, by February 22, they reported that he "relaps'd, and lies dangerously ill" (Daily Post). Then, once again, he is reported as improving on February 23: "The Right Hon. the Earl of Orford is so much better that 'tis thought his Lordship is now out of danger" (Westminster Journal). This is the last report for several weeks, until suddenly on March 19, they reported his death: "Yesterday, about One o'Clock died, at his House in Arlingtonstreet, Piccadilly, of an Inflammation in his Lungs, aged 71 Years, the Right Hon. Robert Walpole..." (General Evening Post).
} 
Walpole's case is one of many, and if an interested public wanted to follow the goings-on of his life, the newspaper reports gave them the ability to do so. While we cannot know the number of readers that would have read these reports_ - or those who subsequently read Ranby's narrativethe frequency and availability of the reports indicate that Walpole's illness was not a secret and that a great deal of information about his illness circulated amongst the public.

Ranby's narrative, which could be bought "at the Crown in Ludgate Street for just a shilling," picks up where these reports left off, appearing less than two weeks after the last newspaper report, to give voice to Walpole from beyond the grave (Daily Gazetteer 9 April). As such, it engages with the potential public interest and readership that the Earl's fame elicited. As the author of Advice point out, this adds not only to the potential for Ranby's reputation to grow, but also to the potential reach of the narrative over time. Furthermore, this narrative does not simply demonstrate an isolated moment, but instead serves as a case study for a much larger trend, in which medical practitioners engaged with industries of fame to appeal to and influence patients. And eighteenth-century patients, in particular, were susceptible to these appeals.

As consumers in a medical free market, patients often used the medical information made available to them through public print media in order to make decisions about their personal health. Porter claims that the vast majority of eighteenth-century patients were deeply invested and interested in their personal health and the treatment they should receive (34). He tells us, "Educated Georgians believed it was their positive duty to know enough about medicine to evaluate and collaborate with their physicians...[and] there were many organs through which such medical knowledge circulated to the laity. The vast expansion of the press proved a particularly good medium for public information and discussion" (34). The appeal that Ranby makes, then, is not to an uninformed or uninterested public, but to an audience for whom this 
type of content already existed - the narrative plays upon that public interest. Because this particular narrative is about a famous figure, it carries more cultural cachet, which increases its impact as a marketing tool. Readers, interested in how bladder stones should be treated, could apply the conclusions they drew from Ranby's narrative of Walpole's illness to their lives. Moreover, their experience of acquiring and absorbing what they read would have been influenced by Walpole's presence in the narrative. In this way, the narrative echoes a marketing genre often employed to influence patients' opinions and perceptions of drugs specifically: the patient testimonial.

Before clinical trials became a scientifically and socially accepted means of validating the efficacy of a specific medical treatment, patient testimonials legitimized physicians, along with their diagnostic ability and methods of treatment (Porter 52-53). Often associated with quack medicine, patient testimonials appealed to consumers, as they shed light on the type of experience they might have should they seek treatment from the physician in question. Patient testimonials, printed in newspapers, dramatized the experience of patients with illness and treatment, though "critics warned that no credence should be vested in these testimonials" (53). True, exaggerated, or completely false as they may have been, as a marketing tactic they worked because they appealed to one of the most powerful market forces: the patient's experience. And, as Porter argues, consumers and patients of all social ranks and education could be taken in by such testimonials (53). Moreover, Porter argues that not only could people of rank and fashion be duped by the testimonials, but they were also known to participate in them (53). People such as Horace Walpole, Henry Fielding, and Byron "publicized their own attachment to [quack doctors]" (53). 
Porter blames the rise in commercialized quack medicine on the industries that made this type of information available to the public. Referring specifically to newspapers, and all they contained, he claims, "newspaper advertising constituted an epoch in quack medicine promotion by vastly multiplying the number of potential buyers accessible to a vendor" (117). Advertising and printed information about medicine, aimed at influencing patients, filled newspapers and stimulated both the supply and demand for medical treatment, and quack medicine in particular benefited. As such, patient testimonials were double-edged swords that simultaneously influenced patients with their narratives and sometimes because of who was writing the testimonial, but those accounts were not necessarily based in scientific fact. Moreover, they proliferated the logical fallacy that the medical experience of one patient could be applied to many.

While it was not written in the form of a patient testimonial, I would argue that Ranby's narrative evokes this genre because he claims to be relaying Walpole's experience. Walpole supposedly not only commands Ranby to write the narrative as his final wish, but he also orders him to reveal the truth of the lixivium, which he thought was dangerous. So, while Walpole did not write the narrative, a narrative of his supposed experience exists nonetheless. Even readers who assumed Ranby fictionalized everything would be unable to disassociate Walpole from the narrative. The narrative that Ranby writes intersects with and influences a reader's perception of Walpole because perceptions of public figures are created through narrative. This is why patient testimonials made by public figures worked as a marketing technique because they added to the narrative of that public figure the reader already possessed. This phenomenon which enables that 
success has been identified by celebrity theorist Marvin Carlson as "ghosting" (7). ${ }^{22}$ Ghosting is the process by which representations of famous people are influenced by their previous representations. For instance, as will be discussed in Chapter 3, when an eighteenth-century actress like Susannah Cibber took the stage, her previous roles and any other narratives audiences had of her influenced how audiences perceived her in that current moment and in that current role. Patient testimonials from famous figures rely on this phenomenon by adding a famous person's experience with medicine to the other narratives and context that readers might have of that famous person. As such, regardless of whether or not Ranby is telling the truth or if readers believe him, this narrative is impacted by the other representations and narratives of Walpole readers possessed. By claiming to share Walpole's experience as a patient, Ranby uses the former prime minister's fame and the potential for the narrative to be ghosted by narratives of that fame, adding cultural cachet and significance that would not exist if the narrative were about someone less famous.

Moreover, the ultimate goal of a patient testimonial is to persuade readers about a particular drug, so that they may purchase or avoid that drug. While members of the medical community may not have respected patient testimonials, they appealed to the general public who prioritized their experience of medicine over the knowledge of their physicians. As such, when we read the narrative within the context of a medical free market in which patients could be influenced by marketing tools, Walpole's fame functions as a highly effective way to increase the impact of the narrative on the public. Subsequently, Ranby's narrative participates in an eighteenth-century medical market that valued patient experience and opinion, and by writing

\footnotetext{
22 "Ghosting" was first used by Carlson to describe a phenomenon that occurred specifically in the theater, and celebrity theorists such as Joseph Roach and Laura Engel discuss the term specifically in relation to eighteenthcentury celebrity. My interpretation of the term builds off of their theorizations.
} 
Walpole's experience, Ranby propagates notions that unverified or faulty individual patient testimonials should serve as the basis for decisions about the efficacy of medical treatments. The narrative, as a result, validates other means by which patients acquired dangerous misconceptions about medicine (i.e. advertisements, anecdotes, patient testimonials, and their own experiences). Ranby's narrative, however, not only exploits the fame of Walpole to influence public opinion, but to a lesser degree exploits the renown of Walpole's physicians as well.

Throughout the narrative, Ranby questions the judgment of Walpole's physicians. In addition to questioning their course of treatment and use of the lixivium, he also accuses them of misdiagnosing Walpole. The question of whether or not Walpole's stones reside in the bladder or the kidney is brought up several times in the narrative. Each time, Ranby says Walpole's physicians believed it to reside in the kidneys, whereas he believed it to reside in the bladder. He confirms his hypothesis in his brief discussion of Walpole's autopsy, which was the second part of Walpole's dying wish. As aforementioned, in addition to "communicating to the World a faithful Relation of all the Circumstances," Ranby was also asked to “explor[e], by Dissection, the Seat, and, of course, the Cause of his Disorder" (Ranby n.p.). The implication of this statement being that the physicians in charge of diagnosis and treatment had missed the cause of the disorder and not located the seat, or root, of the problem. In Ranby's autopsy, he focuses almost exclusively on the bladder. He tells the reader "the Contents of the lower Belly were all, except the Bladder, in a natural State. This Vessel had expanded itself above the Os Pubis at least four Inches: On cutting into its Cavity there issued a Quantity of Urine, with three large Clots of coagulated Blood; which no doubt had lain there for some Time" (38). He continues to describe the bladder, which has several spots of inflammation and "several small Stones" lodged 
in its membrane (38-39). He concludes by describing the prostate, which was harder and larger than normal, as was the pelvis, but "no Defect was discoverable in the Kidneys, nor Ureters" (39). The autopsy, while brief and straightforward, confirms that Walpole's physicians were incorrect in their assessment of the seat of the disorder. Ranby, who stated several times that the stone was in the bladder, is proven right. To the "unwary Reader" this seems like a complete validation of Ranby's accusations against Jurin, Hulse, and Crowe. According to this portrayal, these respected physicians completely misdiagnosed the former prime minister, and more than that, refused to listen to the surgeon who knew better and consistently insisted upon the correct diagnosis. The autopsy calls their reputations into question not just in terms of how they choose to treat patients, but also because a misdiagnosis of this magnitude would cause a reader to deeply question the merits of Walpole's physicians.

While Ranby's critique of the physicians had the potential to negatively impact their reputations, his critique of Hulse in particular had the potential to improve Ranby's own career and reputation. Edward Hulse was a very well-respected physician at court and in the medical community. In 1739, he was made a baronet and he was appointed as first physician to King George II in 1741 (Power n.p.). While the other physicians involved certainly made decisions about Walpole's treatment, and Jurin was responsible for the lixivium, Hulse was Walpole's first physician, and as such served as the overseer for his diagnosis and treatment. When Ranby wrote his initial pamphlet, arguably the tamer of the two, he essentially called Hulse's judgment as a physician into question because not only did Hulse misdiagnose Walpole, but he also let him take a potentially harmful drug. And by making this accusation, Ranby is accusing the king's physician of lacking judgment. Not only was this a heavy criticism that could easily destroy 
Ranby's credibility in the medical community, but he makes the accusation at an incredibly risky time.

When Ranby became embroiled in this pamphlet war, surgeons all across England were preparing to take a significant step up the social, political, and economic ladder. On May 2, 1745, just three weeks after Ranby's publication, Parliament passed a bill that separated surgeons from barbers and founded the Company of Surgeons, what is now the Royal College of Surgeons (Jarvis 117). The bill improved both the professional and social status of surgeons “incorporate[ing] them under the name of Masters, Governors, and Commonality of the Art and Science of Surgery" (South 269). Ranby was at the center of this political triumph as the future of the company depended largely "upon the influence Ranby was known to have with the King" (Jarvis 116). To reward Ranby's contributions to the Company, his peers elected him to the position of first Master of the Company of Surgeons (South 271). Ranby’s pamphlet was published just in time for members of Parliament to read, and his accusation had the potential to make all surgeons seem ill-equipped to participate in the professional medical community for the many reasons the other pamphleteers pointed out. As one historian put it, "[it] was somewhat indiscreet to choose to quarrel with the physicians at this particular juncture" which he attributes to Ranby's general lack of “tact” (Jarvis 116). This statement implies that Ranby's decision to attack prominent physicians at this critical time was rash rather than reasoned. However, such a rash action contradicts the character of someone invested enough in the establishment of the Company that he was elected its first master and then re-elected in 1751 (South 271). Why would he act against his own professional interests by jeopardizing the passage of the bill? Was it that he felt so bound to Walpole's last wishes, if they existed, that he needed to publish the pamphlet regardless of its possible consequences? That seems doubtful when he could have 
simply waited a few weeks. Regardless of his motivation, I propose we read this decision to publish before the bill passed for its potentially positive influence on members of Parliament and the king.

Because Ranby is not simply criticizing any physician or any one particular mistake made by a physician, but is instead questioning the very judgment of the physician to the king, the narrative implies that perhaps the best physician has overblown his skill. After all, the narrative does not portray Walpole's illness as something all of the medical practitioners involved misdiagnosed and mistreated. Rather, the narrative portrays Ranby to have been right all along, while Walpole's physicians refused to listen. Here, Ranby's position as a surgeon within the medical profession potentially matters a great deal. In Ranby's account of Walpole's case, it is the surgeon who diagnosed the patient correctly, and the physicians who missed it. And it was the surgeon who disagreed with the use of the lixivium, while the physicians consistently increased Walpole's dosage despite signs that it might be harmful. His narrative, in this way, is not simply a critique of Walpole's case and the physicians involved, but a critique of the physicians on the case and a veneration of the surgeon. What better way to demonstrate the importance of the profession of surgery, which so many looked down upon, than to expose some of the most esteemed medical practitioners as incompetent enough to kill the former prime minister?

Moreover, his accusation gains more traction because it focuses on the identities of wellknown physicians. By criticizing Hulse's diagnosis, Ranby questions the judgment of the first physician to the king, implying that if these were the decisions he made for Walpole, perhaps his judgment would be as faulty when treating other patients at court, such as the king. That is not to draw a false equivalency between the importance of Walpole's health and the king's, but instead 
to demonstrate the potential impact of Ranby's claims against Hulse. As such, when we consider that Ranby's influence with the king was a vital part of the bill's passage, his decision to publish does not appear rash but instead appears to bolster the importance of his profession. Based on the little biographical information that exists on Hulse and the information historians have written about George II's physicians, it is unclear whether or not Ranby's pamphlet had any impact on Hulse's career or the king's opinion of him. However, this does not negate the fact that Ranby's pamphlet had the potential to influence the reputation of Hulse and the other physicians in the medical community, at court, and in the general public. Thus, Ranby's decision to make these criticisms public just before the bill went before Parliament demonstrates how a medical practitioner could exploit the public recognition of his patient and peers to influence the social, cultural, political, and economic status of his profession.

Subsequently, we see the narrative demonstrate how the cultural mechanisms that enabled celebrity impacted the medical market. Unlike the case study of the Hunter brothers, here no one particular person emerges as a medical celebrity. Ranby is not a medical celebrity because he does not attain the level of cultural recognition of the Hunter brothers. While Ranby could have benefited from the narrative in terms of its influence in founding the Company of Surgeons, and his legacy is connected to Walpole's case, he did not even achieve the level of fame of William Hunter, let alone the medical celebrity of John. Neither is Walpole a medical celebrity. Not only is he not alive to experience any impact this narrative might have on his fame, his illness and treatment do not significantly impact public perception of the prime minister as a whole. Unlike what we will see in the next chapter in the case of the actress Susannah Cibber, whose relationship with her audience was consistently impacted by her illness, or Peg Woffington's very public and abrupt end to her consistent reign of health on stage, 
Walpole's fame and reputation are too bound up in his political and economic influence to be significantly impacted by this pamphlet war.

Rather, the narrative, its appeal to the public, and the ensuing pamphlet war demonstrate how medical celebrity functions as a sociocultural phenomenon wherein mechanisms like fame, reputation, and public interest impact public perceptions of medicine and ultimately the medical market. ${ }^{23}$ Graeme Turner theorizes the function of celebrity as a cultural process whereby celebrity is "a genre of representation," "a discursive effect," and "a commodity traded by promotions, publicity, and media industries that produce these representations and their effects" $(10-11){ }^{24}$ This case study of medical celebrity exhibits each of these qualifying factors. For Turner, "genre of representation" refers specifically to modern forms of media such as film or TV. Essentially, though, he is referring to genres that depict a narrative of celebrity to an audience. I would argue the narrative of Walpole functions within this classification, as it is built upon a narrative about the famous figure, which was available to public audiences. Celebrity also has a "discursive effect," which Turner theorizes as the cultural impact of discursive representations of famous figures and celebrities (8-9). As such, the narrative's potential appeal to the public to change their opinions and perceptions on the lixivium and medicine in general

\footnotetext{
${ }^{23}$ Unlike the Hunter brothers who engaged with and were represented by fame-making industries in order to influence their own reputation, legacy, fame, and celebrity, Walpole's fame serves as a source of cultural cachet for the narrative. While we could analyze Ranby's narrative as a means of attempting to achieve medical celebrity for himself, his emphasis on Walpole, who was a great deal more public and famous, impedes that reading. Whereas with the Hunter brothers, celebrity was self-fashioned to benefit their medical careers and legacy, here celebrity is used to influence readers and patients. If the Hunter brothers were most well known for their treatment of a famous patient, they would have most likely been eclipsed by that fame and unable to achieve medical celebrity.

${ }^{24}$ While Turner theorizes modern celebrity as opposed to eighteenth-century celebrity, his definition is an attempt to create a broad understanding of celebrity as it has been discussed thus far by theorists. Moreover, I am applying a common but precarious practice of early celebrity studies wherein modern celebrity theory helps elucidate celebrity from the past. This type of work relies on the foundational research of Leo Braudy in The Frenzy of Renown, Fred Inglis in A Short History of Celebrity, and others who claim that modern celebrity can be traced back to the eighteenth century.
} 
could be interpreted as its discursive effect. ${ }^{25}$ Lastly, celebrity is "a commodity traded by promotions, publicity, and media industries that produce these representations and their effects." In other words, because the representations of celebrity have a cultural discursive effect, celebrity becomes valuable both as an economic and cultural commodity. For example, any form of media that portrays someone like Kate Middleton and which might impact the public's perception becomes a commodity—not because Kate Middleton possesses anything intrinsically, but because anything that invokes her celebrity has more economic and cultural value than it would without her celebrity. Certainly, this is true of Ranby's narrative. Without Walpole, Ranby's narrative still has the potential to influence patients but not to the same degree; with Walpole, his narrative becomes more valuable both economically and culturally. Because of the potential impact of the narrative on the medical market, it functions like a commodity to be capitalized on by Ranby and the other pamphleteers. As such, the narrative emerges from my analysis as an example of how medical celebrity as a sociocultural phenomenon functioned on the market in which a medical practitioner engaged with the media industry of the newspapers and their advertisements in order to publicize his narrative.

Ultimately, analyzing this function of medical celebrity in eighteenth-century Britain adds to the study of celebrity and also to the study of the eighteenth-century medical market and the means by which medical knowledge about drugs, treatments, illnesses, and physicians was marketed to patients. While economic, political, and social factors may have influenced how

\footnotetext{
${ }^{25}$ Here, I am emphasizing the potential for this discursive effect as discussed based on the historical and economic context in which the pamphlets were published. I am not asserting that Ranby's narrative was successful in decreasing sales of Jurin's lixivium, merely that this is a potential outcome of the narrative and, based on the textual evidence, it was Ranby's aim. According to my search of the Burney Collection of $17^{\text {th }}$ and $18^{\text {th }}$ century newspapers, Jurin's lixivium was not featured in any advertisements specifically devoted to the lixivium. Patients would have known about the medicine based on Jurin's initial publication of his experience with bladder stones, and they would have encountered it through their physicians. There is at least one instance in which one of Jurin's patients expressed anxiety about taking the medicine for fear of its potential side effects (Rusnock 45).
} 
patients perceived medicine, so too did fame and fame-making industries. That potential influence is the function of medical celebrity that this case study demonstrates. The pamphlet war is merely one example of how a medical practitioner could exploit the fame of his patient and peers to help influence public perception of a drug and of certain physicians. Future work should be done to unearth other examples of this function of medical celebrity, which on the one hand promotes the democratization of medical knowledge to consumer patients, but on the other hand, has potentially dangerous consequences.

Ranby's narrative of Walpole's illness may have been correct in its assessment of the lixivium, in which case the narrative would have served a public good. However, by employing fame-making industries to shed light on one particular case, Ranby's narrative utilizes the identity and fame of the patient to add credibility and cultural cachet to its content. As such, Ranby propagates a false understanding of how patients should make decisions about medicine. His narrative capitalizes on the cultural assumption that the experience of one individual patient contains enough information for people, both physicians and patients, to base future medical decisions on. Walpole's experience with the lixivium and with his physicians was Walpole's experience, and it should not have been upheld as an example to be applied to all uses of the lixivium, bladder or kidney stone cases, or all experiences with physicians. The narrative implicitly denigrates, as a result, more empirical means of studying drugs and determining the success of physicians.

In terms of the development of modern medical practices, Ranby's narrative reflects the shift in eighteenth-century medical culture from qualitative accounts of individual patient experiences to quantitative analyses of large-scale surveys of patient experience. Future medical 
publications that discussed how to treat bladder stones tend to rely on this type of data. ${ }^{26}$ As eighteenth-century medicine was influenced by more regimented and methodical scientific approaches to studying the efficacy of drugs, diagnosis, and treatment, medical practitioners increasingly relied on this quantitative data. The celebrity of an individual patient or physician mattered a great deal less when the conclusions were based on the experiences of hundreds of patients versus one. But this does not mean medical celebrity's impact on public perceptions disappeared as scientific and empirical approaches to medicine increased; rather, I would argue that individual medical practitioners were no longer responsible for the exploitation of a patient's fame.

With the commercialization and vast expansion of the medical market in the $20^{\text {th }}$ and $21^{\text {st }}$ centuries, utilizing the fame of patients has been outsourced to the advertising and marketing agencies associated with certain drugs, hospitals, physicians, etc. Whereas Ranby, and other medical practitioners, had direct access to fame-making industries that allowed them to influence the medical community and the public, now this access is more indirect. Our contemporary version of this function of medical celebrity comes in many forms: exposés about celebrity illness, treatment, and usually death; celebrities paid to advertise, endorse, or support pharmaceutical companies and their products; or celebrities who use their public platform to support, condemn, or draw awareness to certain illnesses or treatments. Recent examples of celebrity exposés include the books written about Michael Jackson's death and ultimately his use of the drug Propofol, or the media frenzies that surrounded the deaths of celebrities who overdosed on prescription drugs such as Heath Ledger, Brittany Murphy, or Anna Nicole Smith. Recent examples of overt endorsements include Brooke Shields advertising Latisse, a drug that

\footnotetext{
${ }^{26}$ As one medical historian points out, in Jurin's second edition of his treatise on bladder stones, he emphasizes the statistical improbability of Walpole's case being applicable to other patients (Maehle 77).
} 
grows eyelashes, and which probably would have appealed equally to eighteenth-century consumers; celebrities such as Katie Holmes, Juliette Lewis, and Lorraine Toussant participating in the Go Red for Women Campaign; the hundreds of celebrities who have endorsed the Pink Ribbon Campaign; or Blythe Danner serving as the voiceover for UPMC commercials. ${ }^{27}$

The power of celebrity can also be harnessed to negatively impact a specific treatment or drug. Most recently, Jenny McCarthy launched an advertising, marketing, and publicity campaign condemning the vaccination of young children. Her claims, founded on junk science but promoted through her rhetoric and amplified by her celebrity, launched what is now called the "Anti-vaccination" movement ("Jenny McCarthy"). Physicians, scientists, companies, and even schools have responded to the movement, as an increasing number of parents refuse to vaccinate their children. Her campaign relies on the same source of credibility as eighteenthcentury patient testimonials and Ranby's narrative: patient experience. While such examples barely resemble the narrative of Walpole's illness—-Ranby did not take out an ad under the guise of Walpole in which he told people to stop taking the lixivium, after all- they exist because members of the medical field utilized the fame-making industries to influence public opinion. Subsequently, they reflect the cultural processes of medical celebrity our consumer medical market has inherited from the eighteenth century.

\footnotetext{
${ }^{27}$ The fact that all of the celebrities I refer to in these modern examples are women speaks to a larger gendering of celebrity, marketing, and advertising in contemporary culture, which has roots in the eighteenth century and which I will discuss in future versions of this project, but which is outside of the purview of this chapter.
} 


\section{$\underline{\text { Chapter } 3}$}

The Medical Celebrity of Actresses: Susannah Cibber's Illness and Margaret "Peg" Woffington's Health

In their seminal history of celebrity in the British theatre, Mary Lockhurst and Jane Moody claim "the celebrity of performers is about the experience of seeing an actor in the flesh" (3). It is the flesh of actors with which this chapter is concerned. Over the past few decades, scholars have expanded on the definition of celebrity as laid out by Lockhurst and Moody, "a concept which focuses attention on the interplay between individuals and institutions, markets and media," as it is found in the British theatre (1). Scholars such as Laura Engel, Felicity Nussbaum, and Joseph Roach claim the eighteenth-century British theatre as the birthplace of modern celebrity. Echoing theorists like Wanko and Brock, Lockhurst and Moody argue that modern celebrity, as opposed to fame or reputation, is "above all a media production" and "only in the eighteenth century does an extensive apparatus for disseminating fame emerge" (3). But while theorists have discussed the celebrity of theatre as far as plays, authors, and performers are concerned, few have focused on the actual flesh of the performers. Notable exceptions include scholars such as Kristina Straub and Felicity Nussbaum, who discuss the body on stage for its sexual, political, and social implications. ${ }^{28}$

If the "celebrity of performers is about the experience of seeing an actor in the flesh," we must give due diligence to all of the ailments, illnesses, treatments, and periods of good health experienced by that flesh. By examining the bodies of performers in this way, we see how their experiences with illness, health, and medical treatment affected their onstage performances and

\footnotetext{
${ }^{28}$ In Sexual Suspects: Eighteenth-Century Players and Sexual Ideology, Kristina Straub discusses the discourse and representation of the sexuality of performers. Her book is seminal in theorizing the sexual body on the eighteenthcentury stage. In Rival Queens: Actresses, Performance, and the Eighteenth-Century British Theater, Felicity Nussbaum theorizes the political implications of actresses' bodies on stage.
} 
by extension, their celebrity. Because performers use their bodies to create characters, drama, feeling, sensation, and intimacy with audiences, significant moments of illness and medical treatment affect their performances and can change the experience of the performance for both the performer and the audience. Even an imperceptible change in the audience would be noticeable to the performer. The ephemeral quality of theatre with its unique embodiment, as Moody and Lockhurst note, comes partially from the physical nature of performance. Something as common and trivial as a tired performer could change the theatrical experience of one night versus another. Thus, when a performer experienced illness, diagnosis, and treatment, their experience extended beyond the theatrical experience and influenced the perception of the actor/actress, which had the potential to impact their fame, reputation, and celebrity. As Moody and Lockhurst claim, "The most significant distinction between theatre and film is that theatre is a live event: the power of the theatrical performance has to do with the uniqueness of the occasion and the impossibility of its reproduction" (3). Because of that uniqueness, whether or not a performer was physically able to appear on stage mattered a great deal. Theatre, particularly in the eighteenth century, could not be replicated and as such, there was an increase in the cultural value of the performer's physical body. Moreover, that cultural value skewed heavily towards performers who were able to perform consistently and regularly—in other words, those who were not ill.

In this chapter, I present two case studies, one of an incredibly popular actress, Susannah Arne Cibber, who had a chronic illness, and the other, Margaret "Peg" Woffington, who was equally popular but experienced prolonged periods of health. ${ }^{29}$ I examine how their physical

\footnotetext{
${ }^{29}$ While there are many other performers, both male and female, at various points in history of the eighteenthcentury theater, I chose these two actresses based on the following criteria: 1. their experiences of illness and health were public knowledge, 2. they were both incredibly popular actresses and many people would have been aware of their experiences with illness and health, 3. they were contemporaries, and 4. they were actresses and not actors. By
} 
ability to perform on stage impacted how they were perceived by theater managers, critics, and audiences. I reconstruct the actresses' experiences of illness and the discussion around their physical ability to perform, and argue the eighteenth-century theater perpetuated the perception of illness and health as a binary. In this binary, illness was associated with lying or a lack of devotion to audiences, while health was associated with honesty and loyalty to audiences. Illness and health, as a result, emerge as two fixed categories that actresses had to balance in order to maintain their public appeal and celebrity. I then argue that the relationship between each actress and her audience demonstrates how their onstage presences both reified and collapsed this binary of illness versus health. In order to theorize that relationship, I apply Joseph Roach's concept of charismata versus stigmata. Charismata refers to "marks of strength" displayed by the performer, while stigmata represent "signs of vulnerability," and the two "work cooperatively, like muscles in opposable pairs" (Roach 24). Marks of strength are those qualities the celebrity possesses which make them likeable, talented, attractive, appealing, etc., and signs of vulnerability are those things which make them appear to be weak at times, such as drug addiction, sickness, personal loss, etc. Similarly to Rojek's theory about private and public selves, charismata and stigmata refer to those qualities in celebrities that make them seem inhuman and human, and performers need both in order to fascinate, and continue to fascinate, audiences. I argue that Cibber and Woffington's manifestations of charismata and stigmata contributed to audiences' devotion towards them, which demonstrates that their perceptions of illness and health altered as a result. Ultimately, this chapter presents how cultural perceptions of illness and health were gender. 
influenced by the mechanism that early celebrity theorists would argue is most responsible for creating celebrity culture: the eighteenth-century theater.

\section{$\underline{\text { Part I: Susannah Cibber }}$}

\section{Experience of Illness}

Susannah Cibber was notorious for her "delicacy," which was the effect of a mysterious stomach illness that plagued the tragedienne for over two decades. Her illness was an erratic ailment that could flare up just before a performance and prevent her from performing, or lay dormant for an entire theatrical run. Consequently, Cibber was known for cancelling performances, and I argue that rather than damage audience's perception of the actress, it actually added to their devotion for her. I begin this case study by examining the details of Cibber's illness and treatment to serve two purposes: first, to recover her embodied experience of illness and treatment; and second, to establish how her illness impacted her reputation as an actress. I then establish the suspicion that people in the theater and audiences had of a performer's claims of illness. Ultimately, I argue that the nature of Cibber's illness and her personae on/offstage contributed to Cibber's ability to cultivate a relationship with her audiences that increased her public appeal and subsequently audiences' loyalty.

Susannah Arne Cibber (1714-1766) began her stage career as a singer, and while starting to make a name for herself at the Little Theatre, she met and eventually married Theophilus Cibber, the son of theater-giant Colley Cibber. The marriage between the two rising performers was an unhappy one, but as Susannah and Theo continued to perform, Colley Cibber became keenly aware of Susannah's ability to move audiences with her voice. He trained Susannah in his method of acting, and this, combined her particular penchant for tragedy, captivated audiences for the next three decades. Unfortunately, her private life also captivated the attention of 
audiences when her unhappy marriage ended in an incredibly scandalous, lengthy, and public divorce trial, wherein Theo sued Susannah for having an extramarital relationship with William Sloper, a tenant of the couple's home. After the trial, the somewhat-vindicated actress and Sloper moved to the country, where she took a two-year hiatus from the stage. This was probably to let the fervor of the trial die down, and to be sure that she was completely free of Theo's influence. Following her two-year hiatus, Cibber resumed her acting career in 1741 when George Frederick Handel and James Quin invited her to perform in Dublin (Nash 67). Cibber returned to the stage to play Indiana in The Conscious Lovers (Nash 169-170). After a poorly attended opening night, the play gained a much more substantial audience the second night when the Duke and Duchess of Devonshire attended, prompting audiences to flock to see the notorious actress (Nash 169170). Cibber gained roles portraying mistreated wives and other tragic figures, as well as a reputation for moving audiences to tears through her powerful portrayals of tragedy. ${ }^{30}$ As she acquired more roles and fame, she began acting at Drury Lane.

It was while she was at Drury Lane, during the most successful portion of her career, that Cibber experienced a serious stomach illness. The nature of this illness is unclear, but based on the description of her illness post-mortem, what she discloses about her symptoms, and the common eighteenth-century treatments for stomach conditions, we can create a rough picture of what her experience of illness would have been. Scholars have most often described her illness as a "stomach ulcer," while at the time she was thought to have "bilious colic" (Davies 2: 33-34). However, the autopsy after her death revealed that in fact she had stomach worms. In David Garrick's memoirs, the editor describes her condition:

\footnotetext{
${ }^{30}$ Elaine McGirr discusses the role her background as a mistreated wife played in her celebrity and reputation as an actress in her article "Authorial Performances: Actress, Author, Critic."
} 
Mrs. Cibber had been for a long time so subject to a disorder which was unfortunately unknown to her physician, and consequently treated improperly...she had been strongly

pressed to bathe in sea water, to which she had a most fixed aversion: however she complied with the advice of a very eminent and skilful physician, and that compliance precipitated her death. Her indisposition was supposed to be bilious colic; but on her body being opened it proved that her disorder arose from stomach-worms. (Davies 2: 33-

Cibber's sole biographer of the 20th century has argued that the phrase "stomach-worms" in this case does not refer to literal worms, but instead denotes the other meaning of "worms" in eighteenth-century medicine: "invisible animalculi, called worms, which swirled in [the] noxious airs, ready to penetrate the human body at any of its openings...any organ or part of the body which was inflamed or mortifying was said to be afflicted with worms" (Nash 318). ${ }^{31}$ Certainly that is one interpretation of the phrase "stomach-worms," but based on my analysis, there is ample evidence supporting the claim that this phrase refers to literal worms in the stomach. ${ }^{32}$

\footnotetext{
${ }^{31}$ It is worth mentioning that the source Nash references for her specific definition of "worms" as an eighteenthcentury medical term is Lester King's The Road to the Medical Enlightenment 1650-1695, a text that focuses on medical practices and terms existing over 70 years before Susannah Cibber's death.

32 Johnson's dictionary, originally published eleven years before Cibber's death, contains seven definitions for "worm" in the noun form: " 1 . a small harmless serpent who lives in the earth. 2. a poisonous serpent 3. animal bred in the body. 4. the animal that spins silk; silkworm. 5. grubs that gnaw wood and furniture. 6. something tormenting 7. anything vermiculated, or turned round; anything spiral" (Johnson). The example provided for the third definition is as follows, "Physicians observe these worms engendered within the body of man" (Johnson). It is easy to see how a mid-late eighteenth-century definition of worm as an "animal bred in the body" would lead physicians to describe Cibber's condition as "stomach-worms," if indeed she had worms. But, admittedly, the Johnson definition is still open to interpretation. The enigmatic use of the words "bred" and "engendered," both meaning to "produce" according to the same source, could be read as worms that arise out of the body, not dissimilar to what Nash describes. Another definition of the same word, however, does seem to support the definition of a worm to mean a visible parasite as opposed to "invisible animalculi." The OED has a more specific definition containing an entry not simply for worms but for "stomach-worm": "a. a common intestinal roundworm, Ascaris lumbricoides, sometimes found in the human stomach b. slang." The examples given for the first definition are from the late seventeenth century, while the example from the eighteenth century is to support the slang definition. However, in this same entry we are told that stomach-worm is synonymous with "maw-worm," and the entries for maw-worm contain examples from the eighteenth century using "maw-worm" to mean a round worm found in the human stomach. Synthesizing the definitions of these two imminent dictionaries as they refer specifically to the years surrounding Cibber's death, leads me to believe that when the physician performing the autopsy claimed that Cibber had
} 
It is impossible to know exactly what type of worm they found when Cibber's autopsy was performed, but there are a few likely possibilities. The most common type of intestinal worm is a roundworm, of which there are many varieties; however, most of these worms present similar symptoms. The most common type of roundworm is "ascariasis," which presents symptoms of "vague abdominal pain, nausea and vomiting, diarrhea or bloody stools, severe abdominal pain, fatigue...weight loss or malnutrition, [and] a worm in your vomit or stool," (“Ascariasis"). The best picture of her symptoms comes into focus when we combine the symptoms of roundworm with the symptoms of the disease her physicians thought she had: bilious colic.

If Davies is referring to a physician's specific diagnosis when he tells us she has bilious colic, then Cibber's illness can be found in The Physical Dictionary (1726), an extensive and widely used medical dictionary at the time. The phrase "bilious colic" does not exist in the dictionary; instead, it is referred to as "Colica Passio" or "Colicus Dolor," Latin for colic passion and colicky pain. It is

the Cholic which has its Name from the Intestinum Colon, but erroneously, since it affects also the other Intestines. It is either Continual or Intermittent, sometimes keeping its certain times, attended with pungent Pains, that sometimes move from place to place, sometimes are fix'd in one with Vomiting, violent Belching, Fever, Inquietudes, and Suppression of Urine; if it continue long, it proves violent and fix' $d$ in one place; it is often succeeded by a Palsy in the Limbs. The Cholick is a vehement Pain in the

\footnotetext{
stomach-worms, he meant actual visible parasites. That definition would also support the observer's report claiming that her physicians had misdiagnosed her for years. Determining Cibber's diagnosis is important because it narrows the scope of what Cibber's illness may have consisted of in terms of symptoms. Moreover, from this conclusion, we gain a deeper understanding of the chronic nature of Cibber's illness, which was misdiagnosed.
} 
Abdomen, from an ill disposition of the Animal Spirits, begun in the Nervous foldings of the Mesentery and is sometimes falsly imputed to this Gut Colon. Some make this Disease to proceed from an Acid Pancreatic Juice, or the Acid Juices in the Intestines and Glands of the Mesentery; others other ways, but falsly. (Blankaart 96) According to this definition, the disorder can have a variety of symptoms pertaining to the abdomen, and the disorder can happen continuously or it may come and go. Additionally, the primary symptom is abdominal pain, but it too can move in various areas of the abdomen or it may stay in one place.

It is also possible that Davies was not using medical terminology but a general expression. Johnson's Dictionary confirms this and provides a definition of the phrase "bilious colic" as "a disorder of the colon" in particular, and in general, "any disorder of the bowels or stomach that is attended with pain." There are four types of colic; bilious colic is listed as the first: "A bilious colick, which proceeds from an abundance of acrimony or choler irritating the bowels, so as to occasion continued gripes, and generally with a looseness, and this is best managed with lenitives and emollients." Continued gripes refers to abdominal pain, and looseness refers to "diarrhea; flux of the belly" (Johnson). Since Cibber was diagnosed with bilious colic specifically, it is fair to assume that the symptoms and treatments described for the disorder would have applied to her illness as well.

By synthesizing the definitions of roundworm, the medical definition of "cholick," and the general definition of bilious colic, I conclude that Cibber most likely experienced some combination of the following symptoms: abdominal pain, vomiting, and looseness. This description is certainly more detailed than Cibber's own description of her "delicacy," which she refers to vaguely in her letters. She is a "queer uncertain animal, and a week or ten days 
often make an amazing alteration"; often, she is "ill" or unable to handle "fatigue" (Cibber 200201, 207-208). Her descriptions are so open to interpretation that it is difficult to understand the toll her illness might have had. Continual pain and diarrhea would have been remarkably difficult to deal with considering her profession, particularly when we remember that her illness was unpredictable and fluctuated in its severity. Perhaps she may have been able to tolerate the pain, but an actress on stage could not possibly perform during a bout of serious "looseness," especially considering both eighteenth-century sanitation practices and wardrobe. No wonder she stayed at home. Knowing these symptoms gives a clearer picture of Cibber's struggle with her "delicacy," and her choice to act in between bouts of sickness reinforces how committed she was to performing.

The treatment for bilious colic seems painfully ironic from our $21^{\text {st }}$-century perspective. The disorder was "best managed with lenitives and emollients." A lenitive was "any thing medicinally applied to ease pain," while emollients were "such things as sheath and soften the asperities of the humours, and relax and supple the solids at the same time" (Johnson). In other words, anything to ease the pain and a laxative were used to treat bilious colic. In eighteenthcentury medicine, this treatment would have been completely sound. If bilious colic indicates that a patient has too much bile, hence the body's attempt to get rid of it, the way to treat this imbalance is to supplement the body's attempt to rid itself of the excessive substances. ${ }^{33}$ The Physical Dictionary does not list any specific treatments in its definition of "colica passio" or "colico dolor," but contains many treatments for "the cholick" in other definitions. Remedies

\footnotetext{
${ }^{33}$ Of course, in modern medicine, physicians would take the exact opposite approach. While diarrhea and abdominal pain are still viewed in many ways as an imbalance within the body, today those symptoms are most often attributed to a viral or bacterial infection, commonly in response to an ingested pathogen. Treatment, therefore, would seek to alleviate rather than exacerbate the symptoms. Modern medicine focuses more on the imbalance in the body diarrhea might cause, such as dehydration, rather than the imbalance the symptom would indicate.
} 
include holly berries, milk-wert, and rhubarb to purge choler; chamomile to loosen stool; and ground ivy to "move the courses" $(11,277,295,82,179)$. These are the emollients Johnson describes, while geranium, opium, and baths eased the pain of colic $(170,253-254,338) \cdot{ }^{34}$ As such, when Cibber experienced a bout of illness, more than likely her physicians gave her a laxative or something to purge her intestines, combined with something to ease her abdominal pain. The treatment makes sense for the time but probably made the already weakened actress feel worse. It should not be surprising, particularly to modern scholars, that her periods of illness often lasted longer than a day or two and the length could never be predicted. It is easy to imagine that a cycle of symptom and treatment might be difficult to break in this case.

While laxatives and lenitives were the most common forms of treatment for bilious colic, physicians tried other forms of treatment as well. Cibber's physician, Sir Noah Thomas, recommended sea bathing for the persistently ill actress. Dr. Thomas "specialized in digestive disorders," and despite Cibber's resistance to bathing in sea waters, she and Sloper visited Thomas's establishment in Scarborough, one of the earliest sea-bathing locations, during summers (Nash 280, Sutherland 63). She also sought treatment at the hot springs in Bath with Sloper "every spring and fall" (Nash 280). Spas, like the one Cibber would have visited at Bath, and sea-bathing became very popular in the eighteenth century. Their healing effects were simultaneously limitless and immeasurable. Unlike the warm, soothing waters from springs at spas, which have been considered to possess healing powers since antiquity, sea-bathing would have been cold and shocking to the system. The cold, salty water was thought to help with an

\footnotetext{
${ }^{34}$ For the purposes of this list of remedies, I have used the colloquial terms provided in the dictionary rather than the Latin terms under which they are listed. Other remedies for cholick include: imperatoria to expel wind (194); lactuca, lettuce, to cool the stomach (204); laurus to ease pain (206-207); nephriticum, used in the treatment of cholick (243); oleum, oil of chamomile, to "ease in the cholick" (250); oleum e' baccis juniper, oil of juniper berries, is excellent for the cholick (252); purging waters or mineral waters to treat cholick (286); ruta, rue, cures cholick (300); saxifaga to ease (305); tunbridge waters (345-346); veronica mas supina (353); nerve ointment (363-364); and ginger (369).
} 
array of medical issues, from gland disorders to melancholy (Sutherland 61). Sea-bathing, which Dr. Thomas prescribed for Cibber regularly, consisted of the following regimen: "Seawater therapy included bathing in the early morning, drinking at least half a pint of seawater, and massage with freshly collected seaweed. Bathers were advised to have some seawater thrown over their heads when first entering the sea, to equalize the temperature of the body, and to avoid propelling the blood to the head too swiftly. The bath was to be followed by half an hour of rest in bed, and then outdoor exercise" (Sutherland 62). It is easy to imagine why someone experiencing serious abdominal pain or worse would find the cold shock to the system unpleasant, not to mention ingesting half a pint of seawater. And Cibber was not alone in her dislike of this medical treatment; both Jane Austen and Frances Burney write about how frightening sea-bathing could be (Sutherland 62). Nonetheless, both sea-bathing and spas became wildly popular in the eighteenth century, and what started as a strict medical prescription developed into a fashionable and pleasurable destination. ${ }^{35}$

Members of the upper class, fashionable ladies, and actresses frequented places like Scarborough and Bath, and it would have been common knowledge if someone was seeking treatment in the sea or spa. Cibber, who was going to these places based on the recommendations of her physician, would have been one of the actresses who helped make it a fashionable and popular destination. Hence, when Cibber died, the speculation as to her cause of death was wrapped up in the rumors and speculation around sea-bathing. Thomas Davies, the author of one of Garrick's memoirs, writes that although many people thought it was her final part on stage which served as the death blow, it was actually that "she had been strongly pressed

\footnotetext{
${ }^{35}$ For more on the ways in which sea-bathing was commodified and on the development of England's coastal regions as tourist destinations, beginning in the eighteenth century, see Martin Farr and Xavier Guegan's The British Abroad Since the Eighteenth Century, Vol 1: Travellers and Tourists.
} 
to bathe in sea water, to which she had a most fixed aversion: however she complied with the advice of a very eminent and skilful physician, and that compliance precipitated her death" (Davies 2: 84). ${ }^{36}$ While he does not specify who made this claim, the speculation surrounding her cause of death demonstrates the level of interest audiences had in Cibber's state of health. Cibber's connection to sea-bathing and Bath demonstrates the influence of her celebrity. Davies, in this same passage, writes about her stomach worms, but he blames the cause of her death on the sea-bathing treatment in particular. It is clear from Cibber's letters to David Garrick before her death that she was remarkably weak and thin, and presumably, Davies was claiming that her system was unable to handle the aversion and shock of sea-bathing.

\section{Illness On Stage}

Considering the severity of Cibber's symptoms and the demanding nature of her treatments, it is unsurprising that her illness influenced her ability to appear on stage; perhaps what is more surprising, was her success on the stage in spite of it. Cibber's illness spanned most of her career, beginning perhaps as early as 1742 when she was performing for Handel, and they were forced to postpone and provide substitutions for over a week (Nash 172). The illness passed and Cibber was able to perform in his Messiah. But by 1746, her stomach disorder returned in a manner both "serious and chronic," and according to her biographer, her doctors were so concerned about her subsequent weight loss that they "put her on a regime of beer between meals to gain flesh" (Nash 225). Because her illness would come and go, lasting sometimes for a few days and other times for weeks, Cibber was unable to plan her stage performances accordingly. This resulted in many cancellations, the exact number of which is unclear, but during her time at Covent Garden, her "stomach disorder grew so frequent and

\footnotetext{
${ }^{36}$ According to Nash, this physician was Sir Noah Thomas, as aforementioned.
} 
severe that it became a serious problem for the entire company, which always had to have another play ready in case she had an attack" (Nash 263). It speaks to her talent as an actress and the audience's demand for her that she was paid highly by theater managers and revered by most other actors despite the inconvenience her illness could cause.

While her stomach disorder clearly inhibited her ability to perform, there were many, particularly those involved in play production, who were skeptical of how serious and severe the illness actually was. Cibber's biographer refers to these as her "malingerers." For instance, some viewed her illness as a way for David Garrick to manipulate when plays were produced. The editor of Some Unpublished Letters of David Garrick writes, "Mrs. Cibber would be used by the manager as an excuse for postponing the play" (Baker 87). In a particular instance, Arthur Murphy, author of several plays produced at Drury Lane, was so worried when they cast Cibber in one of his plays, he secretly paid another actress to learn the part as her understudy (Baker 87-88). When the time came and Cibber fell ill, rather than postponing the play, Murphy simply pointed to Mrs. Yates who was waiting in the wings to go on stage (Baker 87-88).

The fact that skeptics questioned whether or not the actress was feigning illness or was really ill directly connects to her acting ability. If someone can convincingly portray any array of emotions or sickness on stage, why not off stage? Elaine McGirr addresses the broader suspicion about the sincerity of an actress's behavior in real life in her discussion of Cibber's divorce proceedings. During Theo's lawsuit against Cibber, both the defense and the prosecution used Cibber's ability as an actress to blur the lines between reality and on-stage performance. For the defense, they claimed that her ability to feel passionately on stage essentially made her a more passionate person in real life (McGirr 69). In other words, her affair with Sloper was due to her "voluptuousness of heart" (McGirr 70). The opposition argued that 
Cibber's passions were more calculated, and that her acting, partially because she was so talented, was rational; therefore, what she did off stage in the way of emotion and feeling could also be calculated (McGirr 70). Both the defense and prosecution "encouraged slippage between the actress's performance of passion and her off-stage experience of it" (McGirr 70). What is really at question here is whether or not Cibber had the ability to use her acting to carry out certain emotions and motivations of her own in her off-stage life. Their claims echo concerns about the virtuosity of the first actresses who ventured onto what many considered to be a platform for lies and debauchery in the mid-seventeenth century. When Cibber was on stage, that skepticism about how much an actress could be trusted off stage certainly still existed. ${ }^{37}$ While the legitimacy of her passion were put on trial during the divorce, so too were the legitimacy of her illness questioned and judged by people in the theatre. McGirr proves that while Cibber might say or do one thing, those around her would question whether or not she was sincere or merely acting. That same motivation for skepticism would extend to the skepticism around her illness. When Cibber cancelled a performance due to illness, it would be impossible for those around her to know for certain if she was truly ill, exaggerating her illness, or feigning illness altogether. Actors and actresses certainly had motivation to "act" sick, knowing that their public appearances (or lack thereof) dramatically influenced the success of a play and the theater itself. With Cibber, it was always possible, in the minds of theater managers and playwrights, that she was simply wielding her power.

Such skepticism was not unique to Cibber's situation; actors were often assumed to be feigning illness when they could not perform, and indeed many did. In the mid-eighteenth

\footnotetext{
${ }^{37}$ In her seminal work The First English Actresses: Women and Drama, 1660-1700 (1992), Elizabeth Howe examines how the presence of actresses on stage fundamentally altered the perception of women and those actresses challenged the social and economic hierarchy of the theater and of the culture.
} 
century, as stage performers gained celebrity with audiences, the power inside of the theater leaned increasingly in their direction, as opposed to authors and managers. While they were not dictating what was performed on stage, they heavily influenced who would attend the theater, and more importantly, how much money would be made. Performers could wield this power by agreeing or refusing to attend a scheduled stage appearance. When actors and actresses appeared on stage as scheduled, audiences were satisfied and, by extension, so were the playwrights and managers. When they refused to appear, audiences might riot, leaving playwrights and managers distraught and possibly out of a great deal of money. An anxiety surrounding this possibility emerges in the memoirs of performers and histories of the theatre.

The theatre manager Benjamin Victor discussed the need for specific stipulations in the contracts of performers in the event that they cancelled a performance. In History of the Theatres of London and Dublin (1771), he warns, "These performers to be employed, that have the Power, from their Reputation in the World, to draw Audiences, know that Power, and how to set a due Value on it; and after their worth is properly rated the Accidents that follow, such as ill health, and the like, are to be Drawbacks from the expected Profits of the Manager" (187-188). He acknowledges the star power of actors and actresses, which they are not only aware of because of their "reputation in the world," but which they also manipulate to negotiate their earnings. Victor warns managers about the "accidents," specifically "ill health" that might jeopardize their profits. He implies that actors and actresses should be held accountable as a way to protect profits and asks, "when an Article is signed for the Payment of a great Salary, if Sickness, or any other Accident, prevents the Actor from doing his Business, why should that Misfortune fall only on the Manager? besides it is the only Safeguard against bad Practices. We have heard of AFFECTED Illness at certain Times, to preserve that Consequence which supports their Price" 
(189). Victor suggests that actors be held accountable for their appearances on stage because they are apt to cancel performances to "preserve that Consequence which supports their Price." In other words, a performer, keenly aware of their power in the theater, might refuse to go on stage, which would displease audiences and cost the theater money. Victor's comments create a false binary between illness and health and imply that they are two categories that performers had the ability to move between because of their acting ability. Moreover, because he never provides a rule for how to determine if a performer is acting sick or not, he implies that the performers who are not ill are the ones who are not trying to exploit their power in the theater. Here, the distinction between illness and health has nothing to do with medical evidence; rather, the distinction should be made based on a performer's character.

Garrick echoes the concern of actors faking illness specifically as it relates to Cibber: "Mrs. Cibber (who had really an ill state of health) began the fashion. Mrs. Clive and Mrs. Pritchard, with great deference to the present ladies, were both inimitable actresses, and never copied Mrs. Cibber in disappointing the public--they performed their characters whenever called upon, without notice or murmuring; nor were any frivolous excuses made to incence the audience and discredit the theatre" (lix). He simultaneously defends Cibber for having legitimate excuses (bouts of illness) that warranted disappointing audiences and blames her for starting the fashion of actors frequently cancelling performances due to illness. Garrick creates a false binary claiming that Cibber was "really" ill, but Clive and Pritchard were healthy and never cancelled performances. The actual medical condition or treatment is irrelevant-what matters to the theatre manager is discouraging or preventing performers from faking illness and being able to determine who belongs in the categories of ill versus healthy. But those categories only matter insofar as they relate to the performers' impact on the audiences and theater. Clive and Pritchard, 
as healthy actresses, never cancelled performances, "disappoint[ed] the public," "incence[d] the audience," or "discredit[ed] the theatre." The "fashion" or trend of cancelling performances because of illness, which Cibber starts, was so dangerous because of how audiences might react.

Eighteenth-century audiences expected an explanation when a performance was changed or cancelled; in addition to information about the plays and casts, advertisements contained an apology line, which informed audiences of substitutions, cancellations, and postponements. It was the apology line that was "most carefully prepared," because there was "an intimacy [that] existed between actor and audience" (Stone 4: lxxiv). Regulars of the stage would be keenly aware of a performer's absence, as "probably 30 percent of an audience over a week's time in one of these repertory theatres was composed of the same people--habitues who knew every actor and actress" (Stone 4: lxxiv). This intimacy allowed audiences to feel entitled to explanations for the absence of a performer; otherwise, they would express their disapproval. As stated in The London Stage, "Woe to the manager who substituted another for the name advertised. In case of sudden illness a new bill was printed if time allowed. If the play had to be changed, explanation of the reason was customary and demanded if not made" (4: lxxiv). Audiences demanded formal apologies and explanations if their expectations for a performance were somehow thwarted, which indicates that there was a large portion of the audience who would have known how often and for what reasons actors and actresses missed performances. Depending on how the audiences felt about the performer and/or their reason for cancelling, they could react very poorly, refusing to attend the theater or even rioting.

The mid-eighteenth century theater was no stranger to audience riots. If displeased by a performance, play, or the price of tickets, audiences could do serious damage in a theatre, and managers were aware of the delicate balance that teetered in the pit. Garrick and others sought to 
prevent these types of riots, which could start for a variety of reasons but often when a promised actor or actress cancelled a performance. As a result, the power to tame an audience often fell into the hands of the performers. In one instance, when Garrick sensed the audience was on the brink of rioting, he produced some of the audience's favorite plays featuring Cibber: "The Orphan, Romeo and Juliet, and The Earl of Essex" (Nash 288-289). If a particularly popular actor or actress, like Cibber, was unable to attend a performance due to illness or personal matters, the audience was not afraid to show their disappointment. However, because stage performances require the physical ability to perform, cancellations due to illness were inevitable. The expectation for a performer, as result, is that regardless of whether you were ill or faking it, you were disappointing your audience. As such, the audience's expectation of a performer to consistently appear on stage reinforced the equation of illness with a lack of honesty or devotion to audiences.

Scholars like David E. Shuttleton argue that the increased production and availability of medical print material, accounts of illness, and literary representations of medicine dramatically influenced cultural perceptions of certain illnesses and the state of being ill (273). Because these representations of disease relied upon depictions of class, diet, activity, geography, disposition, and temperament in order to discuss diagnosis, pathology, and treatment, the medical representation became linked with cultural experience (Shuttleton 273). Gout, for instance, as discussed by Roy Porter and George Rousseau, was no longer simply a painful disease but a disease that seemed reserved for wealthy, landed gentlemen whose leisurely lifestyle contributed to the disorder that "everyone knew... was a sign of superiority, with a penchant for princes, patricians - and even philosophers" (71-72). Similarly, Carolyn Day informs us that consumption was no longer just an excruciating and terminal illness; rather, "cultural ideas about 
beauty intertwined with the disease process of tuberculosis, allowing the ravages of the illness to be presented in an aesthetically pleasing light" (603). And Heather R. Beatty proves in her examination of the medical theories and patient experiences of nervous disorders, that despite the real suffering the illnesses caused, they became associated with qualities such as "fashionable sensibility and delicacy" (6). Recent scholars have also demonstrated how treatments such as sea bathing and trips to spas became fashionable forms of health tourism, evidenced by the establishment and success of spa resorts at places like Bath and Tunbridge Wells (Andrews and Lawlor 248). The perplexing phenomenon of fashionable diseases ultimately transformed what was once an entirely negative experience, living with gout, suffering from a bilious condition, or dealing with a nervous complaint, to an experience and status that was desirable and in vogue. Ultimately, their work demonstrates how perceptions of disease carried economic, social, and cultural value. More importantly, it demonstrates how in the eighteenth century the perception of someone having a certain disease was as significant as whether or not they actually had it. That trend was echoed in the theater.

The discussion of performers and illness is complicated one step further, for while trends of fashionable diseases called into question whether or not people had a specific disease, theater managers and audiences called into question whether or not a performer was ill as opposed to healthy. Their suspicion was not rooted in the question of whether Cibber had gout or consumption, but whether or not she was ill at all. The diseases that performers claimed to have did not lessen or heighten the skepticism; the fact that they were actors heightened the skepticism. So, how do people with aging and ailing bodies become successful in an industry that has such unreasonable expectations about illness and health? They have to earn the 
audience's loyalty. In Cibber's case, we find that the audience's loyalty was rooted in her relationship to them and her persona onstage and offstage, a precondition for celebrity.

There is no definitive evidence that audiences knew exactly what Cibber's diagnosis or symptoms were, but because it was common practice for performers to provide a reason why they cancelled a performance, audiences were told that she was ill and told this frequently. Particularly when Cibber's illness was at its height in the last decade of her life, the public was informed on multiple occasions that she would be unable to perform because of an illness. For instance, the entry for March 1755 in The London Stage states, "We can assure the Public, that Mrs Cibber is very much recovered from her late indisposition; and will certainly appear tomorrow night" (4: 474). In November of that same year, Cibber became ill during a performance in which she was only able to perform the first two acts and was replaced by another actress for the rest of the play (4: 537). That same bout of illness made her unable to perform for Mr. Berry's benefit later in the month, and George Anne Bellamy was forced to replace her (4: 537). The reason for her absence during that performance was recorded in a diary, but presumably the audience would have connected her illness at the beginning of the month with her absence at the benefit later in the month. Audiences were given public advertisements that explained a performer's absence, but even when they were not, regulars would have had enough context to know why a performer might be absent. For instance, in March 1758, Cibber was ill, and it is unclear from the records whether or not the public was informed of this; however, Cibber was supposed to perform Jane Shore at a benefit, and the part had to be changed (4: 652). The audience would have known about the parts being switched, and would have known Cibber was absent. The consistency and frequency of her cancellations that resulted from 
illness created a narrative for audiences, and it would have been difficult to see Cibber's name advertised and not think of the chance that she might not be able to appear.

Newspapers also reported Cibber's illness, making it subject to public speculation and rumors. For example, in September 1749, the General Advertiser reported that Cibber was extremely ill at Bath and close to death (Stone 4: 141). However, by the beginning of October, the same publication reported that she was in fact not ill but still in Bath (Stone 4: 141). Similar to Robert Walpole, knowledge of Cibber's illness was circulated through print media and, as such, became part of the public's perception of Cibber. Moreover, the information about her illness contributed to the perception of Cibber as she existed inside and outside of theater, further emphasizing the split between her public and private selves. As a precondition for celebrity identified by Rojek, emphasis on that split fueled public interest and impacted public perception.

Elaine McGirr has discussed the public interest around Cibber's public and private selves in her discussion of how Cibber's public divorce affected audience's perception of her on stage. Her experience as a mistreated wife who eventually left her husband for a loving relationship added something to her performances of characters in similar situations. As McGirr states, "instead of acting bleeding into reality, of the actress becoming "like" the passionate characters she played...it is reality that bleeds into the performance--the celebrity creates the character" (73). In other words, Cibber's real life influenced the characters she played on stage, which impacted her appeal to audiences. I would argue that not only did the public's knowledge of her divorce have this effect, but so too did perceptions of her illness.

The idea that an actress's appeal to her audience was impacted by her life outside of the theater has been thoroughly established by eighteenth-century theater and early celebrity studies scholars. As has been discussed by scholars like Laura Engel, Cheryl Wanko, and others, 
audiences were usually interested in the lives of popular actresses beyond the stage, and many actresses self-fashioned personae that capitalized on that interest. Sarah Siddons is the most famous example of an actress who crafted a persona that reinforced her image as mother and wife, which helped counteract the assumption that actresses were self-interested women with loose morals who cared only about their success on stage. The first actresses at the end of the seventeenth century were assumed to be the worst kind of women, and their ability to act like a woman from any class threatened the social hierarchy. In order to be appreciated by audiences, eighteenth-century actresses had to be both skilled on stage and adept at creating a persona that would please and intrigue fans. This meant discerning what audiences desired when they came to the theater and being able to navigate and use the mechanisms of celebrity that Turner discusses such as publicity, public appearances, on-stage appearances, acting roles, social networking, and more to build a relationship between audiences and an actress's self-fashioned persona. While scholars have thoroughly discussed the process of self-fashioning personae and the ways that motherhood, sexuality, gender, and class affected the relationship between audiences and actresses, no one has discussed how illness contributed to professional self-fashioning.

But first, we must understand the relationship between audiences and performers, which Roach argues relied upon a phenomenon he identifies as public intimacy. Public intimacy is the individual audience member or fan's illusion that the experience they have when they watch a performer is an intimate experience between performer and fan that both builds and sustains a relationship between the two. As Roach states, public intimacy is "the illusion of proximity to the tantalizing apparition [i.e. the celebrity]" and the "consumption of its spun-off products such as plays, magazines, or movies" (44). Celebrities and the media by which the celebrity is consumed perpetuate this illusion of shared intimacy, as was the case with the portraits of the 
Hunter brothers and the pamphlets and about Walpole. The celebrity only feels an intimate connection with fans insofar as fans contribute to their celebrity: the applause, praise, ticketsales, lines outside of the theatre, etc. And fans only feel an intimate connection to the celebrity because their public appearances or performances are available to everyone, which enables public interest in the celebrity that Rojek discusses. They are attracted to and interested in the celebrity, and they fall in love with the illusion of intimacy between themselves and the celebrity. Public intimacy is ultimately an illusion that is both manufactured and necessary to the existence of celebrity. Roach claims that public intimacy does exist in the eighteenth century, specifically between actresses and audiences (16).

Public intimacy as it functioned in the eighteenth-century theater relied on an actress's public appearances on stage. If audiences went to the theater not only to see the work of their favorite authors and portrayals of their favorite characters, but also because of the moment of intimacy created by their favorite stage performers, then the appearance of a particular actor or actress became exponentially important. The play and the character do not create public intimacy, but rather an actress's performance does. Whereas the play creates narrative, meaning, and entertainment, the performer creates public intimacy, which leads to fandom. Subsequently, if a popular actress like Cibber was unable to appear on stage, the audience was not only upset because the character performance they were promised would not occur, but also because Cibber would not be on stage to create their intimate connection. The relationship between audience and performance fundamentally changes if an actress that the audience loves is unable to appear. Whether or not a performer was ill or healthy directly impacted whether or not they could appear on stage, and by extension their ability to participate in public intimacy and build a relationship with audiences. If performers could not build that relationship and acquire fans, it was 
impossible for them to achieve celebrity, make money, establish social connections, and maintain their career.

As such, Cibber's illness could have seriously comprised her ability to become a celebrity because it prevented the very interaction upon which her career depended. To understand why that did not happen, we will return to Roach's theory of charismata and stigmata. As noted earlier, charismata represents "marks of strength" displayed by the performer, while stigmata represents "signs of vulnerability," and the two "work cooperatively, like muscles in opposable pairs." Cibber's chronic illness forced her to demonstrate more stigmata than charismata because of how often it forced her to cancel performances. When combined with the various ways in which audiences were informed of her cancellations brought on by illness, this display of stigmata would have elicited a certain amount of expected unpredictability. Unlike a performer who might cancel on a whim and blame it on a random illness, Cibber was consistently ill and reports of her illness existed throughout her career. That kind of chronic stigmata would have been impossible to fake. By the same token, because she never knew when she would be sick, and her illness was such that her symptoms could be both sudden and severe, audiences never knew when she might cancel a performance. However, there was always a possibility that she might. Going to the theater to see Cibber, then, would have been characterized for audiences by an awareness of her illness and the expectation that anything could happen. Would she cancel? Would she begin a performance and then have to leave? Had she been feeling better? Cibber's stigmata would have been perpetually intriguing to audiences because of both the chronic but unpredictable nature of her illness.

The stigmata related to her illness would have also participated in a larger context of Cibber's vulnerability and humanness both on-stage and off-stage. On-stage, Cibber was the 
most accomplished tragedienne of the age, who starred in many parts written specifically to elicit strong emotional responses in the audience, such as her portrayal of Lady Constance, "a queen without a kingdom, a wife without a husband, and a mother who loses her child" in King John (McGirr 64). Additionally, her singing voice also induced audiences to feel sympathy, sadness, and deep feeling. An example of her voice can be heard when we listen to "He Was Despised" in Handel's Messiah, which he composed with "her voice in mind" (Nash 173). That on-stage persona would have created a relationship with audiences based in feelings like grief, empathy, sorrow, etc., all feelings which arise during times of illness as opposed to health. Cibber's audience members would have been familiar with those emotions in terms of their own illnesses, symptoms, and treatments and those of the people they knew. As such, Cibber's illness enhanced those feelings rather than causing resentment or skepticism, as perhaps would have happened with a comedic actress. Her stigmata, specifically of her illness, would have added to the stigmata she demonstrated on-stage that audiences loved her for. The context of her life off-stage that audiences had access to would have also contributed to her stigmata. The divorce scandal at the beginning of her career, influenced the perception of her performances on stage, which McGirr has discussed extensively. Vulnerability, pain, deep emotion, and tragedy served as the foundation of audiences' perceptions of Cibber. I would argue this too contributed to her overall stigmata. Her illness merely extends and adds nuance to that perception, fitting in with their narrative of Cibber rather than pushing audiences' feelings towards her over the edge into pity, apathy, or skepticism.

By the same token, if audiences only ever perceived stigmata, Cibber would not have been successful because according to Roach's theory, celebrities must strike a balance between both. Cibber did this each time she returned to the stage after a bout with illness, and every time 
she decided to do another play and continue her career. Audiences knew that she was ill, and it was clearly chronic, which for many would have been reason enough to stop acting. Instead, Cibber appeared night after night to give powerful, physically taxing, and emotionally draining performances for her audience. Moreover, audiences would not have understood why she was physically able to do this and how she had the strength to perform despite how sick she often was. This would, no doubt, have seemed slightly inhuman and larger than life, and would certainly have been perceived as a mark of strength. Whereas audiences were unaware of how she was physically able to perform, I argue it was the nature of Cibber's illness that enabled her to demonstrate charismata and stigmata. Whether it was bilious colic, stomach worms, or both, as discussed earlier, Cibber's symptoms would have been erratic and severe. Her treatments would have provided relief at times and discomfort at others. Her physical experience with illness and treatment caused her to cancel performances one week and have the strength to perform the next. Without that context, we cannot understand the complexity of Cibber's power over audiences.

As such, I argue that when Cibber cancelled performances, she increased the demand for her appearances. Audiences craved the public intimacy and emotional response she could create, and that craving became even stronger when audiences were denied her presence. Her frequent cancellations did not diminish her celebrity; instead, the cancellations enhanced it. And her cancellations only happened because of her illness; therefore, Cibber's illness played a direct role in her celebrity and increased audiences' demand for her.

The result was an extremely popular actress who had an incredibly devoted audience, which increased her value in the theater. The terms of her contract in 1745 demonstrate how her acting skill and its power over audiences increased her value in the theater, which earned her a 
higher position. Cibber had "the right of first refusal over all new plays, complete control over her repertoire, a costume allowance and separate salary for her dresser; unheard of perks not extended to another actress until the end of the century," in addition to the fact that she was paid "double the salary of any other actress" at Drury Lane (McGirr 106). As the most celebrated tragedienne in his theater, "Garrick knew that nothing guaranteed a full house like her name in the bills, and he risked a riot every time she cancelled a performance" (McGirr 95). The fact that she cancelled performances consistently did not dissuade her fans.

I conclude, as a result, that audience's heightened devotion demonstrates how the cultural mechanisms of public intimacy, public persona, and the theater shaped how the audience perceived Cibber's illness. Thus, it becomes clear that the eighteenth-century theater created the circumstances whereby a culture of medical celebrity emerged. As a sociocultural phenomenon, medical celebrity impacted both Cibber's experience of illness within the theater and audience's perception of her illness. It was not medical evidence or medical knowledge that influenced their perception of her illness, but the relationship created between performer and spectator in the theater. As such, we can conclude that the eighteenth-century theater shaped cultural perceptions of what it meant for someone to be ill. We cannot know how exactly that perception altered because we would need evidence of audience members discussing how their perception of a chronically ill woman changed when they saw Cibber on stage. However, this case study demonstrates that Cibber's persona, fame, reputation, and stage presence were capable of affecting the audience's perception of her illness. Whereas typical audiences would lose interest in someone who was sick so often, if they believed them at all, Cibber's audiences became more devoted. Thus, this case study is an example of how the theater contributed to a culture of 
medical celebrity, whereby perceptions of illness and health operate along the lines of the cultural mechanisms of celebrity.

\section{Part II: Peg Woffington}

\section{The Healthy and Devoted Actress}

While Susannah Cibber was well known her unpredictable performance record, Margaret "Peg" Woffington was praised for the exact opposite reputation. Peg Woffington was known to be dutiful and reliable on the stage, and her dependability was said to be part of what made her such a great actress. I argue that she used her physical ability to perform consistently to help cultivate a reputation for being devoted to her audiences. When other actors and actresses cancelled appearances due to illness, Woffington was there to substitute, and when she became ill, she refused to cancel performances. I begin this case study by establishing Woffington's reputation as a devoted actress, and provide evidence to suggest she purposefully cultivated that reputation by capitalizing on her physical ability to perform, thereby increasing the appeal of her charismata. I argue this reveals how people perceived a performer's physical ability to perform as directly connected to their character. Finally, I reconstruct her public, on-stage stroke from which she never recovered, and discuss how that public illness impacted her reputation of health. I analyze the portrait Woffington commissioned after the stroke and argue that she uses this visual representation to reassert her reputation as a devoted actress.

Woffington first appeared on stage at the remarkably young age of ten years old, as Macheath in John Gay's The Beggar's Opera with a company of Lilliputians in Dublin (Cave n.p.). Some sources claim that she began acting at such a young age to help support her mother and sister, but the early years of her biography are disputed. She certainly supported her mother and sister throughout her life, so it is likely that this was the reason for such an early start to her 
career. As the company toured the Haymarket Theater in London, Woffington was assigned the role of Polly, and she acquired an increasing number of roles over the next few years (Cave n.p.). As her acting ability developed, so did the range of roles she could play, and by 1740 she was cast as Sir Harry Wildair in The Constant Couple, what would be her most famous breeches role (Cave n.p). ${ }^{38}$ Peg utterly captivated the audience in this role; her premiere performance lasted for ten nights, and she reprised the role numerous times over her career, as no one else (male or female) was said to be able to perform it as well (Nussbaum 191-192). With her tightly fitted breeches and arresting masculine air, the actress possessed a liveliness and force on stage that audiences craved. The success of this role prompted her to leave Dublin for Covent Garden, where John Rich paid her 5 guineas a week, an impressive salary for such a young actress (Cave n.p.). During her time at Covent Garden, she added several new roles to her repertoire and after about a year, moved to Drury Lane.

Woffington became famous for many things as an actress, particularly her sense of duty to the stage, which was rooted in her insistence to be on stage as much as possible. As discussed with Susannah Cibber, an actor's ability to be on stage depends upon their physical ability to perform, not only their sense of loyalty to their audience. However, when discussing Woffington's attributes as an actress, critics seem to ignore this connection between physical ability and on-stage appearance. Instead, they depict Woffington's unfailing appearances on stage as reflective of her sense of devotion and duty. In his Historical View of the Irish Stage, Robert Hitchcock recalls that "she had none of those occasional illnesses which I have sometimes seen assumed by capital performers, to the great vexation and loss of the manager and

\footnotetext{
${ }^{38}$ For more on the importance of Woffington's breeches roles, see Felicity Nussbaum's chapter, "The Actress, Travesty, and Nation: Margaret Woffington" in her book Rival Queens: Actresses, Performance, and the Eighteenth-Century British Theater (2010).
} 
disappointment of the public: she always acted four times each week. Not the lowest performer in the theatre did she refuse playing for, out of twenty-six benefits, she acted in twentyfour...Such traits of character must endear the memory of Mrs. Woffington to every lover of drama" (221). As we saw with Benjamin Victor, Hitchcock also suggests that actors often faked illnesses, and when he praises Woffington for her frequent appearance on stage he attributes them to her "traits of character." Hitchcock implies that Woffington was too devoted and goodnatured to ever fake illness. Woffington's appearances on stage are not attributed to her health or her physical ability to perform, but rather to something beyond corporeality like character, will, or determination. Unsurprisingly, when discussing Woffington, Victor expresses a similar sentiment: "she seldom performed less than four Nights a Week, [and] she never disappointed one Audience in three Winters, either by real or affected Illness; and yet I have often seen her on the Stage, when she ought to have been in bed" (190). Unlike some critics, he does distinguish between real and affected illnesses, thereby acknowledging the actor's dependence on their physical ability. But although Victor makes this distinction, he still praises Woffington for appearing on stage even when visibly ill. Such praise implies that it was Woffington's devotion to her audience and the theater which fortified her. While Victor acknowledges that she should have been in bed, he also praises her for ignoring the physical needs and ailments of her own body for the sake of performing.

The underlying message from these critics is that the physical condition of the performer only matters insofar as it impacts their ability to be on stage. The other actresses should either not be sick or should stop faking it. Moreover, the only way an actress can prove whether she is ill or healthy is to appear on stage — not appearing could potentially cause people to think you are faking. As such, it is not the actress who determines the discussion around her physical 
condition, but rather the perception of those around her. These critics reveal how the perception of an actress's physical ability to perform was connected to the opinion about their devotion or overall character. The actress cannot escape such a binary; she must attempt to succeed in spite of it. Whereas Cibber succeeded while ill, Woffington succeeded because she was on the other side of the binary, or at least she wanted to appear to be so.

Woffington seems to have been aware of the significance of how others perceived the health or illness of a performer. There are several accounts of Woffington expressing a level of disapproval for letting illness interfere with performances. Her most-often quoted words demonstrate that disapproval: "I will never destroy my own reputation by clinging to the shadow after the substance is gone. When I can no longer bound on the boards with at least some show of my youthful vigor, and when the enthusiasm of the public begins to show signs of decay, that will be the last appearance of Margaret Woffington" (Daly 149). She acknowledges that her reputation depends upon her physical ability to perform rather than simply be a shadow of her former self. She also acknowledges that without her "youthful vigor" the public would no longer be interested. Moreover, the audience's enthusiasm would "show signs of decay" just as her body would. She draws a direct link between her physical health and the audience's devotion; if one starts to deteriorate, so will the other. But rather than resent this opinion, Woffington acknowledges it and agrees, stating matter of factly that "that will be the last appearance of Margaret Woffington.” When we examine evidence about her attitudes towards performers who were ill, we see how Woffington created a persona of an actress who would not disappoint the audience in order to make them more loyal.

Woffington and Cibber were employed at Covent Garden in the early 1750s when Cibber's illness was quite frequent, and Woffington was one of the performers affected by her 
cancellations. While Cibber benefited from the backup play that the theater "had to have...in case she had an attack," Woffington was one of the actors who had to perform in that play at the last minute. According to Cibber's biographer, Woffington was hardly sympathetic: "Peg Woffington regarded Susannah's failing health as a provocation against herself. It was she, after all, who was frequently called back to the theater from an evening of revelry to substitute for a woman who she felt was a sanctimonious malingerer" (Nash 263). Woffington seems to concur with those who were suspicious about Cibber's illness. It is also possible that part of her feelings towards Cibber were due to a more general conflict between the two actresses. Rumors of a rivalry between Woffington and Cibber circulated, and while such rumors about actresses were quite common, the favoritism that Garrick often showed Cibber would certainly have been motivation enough for having a "cool contempt for each other, which was frequently communicated by looks, whispers, and half speeches" (Davies 1: 100-101). ${ }^{39}$ Rivalry or no rivalry, the good-natured comedic actress seemed to resent filling in for Cibber, which is certainly understandable since Cibber was highly paid while performing less than Woffington.

When Woffington was ill, she refused to cancel a performance, choosing instead to seem devoted to her audience. In January 1742, she was to play Helena in All's Well that End's Well, but the stalwart actress was ill. Instead of cancelling the performance, she attempted to please her audience by going on in spite of how she felt physically: "Woffington, who had fought against every advice to the contrary, came to the theatre from a sick bed, dressed for her part, and even went out upon the stage and stood by the scene, ready to make her entrance, when she fainted away and had to be carried back to her dressing room, and eventually home" (Daly 31). On the

\footnotetext{
${ }^{39}$ Garrick's favoritism would have also upset Woffington because of their prior history together as lovers. Woffington and Garrick were in a relationship during the early part of Woffington's career. It was serious enough for Garrick to propose to the young actress. He was turned down, and Woffington would go on to have many relationships and never marry.
} 
one hand, this behavior exemplifies Woffington's determination and perseverance to perform her professional duty, but this is also an example of Woffington working to maintain her reputation for not being ill. She was known for not disappointing audiences, and the "amiable" actress wanted to keep it that way, lest the audience waver in their devotion. ${ }^{40}$

There is, however, a record of one performance where she purposefully disappointed the audience, the circumstances of which reveal how much actors and managers relied on Woffington to never falter. While Woffington was acting at Covent Garden under the management of John Rich, her fellow players, including Cibber, were frequently unable to perform due to illness, and Rich relied on Woffington to substitute:

Mrs. Cibber was not the only one in the Covent Garden company whose frequent indisposition embarrassed the manager and disappointed the audience this season. Mr. Barry very often refused to play on account of his voice. He had a weak throat, and was in such dread of hoarseness that he would not go to the theatre unless the weather was favorable...The manager had no resource at such irritating time but to rely on the good nature of Mrs. Woffington, who, in contrast with the other members of the company, was amiability itself. (Daly 93)

While Rich was eager to rely on Woffington's sense of duty and amiability, he was not eager to give her the attention in the playbills that she thought she deserved, such as her name "underlined in large type" as Mrs. Cibber's was (Daly 93). Rich refused her request, and Woffington threatened to no longer substitute when another actor was ill. It speaks to how

\footnotetext{
${ }^{40}$ In addition to the devotion of audiences that her memoirists speak of, one of the best examples of her popularity in the theatre was the comedy, Masks and Faces; or Before and Behind the Curtain, written about her life postmortem. The play written by Charles Reade and performed in 1852 was such a hit, that the author wrote a follow-up novel: Peg Woffington. In fact, the Garrick Club Collection features a portrait of the actress Fanny Stirling in the character of Woffington. It speaks to her success on the stage that almost a century later she would be the subject of a successful play and novel.
} 
regularly Woffington filled in for her fellow players that merely threatening to stop filling in was enough to exert power over Rich.

Invariably, when Cibber cancelled her next performance, Woffington refused to go on as substitute. Naturally, Rich was furious, but what Woffington had not anticipated was how the audience turned against her. When she next appeared as Lady Jane Grey, the "audience treated her very rudely, bade her ask pardon, and threw orange peels on the stage" because of her refusal to perform (qtd. in Daly 95). A back-and-forth between an angry and insulted Woffington and a disappointed and hostile audience ensued:

She behaved with great resolution, and treated their rudeness with glorious contempt. She left the stage, was called for, and with infinite persuasion was prevailed upon to return. However, she did so; walked forward to the footlights, and told them she was ready and willing to perform her character if they chose to permit her--that the decision was theirs-on or off, just as they pleased--a matter of indifference to her. The ayes had it, and all went smoothly afterwards. (qtd. in Daly 95)

Rather than dig in her heels and refuse to perform because the audience turned against her, she relinquished control, allowing them to determine if she stayed on stage or not. Woffington's response worked because by making the audience think they had a say in whether or not she performed, she reaffirmed her sense of duty to the audience. She was there to please them, not the other way around. In that moment she manipulated the delicate balance between audience and actress. If the audience grew tired or irritated with her, she had no power on stage; however, if Woffington was mistreated by her audience, she could deprive them of their favorite roles and performances. But by granting the audience power after she disappointed them, Woffington takes control of this symbiotic relationship between audience and actress. In so doing, Woffington 
further intertwines her persona with the audience's perception of her health. Her ability to recalibrate her relationship to the audience demonstrates how aware Woffington was of the degree to which her value to the audience was connected to her physical ability to be on stage.

Ultimately, Woffington, as opposed to Cibber, used the audience's attraction to her charismata to create the persona of a devoted actress who valued her audience as much as they valued her. The public intimacy she created was not connected to the unpredictable vulnerability of Cibber's, but was instead built on feelings of loyalty and consistency. No doubt her comedic roles bolstered this persona. She could not have elicited the deep feelings of grief and sorrow that a tragedienne like Cibber did, but then also always appear to be full of life and vigor. Her persona, as such, goes hand-in-hand with what she knew to be her acting skill and talent. Her charismata works, in this way, because the comedic performer is desired to be available and loyal, as opposed to aloof and unpredictable.

Her charismata also works because Woffington had the physical ability to create a persona who was more devoted to her audience than those performers who cancelled and were ill. For Cibber, as well as performers with other illnesses or physical disabilities, that persona was not possible. Woffington managed to take advantage of a system of desire that privileged health, but only because she was physically capable of doing so. The illusion of Woffington's charismata is, of course, that physical health and loyalty are connected. Because of the bifurcated view of illness and health held by audiences, theater managers, and critics, there was no room to acknowledge that sometimes performers were ill and sometimes they were not, and these two things have nothing to do with their will to perform, devotion, or disposition. Rather, it is a system that privileges those who fit neatly into one of the two categories. Woffington had sustained periods of health, and she crafted a persona in which her health represented her 
dedication to the stage. But given the nature of being human, the illusion of perpetual health could only last for so long.

\section{Illness On Stage}

Fifteen years after she fainted off stage waiting to make her entrance as Helena, Woffington's desire to uphold her reputation of health culminated in a remarkably public spectacle of illness. There are many accounts of this story, but Tate Wilkinson describes it most thoroughly, having witnessed it first hand:

She went through Rosalind for four acts without my perceiving she was in the least disordered, but in the fifth she complained of great indisposition. I offered her my arm, which she graciously accepted; I thought she looked softened in her behaviour, and had less of the hauteur. When she came off at the quick change of dress, she again complained of being ill; but got accoutred and returned to finish the part, and pronounced in the epilogue speech, 'If it be true that good wine needs no bush--it is as true that a good play needs no epilogue'...But when arrived at-- 'If I were among you I would kiss as many of you as had beards that pleased me.'-- her voice broke, she faultered, endeavored to go on, but could not proceed--then in a voice of tremor screamed, O God!

O God! tottered to the stage door speechless, where she was caught. (118-119) A more dramatic exit could not have been written into the epilogue. In spite of the fact that it seems quite obvious to Wilkinson, and to others who report this performance, the audience cannot seem to comprehend what they are witnessing: "The audience of course applauded till she was out of sight, and then sunk into awful looks of astonishment, both young and old, before and behind the curtain, to see one of the most handsome women of the age...struck so suddenly by the hand of death" (Wilkinson 119). The audience, accustomed to only seeing Woffington at her 
best, is shocked by the realization that she could be ill. Their applause and "astonishment" reflect the confusion they were experiencing not just from witnessing an actress become ill on stage, but from watching their faithful Peg become mortal. Her celebrity had buoyed her to the illusion of immortality, or unembodiedment, in the eyes of her audience, and when she screamed, "O God! O God!" that illusion was crushed. The charismata of perpetual health and Woffington's ability to appear reliably on stage were diminished by this public spectacle of stigmata. In that moment, the audience was forced to acknowledge that their devoted Peg was ill and that the onset of her illness had nothing to do with her dedication or amiability.

Very little description is given of Woffington's diagnosis or treatment, but several sources claim that she had a "stroke of paralysis" (Daly 149). ${ }^{41}$ Wilkinson's description supports this conclusion when he says that she was "struck by the hand of death." A stroke, particularly a paralytic stroke, would also account for the reason why Woffington never recovered, and as a result, never returned to the stage despite living for another three years. A description from one of Garrick's memoirists supports this conclusion as well: “decay had already set in--the old charms had already begun to lose their spell--the fine fuel had been worn by sudden and mysterious strokes and sickness--the voice was growing more shrill--and her admirers had fallen away" (Davies 1:166). His description indicates that she may have had a few smaller strokes leading up to the stroke that ended her career. Assuming it was a paralytic stroke, Woffington's retirement into relative seclusion would have been most likely due to her inability to perform, as opposed to her decision not to continue performing. Yet the sudden and swift end to her career might help explain the public re-appearance she orchestrated while in her retirement.

\footnotetext{
${ }^{41}$ According to the Biographical Dictionary of actors, actresses, musicians, dancers, managers \& other stage personnel in London, 1660-1800, she "suffered a paralytic seizure on stage" (16: 216). The Oxford Dictionary of National Biography states that "she became paralyzed while speaking the epilogue."
} 
After her final performance, Woffington retired to Teddington, and her last three years were spent quietly tucked away from the theater. She was very ill and partially paralyzed, and as such, neither she nor her audience had access to her celebrity as embodied on stage. Her reputation and fame shifted to the words of theater-goers as they remembered her; no longer embodied, her celebrity existed through representations made by others. It is through visual representation that we get her final public appearance, in the form of a portrait (Figure 3.1). Painted around 1758, not even a year after her on-stage stroke, the portrait shows Woffington lying in her sickbed as she gazes at the viewer through her bed curtains. The painting was most likely done by Arthur Pond, and by analyzing the layers of paint, the National Portrait Gallery has concluded that the painting "must have been painted after Peg Woffington took to her bed after her collapse on 3 May 1757” ("Peg”). Rather than completely retreat after her collapse onstage, Woffington arranged to be painted as she lay partially paralyzed. A final public appearance, the portrait demonstrates Woffington's willingness to exploit the public spectacle of her illness and her attempt to reclaim her reputation as a devoted actress. Moreover, the portrait serves as an example of the kind of self-fashioning Engel discusses wherein the actresses used media to self-fashion her persona, and by extension their celebrity. 


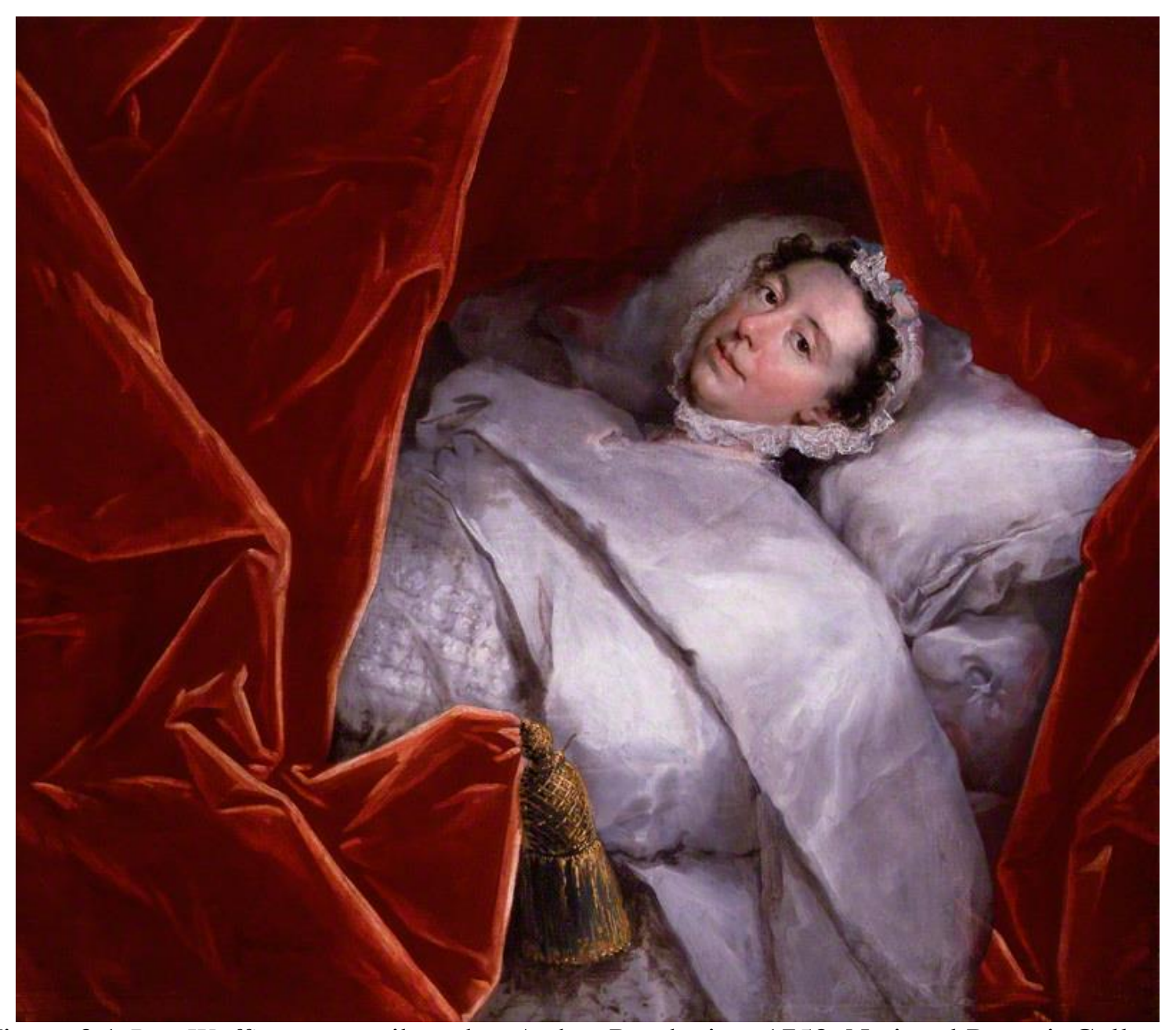

Figure 3.1 Peg Woffington, attributed to Arthur Pond, circa 1758, National Portrait Gallery.

Fintan Cullen discusses Woffington's portrait in his writings on Irish portraiture. He suggests that the portrait was Woffington's attempt to assert herself as a lady of wealth in order to reclaim her reputation near the end of her life. He argues:

the actor has appropriated the iconography of an aristocratic sick-bed portrait. In a tradition limited to the higher ranks of society and stretching back to at least the early seventeenth century, Woffington has been painted in the manner of women who have taken to their bed due either to severe illness or childbirth. There is nothing sexually provocative in this painting...Instead of the sexually provocative nature of the earlier 
portraits, the late bed painting conveys baroque grandeur and the moneyed lifestyle. (Cullen 120)

If we interpret the portrait as a re-appropriation of an aristocratic medium as Cullen suggests, then this portrait is not necessarily that different from her other portraits and those of other actresses. As Laura Engel, Gill Perry, and others have argued, actresses often used portraiture to insert their images into the visual culture and representation of the aristocracy. Woffington doing so at the end of her life would not necessarily have been unusual.

However, what the portrait does on a larger scale is refashion Woffington's fame after her retreat into the country. Presenting herself as a moneyed lady is just one outcome of that refashioning. Certainly, it is plausible that Woffington wanted to present an aristocratic image as her final one, but that reading is also reminiscent of the rewriting of Woffington's final years by her memoirists. Several posthumous depictions of Woffington's life create a narrative of an actress who started with nothing, used her sexual appeal and acting abilities to move up in the world, led a roguish, immoral life, and in her final years repented and reclaimed morality and virtue. While Woffington did retreat to the country, there is little evidence to suggest that Woffington became suddenly pious in her final days. Instead, it is more likely that the authors of her memoirs were attempting to rewrite and redeem the actress. Such efforts of redemption are common in late eighteenth-century and nineteenth-century memoirs.

Cullen's claims about the portrait are not identical to those of her memoirists--suggesting that her only impulse in sitting for the portrait was to align herself with a virtuous, aristocratic lady_-but Cullen also ignores the kind of celebrity Woffington fought to create and maintain. Throughout her career, Woffington created a dependable and unwavering form of public intimacy with her audience. Unlike Cibber, the Irish actress allowed audiences to rely on her 
stalwart devotion to them and the stage. But Woffington's final stage appearance could have destroyed the audience's perception of her as reliable and dependable. When forced to view Woffington's stigmata, as opposed to her charismata, audiences were left shocked and uncertain rather than comforted in the unwavering presence of their dear Peg. As such, her portrait can be interpreted as a way to reclaim and reassert her presence to audiences. She uses her body, no longer healthy and vibrant but bearing the effects of a serious stroke, in order to appear once again before her audience. It is as if Woffington needs to be seen by them. Cullen alludes to this, claiming, "This is a portrait of an Irishwoman who has achieved success, and despite her ailments, she still needs the oxygen of publicity--in eighteenth-century terms an oil painting on canvas--to advertise her newly acquired wealth and achievement" (123). But more than the wealth and achievement, it is the "oxygen of publicity" that drives her. After cultivating a form of celebrity so connected to her reliability to perform and not disappoint her audience, Woffington could not simply be forced off-stage, into oblivion, by a stroke. Certainly, this portrait elevates her in terms of the visual representation of her class, but the portrait also allows Woffington to reclaim her reputation as a dedicated and devoted actress.

The tone and subject of the sickbed portrait is different from many of her other portraits. Earlier portraits feature Woffington in her famous roles, as a young actress, or are of a "sexually provocative nature." Unlike the portraits that feature her as characters, the sickbed portrait and the private portraits of the actress share a tone of intimacy in their setting and style. Moreover, the sickbed portrait participates in the larger context of Woffington's other portraits, in which she demonstrates a similar kind of self-fashioning. One of these portraits features Woffington lounging on a sofa (Figure 3.2), while the other depicts the young actress holding a miniature of her lover (Figure 3.3). 


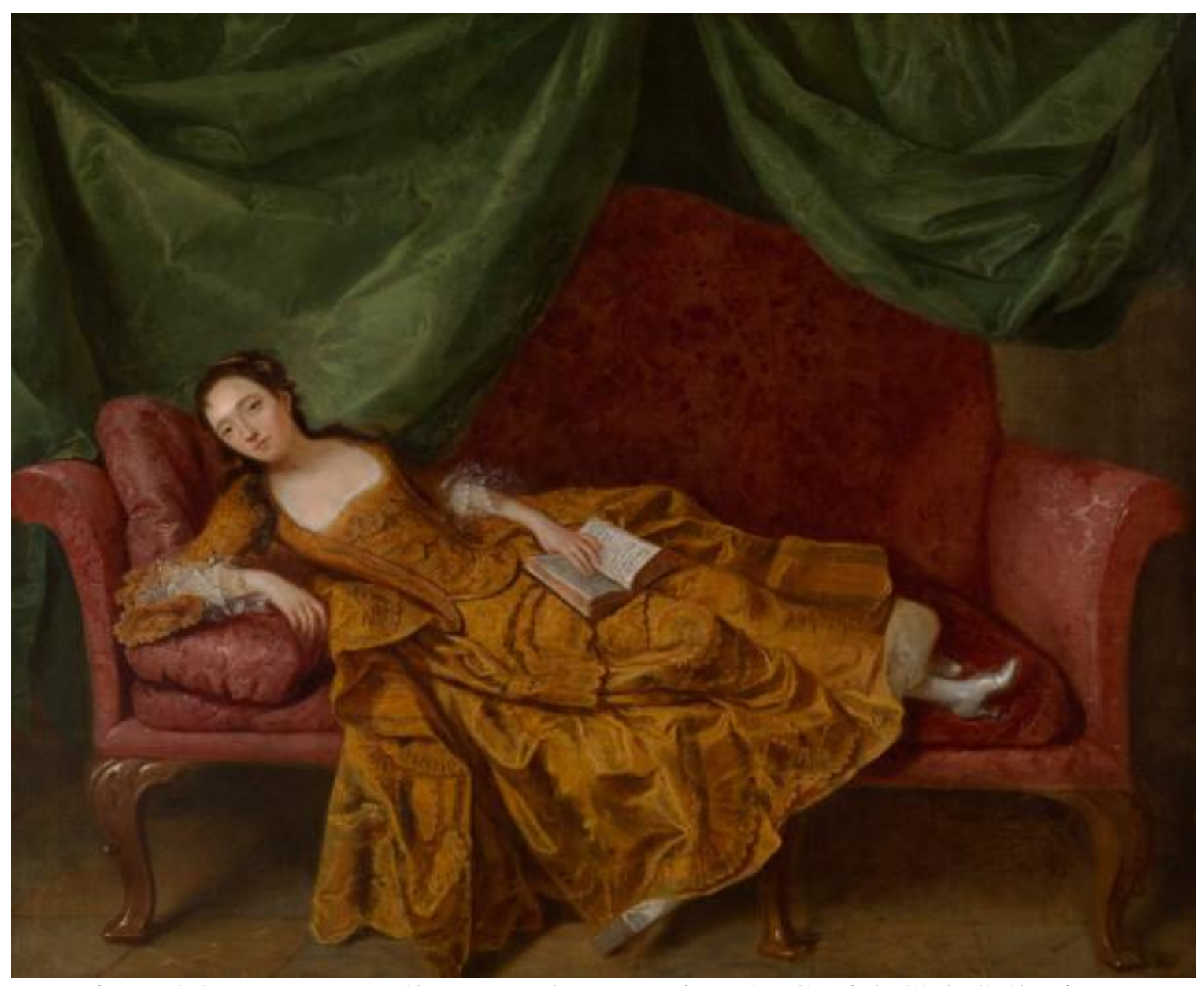

Figure 3.2 Margaret Woffington, unknown artist, The Garrick Club Collections.

In Alison Conway's analysis of the first portrait, she echoes Cullen's interpretation of the sexually provocative nature of Woffington's portraits but claims it is an example of selffashioning. The portrait shows Woffington lounging casually on a sofa and holding a book as she gazes at the viewer with her head tilted to the side. Conway argues that "Woffington's notoriety as a woman involved in various illicit affairs ensured that her private life would be put on display, and it appears, in this portrait, that Woffington has taken control of the viewing experience that her scandalous reputation creates. In particular, the presence of the book signals her agency as a reader--not only of scripts for the stage, but also of the scripts governing social and sexual relations" (78). The actress controls the viewer's gaze within what feels like a private 
and intimate setting. The tilt of her head and facial expression, in addition to the open book, look as though the viewer has walked in on Woffington reading, causing her to place the book down and stare back. The portrait feels simultaneously like an intrusion and an invitation, in which Woffington is in complete control. As Conway argues, we can analyze this portrait as Woffington exerting agency over her sexual reputation and social position, in order to selffashion her image and control the public's narrative of her body and her privacy.

Woffington exerts a similar type of self-fashioning in a portrait in which she gazes at a miniature she holds in her hand. The portrait is said to have been commissioned by Garrick, and he is meant to be the figure in the miniature. Woffington holds the miniature in her lap, which forces her gaze downward. The viewer, following her eyes, is forced to move down her body, including her "low-necked silver dress," down her waist, and finally to rest their eyes in her lap. The portrait is incredibly sensual and intimate, but Woffington is still in control of that intimacy. With her hair loose behind her shoulders, the actress looks down at the small figure of a man in her hand with a look of almost amusement, the corner of her mouth turned ever so slightly upward. There is no longing or devotion in this picture; instead, the woman leans casually back on her arm as if she is contemplating whether or not to drop the miniature. This is not a portrait of a woman wrought by the scandal of her relationship or by the deep affection she feels; rather, this portrait seems to emphasize the temporality of their connection. The only sitter making eye contact with the viewer is the dog behind Woffington's shoulder who looks at the viewer knowingly. This detail adds an element of humor to the portrait, as if the dog is commenting on Woffington and Garrick. This commentary emphasizes the staging of Woffington's pose. Woffington may choose to hold or drop Garrick, and she will do so thoughtfully, without malice. Woffington, as such, exerts control over the public's narrative of her relationship with Garrick. 


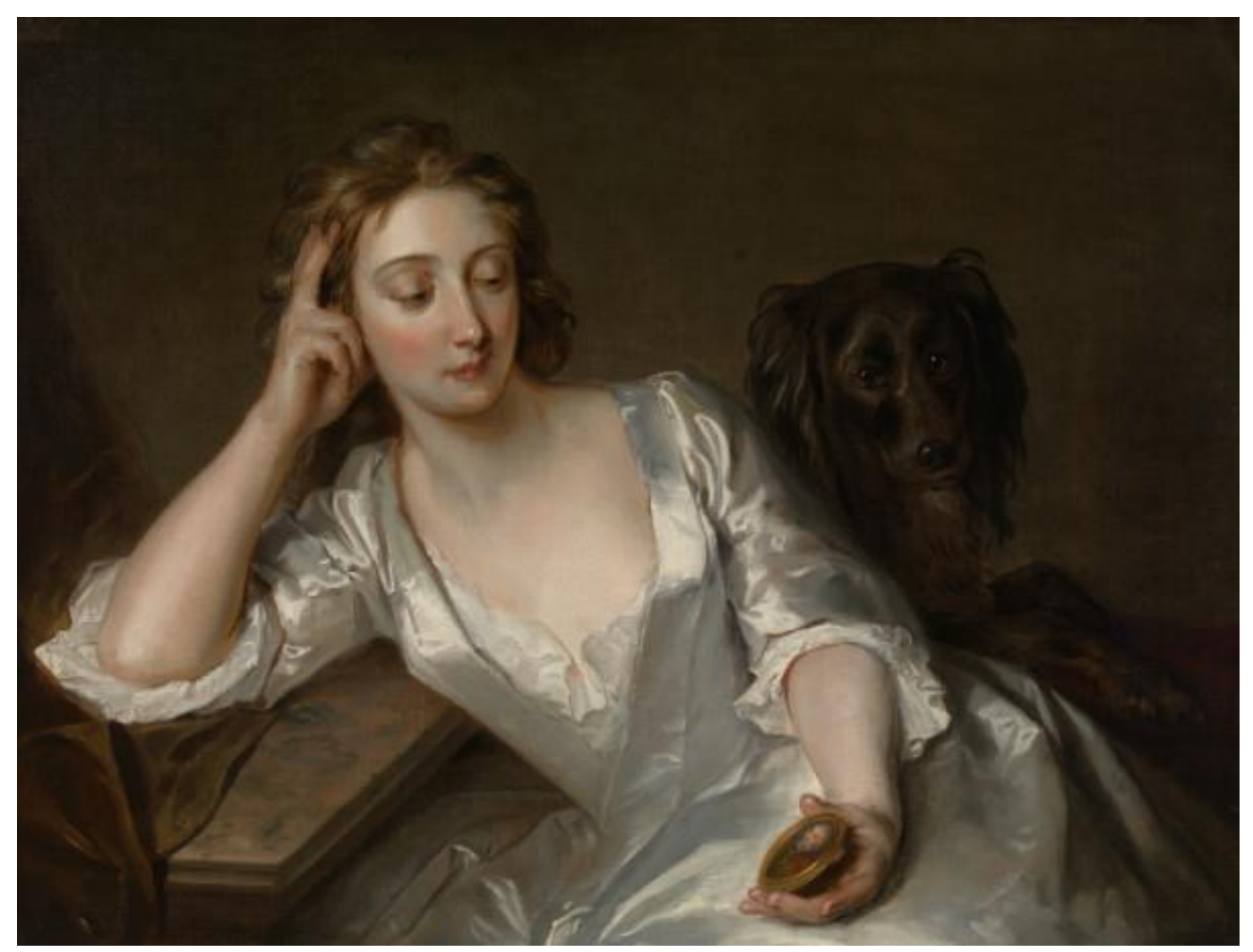

Figure 3.3 Margaret Woffington, Philip Mercier, circa 1735-36, The Garrick Club Collection.

A similar kind of self-fashioning of the actress's body can be seen in the portrait of her sickbed. Her decision to make her illness and its effects public reveal the degree to which Woffington valued her reputation as an actress who would never feign illness or disappoint her fans. The portrait is more than proof to her audiences that she is indeed unable to be on the stage; it is her reclamation of her celebrity persona. For an actress who was so adamant about performing whenever physically able, to have an attack on stage would have utterly shattered the reputation she had crafted and protected. Her celebrity was already medical because audiences, managers, and critics knew her to be the actress who was not ill and who would not fake illness. After her public attack, however, her audiences were forced to see her body as sick, and human. Her portrait allows her to re-embody her celebrity persona because she re-presents the image of Woffington that her audiences have. Instead of the shocked, uncontrolled, and vulnerable actress having a stroke on stage, audiences are reintroduced to a calm and peaceful 
Woffington. She gazes at the viewer from the painting with eyes of reassurance and purpose, as the red velvet curtains frame the close-up of her face. The curtains also evoke the stage curtains she so often walked out of to greet audiences, and which she fled behind during her attack of illness. The curtains in the portrait encroach upon the bed; the lower half of her body is hidden behind the bed curtain, which allows them to emphasize her upper half and face. Woffington has reset her stage in this portrait, dictating precisely what the audience can and cannot see. While a sickbed portrait might at first seem like an act of openness or vulnerability, for Woffington it is a way to reassert her control of her celebrity persona. She fulfills the audience's expectation that she will not willingly disappoint them, by showing them the reality of her sickness which, in the portrait, has left their buoyant, beloved Peg bedridden. In sitting for the portrait, Woffington makes her final appearance for theatergoers, both reassuring them of her devotion and reclaiming her reputation.

Through this visual representation, Woffington is able to challenge the idea that qualities of a person's character, such as determination or devotion, are associated only with health. As such, while her reputation for health during her active career on the stage reified the binary of illness versus health, this painting collapses it. Moreover, she uses the medium of portraiture, a form of representation both she and other actresses used to self-fashion celebrity, to refashion her reputation as an actress whose devotion and loyalty to her fans was not contingent upon her physical ability to be on stage. This particular visual medium enabled Woffington's refashioning similar to the ways in which social media platforms like Instagram and Twitter enable contemporary celebrities to refashion their personae. That parallel exists because of how the eighteenth-century theater impacted the cultural role of medicine to create a culture of medical celebrity that we still have today. 
On the one hand, this chapter reveals that because the eighteenth-century theater relied on the physical ability of actresses to perform, it perpetuated the cultural perception of illness and health as diametrically opposed states of being, wherein one is positive and one is negative. On the other hand, both case studies demonstrate that actresses forced to operate within that binary managed to challenge it because of their personae and relationships to audiences. The eighteenthcentury theater, as a result, emerges from this analysis as a cultural mechanism that enabled medical celebrity as a sociocultural phenomenon. Moreover, as a celebrity cultural mechanism, it contributed to audience's perceptions of illness and health. Actresses, like Cibber and Woffington, had the ability to shape how individuals perceived illness and health as a whole, but also how they perceived the performer's relationship to illness and health. The implications of that in the eighteenth century are vast and immeasurable, but we can see their analogs in contemporary medical celebrity culture.

The birthplace of modern celebrity, the eighteenth-century stage, left an indelible imprint on our contemporary celebrity culture, in which we also expect celebrities to be either ill or healthy. If a celebrity is diagnosed with an illness, we as fans and audience members expect to be informed quickly and to know about the details of the illness. That expectation arises because of our perceived relationship to celebrities through public intimacy and our desire to know about their private lives. When celebrities try to keep their illnesses and treatments private, the public expresses outrage, which sometimes translates into skepticism. By the same token, we expect celebrities to be perpetually healthy. They need to be ageless, fit, perpetually available, and always ready to perform. That bifurcated perception of illness and health has filtered into our cultural understandings of illness, treatment, recovery, health, and medicine. Yet our relationships with celebrities and their individual personas consistently challenge that narrative. 
While the industry of celebrity, particularly of film stars, perpetuates this absurd expectation of perpetual health or career-ending illness, individual fans often remain loyal as the physical ability of a celebrity changes. Their relationship to the celebrity and connection to their persona enables their devotion to transcend corporeality and to see the celebrity as more than their physical condition, thereby changing how the individual fan perceives and understands illness and health. Theater, in the eighteenth century and as demonstrated in these two case studies, is just one cultural mechanism by which celebrity impacts our cultural perceptions and understandings of illness. 


\section{Chapter 4}

Medical Celebrity and the Patient Experience: Celebrity and Fame in Frances Burney's

\section{Mastectomy Letter}

The Guardian recently published an article with the following headline: “"The evil was profound': Fanny Burney letter describes mastectomy in 1812.” The article, despite its misleading title, was an informative piece about a newly digitized collection of over 300 manuscripts at the British Library. Of these manuscripts, they chose to headline with a line from the letter Frances Burney (1752-1840) wrote in 1812 that detailed the mastectomy she received when she was fifty-nine years old. ${ }^{42}$ The byline reads: "Letter, which has been digitized by the British Library for the first time, recounts the novelist's agonizing experience of surgery in an age before anaesthesia" (Flood n.p.). That statement is a succinct representation of how Burney's narrative is typically framed in contemporary conversations. Her letter, unique because of its content and its author, has become well known to both medical and literary scholars and, to a lesser extent, within popular culture. Typically, people refer to the letter as a rare look inside a patient's experience of surgery before anesthesia, which it is. However, as was the case in The Guardian's article, the letter is often sensationalized because of the lack of anesthesia and the violence and trauma depicted in the narrative. Our twentieth- and twenty-first century experiences with medicine and illness make it difficult to read the letter without sensationalizing it. As a result, we have imbued Burney's mastectomy with a cultural significance it did not possess during its time period. Yet the letter is significant because it is a detailed, self-authored narrative of a patient who survived a major surgery during the long eighteenth century. As a

\footnotetext{
42 Copies of this letter exist in several collections of Burney's letters, most notably Joyce Hemlow's The Journals and Letters of Fanny Burney (Madame D'Arblay), vol. 6, (1975). Content from the letter used here will be from Hemlow's edition and referred to in citations as $J L$. The original manuscripts can be found in the Henry W. and Albert A. Berg collection at the New York Public Library.
} 
record of medical experience, her letter offers an important insight into the patient's experience of medicine, surgery specifically, in the long eighteenth century.

Several scholars have analyzed the letter as a record of Burney's personal experience and for what it tells us about gender relations, breast cancer, and the function of narrative. ${ }^{43}$ Most notably, Julia Epstein discusses how Burney's letter operates as a medical narrative that captures a piece of medical history, while also serving as a means by which Burney reclaims her body back from the traumatic experience of the surgery. She writes, "Fanny Burney's mastectomy letter presents, then, an intersection of medicine and the anatomized body with literature: it is a text that articulates medical reality by overlaying it with the imaginative and dramatic possibilities intrinsic to the aptly named operating theater, as it is a text that carves a writer's self-representation out of the body's encounter with the knife. Knowing the body as subjective experience merges with a knowing of the body as objective nature. In medicine, the body becomes spectacle; in imaginative prose, the writer's language repossesses the theater" (162). Epstein's work establishes Burney's letter as a medical case history while discussing the performative and therapeutic nature of Burney's act of writing. As such, this text, more than any other discussion of the mastectomy, serves as the foundation for this chapter's examination of the cultural mechanisms that shape both the content of the letter and its posterity.

\footnotetext{
43 Discussions of the letter exist with the field of literary criticism and medical history. Within the field of literary criticism, scholars have discussed her letter in terms of what it reveals about gender, breast cancer, and female bodies. These include Heidi Kaye's discussion of the male gaze of the physicians and the ways in which Burney reclaims her status as a subject within the letter in “'This Breast-It's Me': Fanny Burney's mastectomy and the defining gaze" (1997). Heike Hartung, “'Doleful Ditties' and Stories of Survival: Narrative Approaches to Breast Cancer in Frances Burney, Maria Edgeworth, and Susan Sontag" (2007) analyzes Burney's letter alongside other female narratives of breast cancer. Annie Pécastaings, "Frances Burney's Mastectomy and the Female Body Politic" (2011) analyzes the letter within the context of the revolution and how women used their bodies in the public arena. Within the field of medical history, scholars examine Burney's letter as it fits into the history of breast cancer or mastectomies as a whole. Notable discussions of the letter are James S. Olson's Bathsheba's Breast: Women, Cancer, \& History (2002); Marjo Kaartinen's Breast Cancer in the Eighteenth Century (2013); June K. Burton's Napoleon and the Woman Question:Discourses of the Other Sex in French Education, Medicine, and Medical Law 1799-1815 (2007).
} 
This chapter provides a close reading of the letter to examine the forces that shape Burney's experience of medicine in terms of her access to a medical practitioner, her diagnosis, and her treatment. I argue this close reading reveals social networks, fame, reputation, and popular print culture influenced every aspect of her medical experience. Ultimately, my analysis demonstrates how the mechanisms that create celebrity as discussed by Rojek, Turner, Wanko, and others shaped the medical experience of patients. We will see how Burney's own celebrity shaped her experience, including her access to famous practitioners and her relationship with her primary surgeon. We will also see how celebrity cultural mechanisms beyond Burney's own celebrity impacted her operation. In this way, her letter serves as a case study of how the medical celebrity discussed in the previous three chapters affected the patient's experience of medicine, and ultimately how Burney represented and recorded that experience. I examine the publication history of the letter and argue that the cultural mechanisms of celebrity also shaped Burney's composition of the letter and how it exists in our contemporary culture. As a result of this analysis, I conclude that Burney's fame and celebrity as a literary figure shaped the posterity of her letter. As such, this chapter is a case study of how medical celebrity impacts patient experiences and the process by which representations of patient experiences become part of our medical and cultural history.

\section{Part I: Consulting Medical Practitioners}

Frances (Fanny) Burney, born in King's Lynn, Norfolk, on June 13, 1752, was one of the most successful authors of the late eighteenth century. She began writing and observing people at a very early age. ${ }^{44}$ She tells us in her dedication of The Wanderer: or, Female Difficulties: "I

\footnotetext{
44 The most notable biographies on Burney are Joyce Hemlow's The History of Fanny Burney (1958); Margaret Anne Doody's Frances Burney: The Life in the Works (1988); Kate Chisholm's Fanny Burney: Her Life (1998); and Hester Davenport's Faithful Handmaid: Fanny Burney at the Court of King George III (2000).
} 
struggled against a propensity which, even in childhood, even from the moment I could hold a pen, had impelled me into its toils" (1: xx-xxi). Burney describes how she was made to feel as though her writing was a compulsion rather than an appropriate pastime for a young girl, and that at age fifteen she burned her writings, which included a prequel to her first novel, Evelina. Her language shows how difficult this was because her creativity, her "passion, however, though resisted, was not annihilated" (1: xxi). Yet the fact that she burned the manuscripts shows how conflicted she was by the principles she was taught, which would make her try to suppress and destroy what was so natural to her. The incident is a good illustration of who Fanny Burney was: someone who wrote constantly as ideas welled up inside of her, and a keen observer who took in the impressions, rules, customs, manners, and thoughts of the people as fodder for the rich characters in her novels and as influences on her own behavior. She says that "in defiance of every self-effort, Evelina struggled herself into life" (1: xxi). Her own life offered many interesting people to observe, starting with the famous friends of her father, Dr. Charles Burney. She wrote detailed journals and letters throughout her entire life that serve as a veritable who's who of the late eighteenth century. However, it was not until Burney published Evelina in 1778 that she too became famous. At the home of Hester Thrale at Streatham Park, Burney was able to fully realize the popularity of her novel. Once it was discovered who had published the anonymous, epistolary novel that followed the young life of Evelina and served as a cornerstone for future comedies of manners, the twenty-six-year-old Fanny became instantly sought after. ${ }^{45}$

By the time of her surgery at age 59, Burney had written two more novels, Cecilia and Camilla, and several plays. The success of Camilla was so great that she was able to purchase a home with her earnings. Her readership extended beyond Britain, onto the continent. However,

\footnotetext{
${ }^{45}$ See Audrey Bilger's "Comedy in Manners: Making Fun of the Angel in the House" in Laughing Feminism: Subversive Comedy in Frances Burney, Maria Edgeworth and Jane Austen.
} 
Burney was a private person and her fame was a "blessing about which she had some reservations" (Doody 66). Despite her reluctance, fame afforded Burney an extensive social network. Although she did not utilize the social network with the same vigor that Thrale and her other bluestocking contemporaries did, her renown gave her access to famous and influential people across several spheres of influence. She socialized with great authors, politicians, and artists of the period. Johnson and Sheridan were friends of hers, along with the likes of Sir Joshua Reynolds, Edmund Burke, and David Garrick, in addition to her connections at court from her five-year period as Keeper of the Robes to Queen Charlotte (Doody 169). Her renown followed her when she moved to Paris with her husband in 1802 . Though it was intended as a temporary move, because of the consequences of the Revolution they were forced to stay for ten years, and during that time she developed an illustrious social circle. But, as scholars have argued, the social network was not simply about enriched personal connections; it also provided the avenues along which social, cultural, political, and economic changes occurred. A robust social network allowed access to power in various spheres.

Burney's letter reveals that her social network gained her access to the medical sphere of power and expertise, which we see in her description of how she consulted physicians. ${ }^{46}$ Burney first consulted a doctor by the name of Jouart, who treated her friend Anna Potts. He prescribed some form of treatment (it is unclear what), but Burney wrote that it "produced no fruit" (JL 6: 599). Her husband then suggested she return to M. Dubois, who had treated her for an abscess a few years prior but had become quite renowned since then (1806-1807). When Burney sought treatment from Antoine Dubois in 1806, he had recently left Napoleon's army in Egypt, as well

\footnotetext{
46 There appears to be very little, if any, record of this operation and/or of Burney in the personal documents of Larrey or Dubois. It is clear that they were both in Paris during this time, and while Larrey was working at the Hospital for the Imperial Guard, Dubois was living at the Tuileries Palace as the obstetrician to the Empress, who had gone through a difficult delivery a few months prior.
} 
as his position there as a member of the Institute of Cairo, and returned to France because of health concerns. ${ }^{47}$ Although having fallen out of favor with the Emperor, Dubois maintained several important positions in medical schools and hospitals (Burton 96). He was a wellrespected surgeon who had risen to prominence before being forced to return to France. In the time since he first treated Burney, he had earned his way back into the favor of the newly wed Emperor because of his reputation as a skilled obstetrician (Burton 96). Because of his prestige and connections at court, he became obstetrician to Empress Marie-Louise in 1810 in Paris, one year before Burney's mastectomy (Burton 96). He delivered their child, who was given the title “King of Rome,” on March 20, 1811--a mere five months prior to Burney’s surgery (JL 6: 599 n. 7).

So, by the time Burney needed an appointment, Dubois had gained a much higher social and professional position. As such, she was hesitant to seek his advice: "M. Dubois, the most celebrated surgeon of France, was then appointed accoucheur ${ }^{48}$ to the Empress, and already lodged in the Tuileries, and in constant attendance: but nothing could slacken the ardour of M. d'Arblay to obtain the first advice" (JL 6: 599). She implies that Dubois's position places him outside of her social reach whereas, prior to his appointment, she had no qualms about seeking treatment from him. Only because her husband insists that she have the best advice does she send

\footnotetext{
${ }^{47}$ Born in 1756, Dubois studied surgery at several colleges, working with prestigious physicians along the way, and chose to study medicine while at the College Mezarin (Burton 96) ${ }^{47}$ In 1791, with a quick rise in the university, he took the position of professor at the École de chirugerie (JL 6: $599 \mathrm{n}$. 7). But the revolution was not kind to establishments (including medical schools) and DuBois was forced to take a position in Melun's military hospital (JL 6: 599 n. 7). To be successful in the Age of Napoleon, particularly as a surgeon, it was almost necessary to practice within the military. From there, he was promoted to "Chair of Anatomy" and quickly rose in position in several hospitals (Burton 96). By 1798, he was chosen to accompany Napoleon as a member of the Institute of Cairo (Burton 96). In Alexandria, he treated General Jean-Baptiste Kleber, who suffered a terrible head injury during the first engagement in the city (Burton 96). Here, he worked with Dr. Larrey, and presumably it is here that we can trace their connection to one another (Cust 276). After this campaign, Dubois fled Egypt and returned to France for health reasons, and for this he would be seen as disloyal by Bonaparte (Burton 96). He held several important positions in medical schools and hospitals, and it was only due to his reputation as an obstetrician that he was able to earn back the respect of the newly wed Emperor (Burton 96).

48 "male midwife"
} 
a request to Dubois through a third person (JL 6: 599). She tells us that he responded only

because he "retained a partial regard for me from the time of his former attendance" (JL 6: 599).

Thus, her previous connection to Dubois and her ability to contact him through another person

allowed her to get an appointment with the Empress's accoucheur. Burney's social network

granted her access to a doctor she would otherwise not be able to seek treatment from. ${ }^{49}$

After his exam, Burney began to "perceive [her] real danger," and Dubois gave her a "prescription to be pursued for a month" (JL 6: 600). He also spoke to M. d'Arblay about Burney's health, who told her that that "a small operation would be necessary to avert evil consequences" (JL 6: 600). Burney informs us that the prescription from Dubois did not work: "Direful, however, was the effect of this interview; the pains became quicker and more violent, and the hardness of the spot affected encreased. I took, but vainly, my proscription, and every symptom grew more serious" (JL 6: 600). The prescription not only did not help, but it made the symptoms worse, thereby increasing the likelihood that Dubois would need to operate. Faced with these prospects, Burney sought a second opinion from a surgeon of equal, if not greater, renown and reputation.

Whereas Burney's social network grants her access to Dubois, both the social network and the rules of reputation dictate how she can get a second opinion from another renowned surgeon. Her husband informed her of a Dr. Larrey, whom he heard about from M. de Narbonne, a friend of D'Arblay's from the military and the godfather of their son. Baron Dominique Jean Larrey (1766-1842) was an incredibly reputable and well-known surgeon who had served as

\footnotetext{
${ }^{49}$ It is worth mentioning that in some ways this might be Burney self-fashioning an image of modesty in the letter. Whether this modesty was genuine is unknown, but Burney does not frame the letter as if she used her connections to get the best doctors but rather that her social and political connections allowed her to come in contact with these doctors. And since Burney is hesitant to see a doctor at all about her illness, it is hard to imagine her bolstering her celebrity clout in order to be treated by Dubois and Larrey. Her modesty in not expecting Dubois to treat her, therefore, seems to be both genuine in some ways but also muddied by her general fear and reluctance to see any doctor.
} 
Chief Surgeon to Napoleon's Grand Army since 1804 and was made a Baron in 1809 (Leroy-

Dupre 99) ${ }^{50}$ He gained a reputation as a skilled, logical, and empathetic surgeon who made groundbreaking innovations in military medicine. Larrey is responsible for both our current system of triage and the modern ambulance. ${ }^{51}$ Narbonne claimed that Larrey cured a Polish woman of a "similar malady," which encouraged Burney to seek treatment from him (JL 6: 600). Another friend of M. d'Arblay also recommended Larrey, who then contacted Jean-Pierre Barbier de Neuville, head of the 3rd division in the Ministry of the Interior who, Burney says, "has an influence irresistible over this M. Larrey" (JL 6: 601). Neuville wrote to Larrey on Burney's behalf to see if he would examine her. ${ }^{52}$ This complicated series of social connections results in Burney receiving a visit from Larrey. Without that series of connections, Burney would not have had another means to get in contact with him; Larrey was not a surgeon who was taking patients regularly or who was working in a hospital. He was merely in France between military

\footnotetext{
${ }^{50}$ His success and reputation was such that Napoleon said, "If the army ever erects a monument to express its gratitude it should do so in honor of Larrey" (Richardson 491).

${ }^{51}$ When Larrey first enlisted in the French Army in 1792, surgeons were treating soldiers according to their rank and class: wounded officers and upper class men were treated for minor injuries before seriously injured soldiers of lower rank (Nestor n.p.). Larrey saw the inadequacies of this system because it placed social value over medical need. Because of this, he came up with the system still employed in emergency medical rooms and situations: triage. Originally referred to as "trier," meaning "to sort," this system placed those who were critically and seriously injured at the top of the priority list, allowing those with more minor injuries, regardless of who they were, to wait to be treated, as the consequences would be less dire (Robertson-Steel 154). Larrey implemented this system in hospitals he worked in, and other surgeons and doctors saw its benefits on the battlefield, which helped the system spread. Larrey's second major innovation was in response to what he noticed about the surgeon's ability to get to the wounded soldier on the battlefield--triage did not matter if you never reached your patients in time to help them. When Larrey began his military career, the primary means of medical transportation on the field were "huge, cumbersome wagons called Fourgons" (Nestor n.p.). This vehicle could take days to reach wounded soldiers who often needed immediate medical attention. Deciding to focus not on his own safety but on getting medical aid to his patients, Larrey opted instead to think on a smaller scale, and designed a wagon made to get to patients quickly and easily. The "Flying Ambulance," as he called it, consisted of one small wagon with two wheels that could carry two patients, with medical supplies on the sides, and a ramp that folded and served as an operating table. Horses pulled the wagon filled with patients laying on padded blankets (Nestor n.p.). This vehicle, a predecessor of our modern ambulances and MASH units, did not guarantee the safety of the doctors (Larrey was injured several times in battle), but instead prioritized patient need and treatment. The "Flying Ambulance" was reproduced multiple times and used throughout the Napoleonic Wars.

${ }^{52} \mathrm{He}$ came to Paris in 1810 to direct the hospital of the Imperial Guard for two years (Leroy-Dupre 99). It was during this brief period that he performed Burney's mastectomy--what is referred to by a biographer in 1861 as the period in which "he remained in a state of comparative inactivity" (Leroy-Dupre 100).
} 
operations. Only because Neuville requested a visit, does Larrey come to Burney.

However, the visit proved unfruitful because Larrey was "full of scruples concerning M. Dubois" and would not examine her until she sought permission from Dubois. She implies that Larrey was worried he would offend Dubois if he gave Burney a second opinion without having informed the doctor currently treating her. This reveals how both Larrey and Burney were operating within the rules of reputation within the medical profession. This situation echoes the emphasis on reputation in Chapter 3, wherein Ranby was expected to pay deference to the position and reputation of the other physicians treating Sir Robert Walpole. Larrey, presumably, wanted to avoid that kind of offense and scandal. Thus, Burney says that Larrey would not "give me his services till I wrote myself to state my affright at the delay of attendance occasioned by the present high office and royal confinement of $\mathrm{M}$. Dubois, and requesting that I might be made over to M. Larrey" (JL 6: 601). Even the way she must request permission from Dubois pays deference to his reputation, because she does not tell him the real reason why she seeks treatment from Larrey. Burney does not think the prescription Dubois gave her worked, and rather than state this, she blames her desire for a new doctor on a fictional concern that he cannot see her regularly enough, what she calls the "delay of attendance." Her health, personal preference, or reaction to the prescription did not dictate the means by which she had to seek permission to get a second opinion; instead Burney followed the rules of professional reputation.

Only because of her extensive social network of powerful and wealthy individuals does Burney gain access to two incredibly well-known and reputable surgeons. Another patient with Burney's medical condition, but without the social connections, would not have been able to access these two practitioners. Neither of them was taking on new patients or had a practice that was open to the public. Burney gains special access to them and, by extension, to their medical 
skill and acumen. In this sense, celebrity cultural mechanisms privilege Burney above other less famous and less connected patients. But because Burney has to seek Dubois' permission before she can be seen by Larrey, the professional system of reputation slows down her examination, diagnosis, and treatment. Celebrity cultural mechanisms, in this case, uphold the medical profession's operations, which benefits the medical profession but negatively impacts the patient.

As discussed in previous chapters, the connections between patients and medical practitioners often operated along social lines. A friend might recommend a physician based on their experience or what they heard about the physician from others. But depending on one's social status and social connections, the available knowledge of medical practitioners, and the affordability of medical practitioners, would vary. Burney's case reveals that the social network enabled patient/practitioner relationships by privileging those patients with an extensive and illustrious social network, by extending the access they had to medical practitioners. Moreover, as we saw in Chapters 1 and 2, reputation clearly dictated much of the operations of the medical profession, but here we see how this impacted the medical experience of the patient. For Burney, that system of reputation impedes her independence and agency as a patient. As such, we can conclude that while some practitioners and patient connections may have occurred within a free market exchange, wherein patients had choices in terms of what practitioner they used and what treatment they took, some practitioner/patient relationships operated outside of that market and along the lines of social networks and reputation.

\section{Part II: Receiving Diagnosis and Treatment}

In addition to influencing Burney's access to her doctors, the cultural mechanisms of reputation and social network, as well as fame, contributed to some of Larrey's decisions in her treatment. Once Larrey examined her, he gave her a prescription, and left Burney hopeful of the 
outcome, but after some time passed, her symptoms worsened again, and Larrey decided to consult two other medical practitioners: Dr. Ribe, who Larrey says is the "first anatomist...in France" and Dr. Moreau, a physician. They all decided she needed an operation, but Larrey was still anxious about making the right decision, and so he brought Dubois back. Burney, growing anxious and frustrated, refused to be seen by Dubois, and she writes, "No, I told him, if I could not by himself be saved, I had no sort of hope elsewhere" (JL 6: 603). In response, Larrey reveals that he has brought in other doctors because she needs to have the "First and most eminent advice his Country could afford; Vous êtes si considerée, Madame, ici, que le public même sera mécontent si vous n'avez pas tout le secour que nous avons à vous offrir" ${ }^{\text {"53 }}$ (JL 6: 603). This very brief statement reveals much about Larrey's state of mind, and it is the only time Burney quotes Larrey directly for more than just a phrase. Larrey was not consulting other doctors purely for Burney's benefit; he was also thinking about the impact her surgery (and more specifically, her possible death) would have on the public. He was thinking about the surgery beyond the medical implications and beyond his single patient. He acknowledges that Burney has a public audience who would be very upset if something happened to her. He was keenly aware of her relationship to the public (her celebrity) and the impact that the tragedy of her death, either from the cancer or from the surgery (both of which were likely), might have on the public. His concern relates to three manifestations of reputation and fame: his reputation, Dubois' reputation, and Burney's fame.

On the one hand, Larrey knows that if Burney dies under his knife, his reputation will be affected. This surgery, which ultimately comes to mean very little to Larrey's biographers and in Larrey's own memoirs, might not affect his reputation as an army surgeon, but word of the

\footnotetext{
53 "You are so esteemed here, Madam, that the public itself would be unhappy if you did not receive all the help that we have to offer."
} 
surgery, if unsuccessful, would travel fast because of Burney's fame. He also defers to Dubois' reputation when he tells Burney that she should have "the First and most eminent advice his Country could afford." His decision to bring in Dubois speaks to a few considerations of his own credentials and reputation versus Dubois's: 1) Dubois was the more established practitioner in Paris, holding a much more permanent position; 2) Dubois was also an obstetrician, and as a result would have had more experience with female maladies than a predominantly military surgeon. Not only is Larrey's concern for his own reputation motivating the decision to bring in Dubois, but his consciousness of Burney's celebrity prompts him to make this decision. As such, her celebrity impacts how she receives a diagnosis. It is easy to wonder if Larrey would have consulted other doctors for a less famous patient. This exchange reveals how celebrity, reputation, and fame influenced medical decisions. What might seem like an entirely logical decision, to bring in Dubois, is not rooted in Burney's particular physical condition, commonly used protocol, or a medical reason-but in public perception and reputation. This moment echoes how Walpole's physicians diagnosed and treated him, and demonstrates that the same cultural mechanisms that create celebrity could also impact the methods for medical diagnosis.

Moreover, because Larrey is thinking, even tangentially, of the public's response to the outcome of her surgery, the public has a presence there. Even if the public never learns of Burney's surgery, because Larrey admits that he is thinking of her public reputation and her fame, Burney's celebrity ghosts her own medical diagnosis, treatment, and procedure. She cannot ever be just Frances Burney, a patient with a tumor in her breast; she must also be Frances Burney, beloved author who is "so esteemed" by the public. Burney's letter, in this way, represents the experience of a celebrity as a patient — which was influenced by their fame, their physicians' reputation, and their awareness of public perception. Those cultural mechanisms 
created the circumstances by which Burney experienced this diagnosis and treatment, as much as medical knowledge, developments, and tools did. Her letter echoes how Walpole's physicians were so concerned with his reputation and their own reputations that they probably gave the former prime minister a toxic level of an unreliable drug. In Burney's case, Larrey’s awareness of his reputation and her fame improve the treatment she received, but it is easy to imagine that celebrity could impact a patient's treatment and diagnosis for the worse.

Burney's description of the medical procedure shows that the treatment she received was informed by the cultural mechanisms of fame and reputation. Her description of the operation is incredibly detailed, and I argue that it mirrors the recommendations for surgery as outlined in Benjamin Bell's A System of Surgery, a textbook in six volumes that details the surgical procedures and common practices used in the late eighteenth century. ${ }^{54}$ Published between 1783 and 1788, it served as a compendium of surgical knowledge and procedures and was a popular reference tool for many practitioners. A comparison of Burney's operation to the procedure for mastectomies outlined in this most popular reference tool for surgeons at the time, reveals that Burney's surgery was not unique to her but was one of many similar operations. As such, I argue that her medical procedure represents the impact of consumer print culture and reputation on the patient's experience of treatment. In Chapter 2, I argued that practitioners could manipulate those same cultural mechanisms to shape the medical market and potentially impact patients' decisions, perceptions, and experiences of medical knowledge and medical treatment. Here, we

\footnotetext{
${ }^{54}$ In the preface to the first volume of A System of Surgery, Bell explains his reasoning for writing a "view of the art of Surgery, as it is as present practiced by the most expert surgeons in Europe" (1: vii). Prior to this, the most recent comprehensive collection of surgical method and procedure was published in 1739, and as Bell argues, there were many changes since then, and a new "general system of surgery" was needed (1:v). As such, for the purposes of this chapter, we can consider Bell's textbook to be a comprehensive study of surgery at the time. However it should be clear that the work is not a collection of methods, but rather a book on the best methodology surgeons should use. As such, these are Bell's recommendations for surgery in particular, while also containing the best methods from surgeons across Europe in general.
} 
see that cultural exchange from the perspective of the patient.

Burney's description of her mastectomy covers three main portions of the procedure: the preparation, the initial cut, and the removal of tissue, and when we examine her descriptions alongside the recommendations for the surgical procedure in A System, the similarities quickly become apparent. The preparations consisted of assembling a surgical table made from a "Bed stead into the middle of the room,...two old mattresses,...and an old Sheet" (JL 6: 610). This surprised Burney because Larrey informed her that she would sit in an armchair for the operation. After Burney lies on the mattresses, a "cambric handkerchief” was placed on her face (JL 6: 611). This is presumably so that she cannot see anything and is less inclined to move her head, but Burney makes it clear that the handkerchief was translucent enough that she could see the figures of the doctors and their movements. They hold her down so she does not move during the procedure, and then the surgeons plan how they will begin the operation through gestures to each other.

According to Burney, what they communicate to each other at this point is how much of the breast will be removed and how the incisions will be made. Burney observes the following through her handkerchief: "I saw the hand of M. Dubois held up, while his fore finger first described a straight line from top to bottom of the breast, secondly a Cross, and thirdly a circle; intimating that the Whole was to be taken off" (JL 6: 611). This same method of incision is described by Bell in somewhat more detailed terms, but the basic principle is the same: "an incision should be made with a scalpel through the skin and cellular substance from one extremity of the tumour to the other...it is necessary that this incision correspond to the length of the tumor by making it commence at one side of the mamma and to terminate at the other" (2: 444). The "Cross" Dubois makes with his finger is less clear, but it is possible that Dubois makes 
a small cross to indicate where the tumor is, or he could be indicating where the other incisions should meet. Or he might have been describing a perpendicular cross with this first "straight line" incision, what Bell describes as the "longitudinal" incision (2: 450). The circular incision Burney describes is more specific, and it directly corresponds to Bell's recommendation that "the portion of the skin which is in any part diseased or that firmly adheres to the glandular part of the breast, should be separated from the sound skin by a circular or oblong incision with which the longitudinal cut out to communicate; and this being done, the operation is to be finished in the manner we have already directed, by dissecting off every part that is found to be indurated, along with the part of the skin that has been surrounded by an incision such as we have mentioned" (2: 450). The circular cut that Bell describes is meant to meet up with the longitudinal incision in order to remove the whole breast, including the skin, and these seem to correspond with the plans for incisions that Burney's surgeons outlined with gestures.

Once the surgeons map out their plan for incision, they begin to cut. She cannot see this and so she describes the feeling of these incisions:

Yet — when the dreadful steel was plunged into the breast—cutting through veinsarteries - flesh — nerves - I needed no injunctions not to restrain my cries. I began a scream that lasted unintermittingly during the whole time of incision — and I almost marvel that it rings not in my Ears still! so excruciating was the agony. When the wound was made, and the instrument withdrawn, the pain seemed undiminished, for the air that suddenly rushed into those delicate parts felt like a mass of minute but sharp and forked poniards, that were tearing the edges of the wound - but when again I felt the instrument — describing a curve — cutting against the grain, if I may so say, while the flesh resisted in a manner so forcible as to oppose and tire the hand of the operator, who 
was forced to change from the right to the left—-then, indeed, I thought I must have expired. I attempted no more to open my Eyes,--they felt as if hermetically shut, and so firmly closed, that the Eyelids seemed indented into the Cheeks. The instrument this second time withdrawn, I concluded the operation over... (JL 6: 612)

It is almost impossible to read that account and focus on the description of the medical procedure because of the trauma she undergoes. The pain that Burney experiences is partially because the surgeons are removing such a significant portion of flesh, which she makes clear when she describes the physical force required. Bell's textbook speaks to the reasons behind such a significant procedure, which helps shed light on Burney's physical condition. Bell describes this kind of incision (the circular that meets with the straight line) only after he has described removing tumors that are in the breast but have not extended to the skin. He only suggests the circular cut, which removes the whole breast, when the tumor has affected the skin in addition to existing within the breast:

In general, before a practitioner recommends amputation of a breast, and almost always before a patient consents to it, a considerable portion of the external teguments are so much diseased as to render it necessary to remove them along with the glandular part of the mamma; or if the skin be not actually diseased, it commonly adheres so much to the most prominent part of the breast that it cannot be separated from it. In either of these events, some portion of the skin must be removed along with the mamma. (2: 449-450) In other words, when the tumor has progressed so much that the skin itself is infected, or if so much of the breast has to be removed because of the pervasiveness of the tumor that the skin cannot be saved, then the whole breast must be taken. ${ }^{55}$ This is when Bell proposes the circular

\footnotetext{
${ }^{55}$ There has been some discussion over whether the tumor was benign or malignant in the modern scholarship on Burney's mastectomy. Julia Epstein asserts that it was very clearly benign based on the writings of physician
} 
incision that meets the longitudinal one, as Burney describes. If we venture to assume that her surgeons were following this surgical procedure and reasoning, then they removed the whole breast was because her tumor was so advanced that it was necessary to do so. Indeed, the brief medical report sewn to the manuscript of her letter says the tumor was "the size of a fist" (qtd. in Epstein 151). The incisions Burney describes align very closely with Bell's and make this theory quite probable.

Burney describes the final portion of the operation, which consists of the surgeons scraping diseased tissue out after having removed her breast, and this final step is parallel to the textbook's procedure. Burney says that after the cutting was finished, she felt the Knife rackling against the breast bone — scraping it!- This performed, while I yet remained in utterly speechless torture, I heard the Voice of Mr Larry...in a tone nearly tragic, desire every one present to pronounce if anything more remained to be done; or if he thought the operation complete. The general voice was Yes,--but the finger of $\mathrm{Mr}$ Dubois - which I literally felt elevated over the wound, though I saw nothing, and though he touched nothing, so indescribably sensitive was the spot—-pointed to some further requisition — and again began the scraping! - and, after this, Dr Moreau thought he discerned a peccant attom — and still, and still, M. Dubois demanded attom after attom (JL 6: 612-613)

The scraping directly corresponds to Bell's textbook. What Burney describes as scraping was most likely the surgeons' attempts to remove cancerous tissue from the lymph nodes. The

\footnotetext{
Anthony R. Moore in his article "Preanesthetic Mastectomy: A Patient's Experience." Whether or not the tumor was in fact cancerous is something we will never know for certain. What remains most important is that by eighteenthcentury standards, the tumor appeared to be cancerous. This is confirmed based on the fact that they operate, the procedure they follow, and the medical report itself: "the schirrus [hardened tumor] showed the beginnings of cancerous degeneration in its center" (qtd. in Epstein 151).
} 
medical report supports this, recording that "all of [the tumor's] roots were removed" (qtd. in Epstein 151). ${ }^{56}$ This practice is described similarly by Bell, outlining the protocol for removing cancerous tissue beyond the breast and skin as follows:

It often happens, indeed, that the diseased parts adhere to the pectoral muscle; and, on some occasions, although it was not previously suspected, even the periostaeum of the ribs is found to be affected. In such instances, as there is a necessity for all the diseased parts being removed, no hesitation should be made in using every proper freedom with the pectoral muscle, as well as with any other part to which the mamma adheres; but whenever the removal of the parts affected can be accomplished without any violence to these parts, it ought by all means to be done....it often happens that the lymphatics leading from the breast to the armpit are much indurated, and that the glands in the armpit itself are both indurated and enlarged. In some instances, too, a number of diseased glands are found to run from the breast to the clavicle, and to spread in considerable clusters along the under edge of that bone. (2: 445-446)

He goes on to describe exactly how to remove the diseased glands, which includes making another incision, possibly the cross Dubois points out, and scraping the tissue out with a scalpel. ${ }^{57}$ If we keep Bell's description in mind, particularly when Burney says it felt as though they were scraping her chest bones, we can infer that the surgeons were scraping the layer of tissue and muscle covering her chest bones in order to remove cancerous tissue. What seemed like invasive and overly persistent actions on the part of Dubois and Moreau, "demanding attom after attom," might have been their attempt to remove all of the cancerous tissue, which had to be

\footnotetext{
56 The medical report can be found in the Hemlow edition directly after the letter (pgs. 615-616); however, here I am relying on Julia Epstein's translation from the original French.

${ }^{57}$ Bell suggests a couple of methods that a surgeon might select here, which I have omitted for the sake of brevity, choosing instead to summarize the method that most closely aligns with what Burney describes.
} 
thorough; otherwise, if tissue was left behind, the entire operation might have been compromised.

Examining Burney's operation alongside the procedure described in A System of Surgery provides medical context for the surgery and the surgeons' methods. As such, we can put it in the context of other mastectomies. Marjo Kaartinen contends that operations like the one Burney received belong to a category of mastectomies she refers to as "early radical mastectomies" (52). She observes that as more surgeons were performing successful surgeries on diseased breasts, ridding the lymph nodes and chest muscles of cancerous tissue became a priority when, previously, it seemed futile (52-53). The procedure became much more common with the development of anesthesia and the method for radical mastectomies as used by William Halsted. Radical mastectomies, which we now think of as overly invasive because they often left women permanently and unnecessarily disfigured, were still common practice up to the 1960s. Burney's surgery, in this context, was not unique in terms of medical practice but was one of many operations that surgeons performed as the primary form of mastectomy from the late nineteenth century into the mid-twentieth century.

Burney's operation resembles the one in the textbook, and those that other patients might have experienced, because of the process by which medical knowledge and practice spread. As we saw in Chapters 1 and 2, medical knowledge and practice spread primarily through practices aimed at capitalizing on an increasingly consumerist culture. Print, media, marketing, and advertising impacted how a medical innovation became practice and how medical theories became knowledge. Such is the case with the medical procedure that Burney receives as well. A System of Surgery helped popularize a particular approach to mastectomies because the textbook offered sound medical advice, but also because of the cultural mechanisms that enabled 
consumer print culture. Bell's six-volume textbook was first published between 1783 and 1788 and by 1801, seven editions were published (Macintyre 177). The book was translated into "Italian, French, Spanish, German, and three American editions" (Macintyre 177). His publisher also "made the work widely available in Britain, America, and latterly in Europe" making it "the most commercially successful of the 600 or so books [he] published" (Macintyre 180 and 177). The manufacturing, publishing, book-selling, and consumer practices that increased popularity of and access to medical publications, as discussed in the previous chapters, were robust enough by the time Bell published A System to enable it to become a "huge commercial success" (Macintyre 180). Moreover, the scientific approach to surgery started by John Hunter had now accumulated enough support within the profession that Bell was able to incorporate methods from surgeons like William Beckett, Pierre Dionis, and Henry Fearon into a standardized textbook that would help lay the groundwork for the standardization of surgery in the nineteenth century (Kaartinen $51)$.

Moreover, Bell's reputation and network helped perpetuate his legacy and A System after his death in 1806. Bell may not have been the most innovative or risk-taking surgeon, but he acquired a solid reputation for his excellent work as a surgeon in the Royal Infirmary at Edinburgh for eighteen years (Macintyre 175). After his work at the Royal Infirmary, he helped found a remarkably successful practice with two other prominent surgeons in Scotland. His partners claimed that he "“was a successful operator and during many years was more employed than any surgeon in Scotland"” (qtd. in Macintyre 176). After his death, his sons and grandson all received the same appointment that Bell held as surgeon at George Watson's hospital, thereby ensuring that Bell's legacy remained intact for at least two generations. There is no definitive proof that Bell's reputation and legacy affected the popularity of the textbook. But when we 
consider the networks of reputation along which the Hunter brothers' posthumous success was formed, it is hard to imagine that Bell's reputation and posthumous legacy had nothing to do with it.

Noting the similarities between Burney's operation and the procedure in Bell's textbook reveals that Burney's procedure was part of the larger, complex network of print culture, consumerism, popularity, and reputation that enabled the spread of medical knowledge and eventually the standardization of medical practice. The details she provides are unique in their specificity, but would have been more or less standard as steps in a procedure. Placing her letter within the larger context of medical knowledge reveals that her letter represents the ways in which the cultural mechanisms that create celebrity culture also enabled the standardization of medical practice.

However, there does seem to be one part of Burney's experience as a patient that is not directly shaped by medical celebrity. While her discussion of finding a doctor, getting a diagnosis, and receiving an operation all indicate that the cultural mechanisms of celebrity influenced these circumstances, her discussion of her relationship with her doctors contradicts this. She only goes into detail about her feelings towards Larrey, which seem to be informed by sentiment rather than by social network, reputation, or fame. More so than any of the case studies heretofore presented, in this case, both patient and practitioner seem to form an attachment to one another. She defends him from public ridicule, writing that "M. Larrey has proved one of the worthiest, most disinterested, and singularly excellent of men, endowed with real Genius in his profession, though with an ignorance of the World and its usages that induces a naiveté that leads those who do not see him thoroughly to think him not alone simple, but weak. They are mistaken; but his attention and thoughts having exclusively turned one way, he is hardly awake 
any other." (JL 6: 601) She refers to him consistently as "the good M. Larrey" or "my good Dr. Larrey" (JL 6: 603 and 601). She compares how he looks to "my dear Brother James" (JL 6: 604). And when he realized she would need an operation, she writes, "the good Dr. Larrey, who, during his long attendance had conceived for me the warmest friendship, had now tears in his Eyes" (JL 6: 603). At one point before the operation, Larrey admits how much treating Burney was affecting him: "Poor M. Larrey was so deeply affected by this sentence... he regretted to his Soul ever having known me" (JL 6: 605). While they dress her wounds after the operation, she expresses sympathy for him and says, “ "Ah Messieurs! que je vous plains! 58 —for indeed I was sensible to the feeling concern with which they all saw what I endured, though my speech was principally - very principally meant for Dr. Larrey" (JL 6: 613). These and other affectionate descriptions of Larrey reveal Burney's attachment to him and suggest that Larrey was emotionally involved in the process as well.

Moreover, Burney's experience of her diagnosis, treatment, and operation seems to be improved because of this attachment. Once Larrey begins treating her, Burney references his reactions and sentiments to each development in her treatment as though they were sharing in the experience. When they told her she must have the operation, she tells us, "Dr Larrey, I saw, hid himself nearly behind my Sofa" (JL 6: 604). And in her description of the operation, she consistently references that he is silent, aloof, speaks with "a voice of solemn melancholy" (JL 6: 611). She shares no one else's reactions as consistently, other than her own. Even at the end of the operation after she has endured what no other person near her could understand, she looks to Larrey for some shared feeling: "When all was done, and they lifted me up that I might be put to bed, my strength was so totally annihilated, that I was obliged to be carried, and could not even

\footnotetext{
58 'Ah Sirs! how I pity you!'
} 
sustain my hands and arms, which hung as if I had been lifeless...This removal made me open my Eyes - and I then saw my good Dr Larrey, pale as nearly myself, his face streaked with blood, and its expression depicting grief, apprehension, and almost horror" (JL 6: 613). She describes him as the "good Dr Larrey" even after what she endured at his hands, and then compares the look on his face to hers, as if he was the only person who could understand what she experienced. Throughout the narrative, their connection seems to comfort her, or at least serve as a source of sympathy and feeling.

Her description of their patient-practitioner relationship suggests that even though many of their interactions operated within circumstances and conventions related to reputation, fame, clinical practice, and medical procedure, there was still room for connection and sympathy. This suggests that, on a larger scale, interactions between patients and practitioners that were deeply influenced by celebrity could still allow for positive connections between patient and practitioner. Ultimately, I would argue the relationship between Burney and Larrey indicates that medical celebrity does not necessarily detract from the experience of a patient, particularly for a celebrity patient. In Burney’s case, circumstances that were largely influenced by her social connections and fame seem to have granted her access to a more productive and positive medical experience than if she were a patient without fame or connection. Based on my analysis of the letter, it is clear that celebrity cultural mechanisms shaped Burney's experience with medical practice, and I would argue that exchange enabled her to have a more successful and effective experience as a patient. This conclusion, of course, can only be made because of the access we have to the letter today. In order to fully understand the ways that celebrity cultural mechanisms impacted Burney's experience as a patient, we must extend that inquiry into how it may have influenced her representation of that experience. As such, we should examine the publication 
history to analyze how access, fame, and reputation shaped the posterity of the letter.

\section{Part III: The Posterity of the Letter}

Not only did the cultural mechanisms that create celebrity generate the circumstances of Burney's mastectomy, but they also created the circumstances for the posterity of the letter itself. As I have argued, there was nothing particularly unique about Burney's operation from a medical point of view. Yet medical, literary, and popular discussions of breast cancer and/or mastectomies often reference her letter, and it is typically upheld as the most significant narrative of a mastectomy prior to the twentieth century. The reason for this is not because her situation was unique medically, nor is it because she was the only one to receive or survive an operation; it is because she is Frances Burney, and Burney brings two unique things to the narrative: her talent and her fame. On the one hand, Burney's ability to articulate such a traumatic and painful experience is a result of the same effort and genius that produced her literary works. No one else could write this letter, and as such, it has more cultural value. On the other hand, her fame and success also afforded her the ability to ensure that her letters were kept safe and were published after her death, thereby increasing the likelihood that her narrative would exist for future readers.

Analyzing the context of the publication of the letter and the development of the manuscript reveals that both the posterity and composition of the letter operated along the lines of fame, reputation, legacy, and self-fashioning. Burney's diaries and letters were originally published, with her permission, by her niece Charlotte Barrett in 1854. In her preface to the seven-volume collection, Barrett ensures the intimacy of these documents that were "originally intended for no eye but her own" (1:31). She also tells the circumstances in which she was given the letters and why, since they are so intimate, the letters and journals are being published less than two decades after Burney's death. Burney started collecting the documents later in her life 
when she felt some distance from her recollections. She set about "arrang[ing] these journals and papers with the most scrupulous care; affixing to them such explanations as would make them intelligible to her successors--avowing a hope that some instruction might be derived from them" (1: 31). Burney arranged at least parts of this collection of letters and journals herself, and she did so with the hope that they would be read by others for the purpose of instruction. Her niece also tells us the circumstances under which Burney decided to publish the letters: "finally, in her last hours, consigning [the journals and letters] to the editor, with full permission to publish whatever might be judged desirable for that purpose" (1: 31-32). She only had one condition to her bequest: "that whatever might be effaced or omitted, NOTHING should in anywise be altered or added to her records" (1:32). The emphasis on the infallibility of the journals and letters in the preface frames them as though they are authentic representations of Burney's personal life. The letters are framed not as doctored, polished, revised narratives, which they were, but as the "window in her breast," as close to knowing the real person as possible (1: 31).

The mastectomy letter does not appear in the original edition Burney's letters and journals, and it was not published until the Hemlow edition in 1975. In lieu of the letter, there is the following paragraph:

During this year Madame d'Arblay's correspondence with her English connexions was interrupted not only by the difficulty of conveying letters, but also by a dangerous illness and the menace of a cancer, from which she could only be relieved by submitting to a painful operation. The fortitude with which she bore this suffering, and her generous solicitude for Monsieur d'Arblay and those around her excited the warmest sympathy in all who heard of her trial, and her French friends universally gave her the name of 
$L^{\prime}$ Ange ${ }^{59}$; so touched were they by her tenderness and magnanimity. $(6: 347)^{60}$

This annotation, as it is positioned in the collection, accounts for the large gap between the letter prior to this one in April 1811 and the one following it from May 1812. Because the letter is not included, we can assume Burney did not want it to be published with the others. However, the details provided position Burney's experience with illness and the operation so that they can be consumed by a public audience. Readers are informed that she had a dangerous illness, cancer specifically, and that she had to undergo an operation. None of this information is necessary-it is all offered up to the reader to be incorporated into their understanding of Burney. The annotation could have just informed readers that her "connexions [were] interrupted...by the difficulty of conveying letters" which refers to the difficulty in sending and receiving letters caused by the Napoleonic Wars and the fact that Burney tried to travel back to England around this same time but could not. Instead, readers are informed of her status as a patient who had cancer, and received and survived an operation. Moreover, within the annotation itself, Burney's medical experience is placed before an audience, or "all who heard of her trial." The annotation would have the reader imagine that news of her illness, operation, and how she handled it spread by word of mouth. Not only this, but her friends were so struck by the tale of Burney's suffering and magnanimity that they called her "The Angel."

Because the annotation exists in lieu of the letter, it suggests to the reader that the content provided should stand in place for the missing year of Burney's correspondence, or the narrative of her life. Moreover, the audience of friends depicted in the annotation serve as surrogates for readers, who can then take in the information about the operation, imagine Burney as suffering

\footnotetext{
59 The Angel.

${ }^{60}$ Here I am using the first edition of Burney's published letters: Diary and Letters of Madame D'Arblay...Edited by Her Niece (1842-46).
} 
but also generous, and subsequently feel "the warmest sympathy" as they also hear "of her trial." As such, the reader is positioned to assimilate their impressions of Burney's experience with that of "her French friends" and visualize Burney as L'Ange. The annotation condenses an incredibly significant medical event in Burney's life to a bite-size impression, allowing readers to move on to the next letter with their impression of Burney unchallenged and intact. Subsequently, what the reader is told about Burney's illness does little to challenge their image of and relationship to Burney. They learn nothing new about her that would cause them to revise their perception of Burney. In this way, the annotation protects Burney's established fame and reputation, whereas the letter might have had the opposite effect. As such, this first version of Burney's narrative of her mastectomy operates along the lines of celebrity: it prioritizes the protection of Burney's reputation and legacy over sharing her experience as a patient.

Similar to the experiences with medical celebrity of Susannah Cibber and Peg Woffington, this annotation represents how a celebrity's experience with illness could be leveraged to impact their relationship with audiences. Whereas with Cibber and Woffington, their ailing and healthy bodies were made visible to their public audiences on stage, Burney, as a literary celebrity, maintained more privacy. Her experience with illness was not made public until after her death, but in the first edition of her journals and letters, the annotation rhetorically positioned her experience as a patient in order to shape her audience's perception of her. The illness and operation were positioned as events that intrigue those around her and prompt them to elevate Burney to a heightened status. As such, the annotation uses Burney's experience as a patient to perpetuate and demonstrate her specialness, her aura, and more specifically her charismata and her stigmata. For readers who did not know of Burney's mastectomy, this passage demonstrates Burney's vulnerability specifically as it relates to her experience with 
illness. Two letters after this one, readers learn of Burney's traumatic and violent experience during her "police-adventure at Dunkirk" while she was attempting to go back to England (6: 352). Her experiences with trauma are not hidden, but the vulnerability of her medical body to the extent that we see it in her narration of the mastectomy is not shown. Instead, the annotation allows the reader to glimpse, just for a moment, the vulnerability of her medical body, thereby creating a moment of stigmata where a weakness, previously unknown, is revealed. But it is immediately followed by a portrayal of her charismata as a figure who is so larger than life, so close to being among the gods, that she ascends to the level of Angel even while she experiences the worst of human suffering. By striking this balance between charismata and stigmata, the annotation inserts Burney's experience as a patient into the reader's narrative of Burney as a celebrity.

For readers who did know of Burney's operation, and as we know there would have been some if not many, the annotation reinforces the authenticity and candidness of the collection. To ignore the operation would feel false to those who knew about it, and would negate some of the intimacy created in the letters leading up to this one. The illusion of public intimacy would be shattered because readers would know that they were being lied to. Instead, as was the case with Cibber and Woffington, the annotation leverages Burney's experience as a patient to perpetuate the public intimacy felt throughout the rest of the collection. This was particularly important since this was a posthumous collection, and the impressions made on readers affected the longevity and impact of Burney's legacy. This annotation, although brief, weaves the connection between author and audience, intimacy and speculation, public and private, demonstrating how celebrity impacts the way patient experience is recorded and presented to the public.

This rhetorical representation of her mastectomy existed for public consumption for over 
a hundred years. For Burney's nineteenth-century readership, there was no medical narrative. The absence of the mastectomy letter from her journals and letters reflects Burney's attempt to protect her reputation and public persona, as the annotation demonstrates. Not only does celebrity impact the letter's initial publication, but it also impacts the existence of the letter today. After the Barrett edition of journals and letters came Annie Raine Ellis's The Early Diary of Fanny Burney 1768-1778 (1889), followed by Joyce Hemlow's collection, which provided a comprehensive collection of Burney's journals and letters beginning at the time she published Evelina. Only then was the mastectomy letter made available to a public readership. Hemlow's impetus for publishing the collection was her scholarly interest in Burney, inspired by her love of Burney's literary works. The mastectomy letter was just one of hundreds of manuscripts that Hemlow included in the collection. Moreover, the letter was not included for its value as a medical narrative, what it revealed about Burney as a patient, or what it tells us about medical practice. It was included because it was written by Burney. We know about this letter now because Burney wrote it. It is only because of her literary and cultural significance in the eighteenth century that we have access to this letter at all. Her fame dictates whether this medical narrative becomes part of our cultural understanding and narrative of mastectomies, breast cancer, and surgery. Without the added value of Burney's fame, reputation, and celebrity as an author and figure in the long eighteenth century, this letter would be lost. The way that the letter was published and the reasons behind its publication, reveal how representations of medicine become part of medical history. In Burney's case, her representation of her mastectomy becomes part of medical history because of her fame and cultural value as a celebrity.

People who discuss Burney's operations, particularly in popular culture, often assume that her operation held some kind of cultural value on its own, outside of her celebrity. We have 
made assumptions about how medical history is written and how Burney's mastectomy fit into the narrative of medicine in the long eighteenth century. These assumptions have enabled us to make statements about Burney's operation that make it seem as though hers was reflected a medical development or a significant moment in medical history. The truth is, that in the narrative of medical history formed in the eighteenth and nineteenth centuries, her operation did not matter. Her operation, her experience, and her story were just one of many. Her experience was somewhat rare because she survived her mastectomy, but what is truly rare is the fact that we have a record of her experience. That record exists because Burney achieved enough literary fame in her life to retain scholarly interest in the twentieth century, she had access to a system that ensured her literary legacy, and she wrote the narrative for a public audience.

Not only did celebrity impact the publication of the letter, but it also impacted the content of the letters. Julia Epstein's seminal article discusses how Burney's letter functions as a medical narrative, specifically as a case history intended for a public readership. She claims the mastectomy letter was written and edited with a kind of narrative awareness that implies Burney was thinking of a public audience. Epstein claims, "the fact that Burney gave this letter a title when she returned to it for editorial work years later suggests a more studied text than the usual casually informative, familiar letter" (Epstein 137). In fact, Burney edited the letter multiple times between 1820 and1835, and while these are not major changes, they do imply that she "reread it...with an ear to style and with an intention to preserve as dramatic a record as possible" (Epstein 139, 140). On the surface, these behaviors may seem contradictory: Burney did not allow the letter to be published posthumously by her niece, but she wrote and edited the letter with a public audience in mind. However, if we go back to the letter itself, we see that Burney was writing for a public audience all along. 
After Burney’s very detailed depiction of her mastectomy in her letter, addressed to her sister Esther, she concludes with a plea to share her story. She writes: "God bless my dearest Esther--I fear this is all written--confusedly, but I cannot read it--\& I can write it no more, therefore, I entreat you to let all my dear Brethren male \& female take a perusal--and that you will lend it also to my tender \& most beloved Mrs. Angerstein, who will pardon, I well know, my sparing myself--which is sparing her, a separate letter upon such a theme" (JL 6: 614-615). Burney has written and addressed this letter to her sister, but she wants Esther to share this story with her friends and family, even going so far as to give explicit permission for someone to borrow the letter. Her choice of the phrase "take a perusal" also implies that she wanted the letter to be read or shown to people, as opposed to Esther simply telling others about Burney's illness. While Burney is not suggesting Esther have the letter published, she does allow the letter to be circulated. So when Burney wrote it, she was writing both to her sister and to those people with whom her sister would share the letter. On the one hand, this is Burney's attempt to share her life with those she loves who are far away. On the other hand, someone so private in her everyday interactions would hardly write a letter this intimate and allow others to see it without crafting it with that purpose. Moreover, according to Hemlow's annotations on the letter, Burney included the medical report in her letter, physically sewing it on. Based on the other circumstances surrounding her handling of the letter, it is clear that Burney was thinking of a public audience and how and when that public audience should read the letter.

As was the case with the annotation in the first edition of her letters and journals, the content of the letter is rhetorically positioned for a public audience. From this I conclude that even Burney's representation of her experience as a patient operated along the lines of fame, reputation, and perhaps self-fashioning. On a larger scale, this letter represents how a celebrity 
patient chooses to share and articulate their experience with medical practice and illness.

Because the celebrity can never be completely removed from the watchful eye of their fans or readers, the public audience ghosts their most private moments. We see this in Burney's letter because of the way it is written and the way it is published. It is almost as though it was never a question whether this mastectomy would be made public, and as such, Burney takes control over what, how, and when the public will perceive her experience as a patient. Thus, while Burney's experience as a celebrity patient enabled her access to better treatment, it also impacted the circumstances by which she could--and did--share and articulate this experience.

Ultimately, Burney's mastectomy letter represents the intersectionality of medical celebrity, which could impact an individual patient's experience with medical practice and illness in a multitude of ways. First, her experience was shaped by all of the versions of medical celebrity discussed in previous chapters: how medical celebrity affected the profession, the market, and the experience of medicine by famous figures. Second, the representation of that experience, the narrative, provides insight into how those versions of medical celebrity shaped individual patient experiences. Third, Burney's own celebrity drastically shaped the access she had to medical treatment and the way she was able to represent that experience. Finally, her celebrity in the eighteenth century shaped the circumstances by which we access and analyze this medical narrative today. Burney's mastectomy letter, as result, emerges as a literary representation of how medical celebrity could shape almost every aspect of a patient's experience with medicine in the eighteenth century. Whereas the other chapters imply that assertion, they create the typology that Burney's narrative represents and expands. Her case study, more than any other, demonstrates the pervasive and foundational nature of medical celebrity as a sociocultural phenomenon. Medical celebrity was not merely a facet of the 
development of medicine in the eighteenth century; it was as vital a part of the development as the scientific progress, political upheaval, ideological shifts, and economic changes heretofore credited with the development of medicine in the eighteenth century. 


\section{$\underline{\text { Coda }}$}

Less than ten years ago, Graeme Turner published "Approaching Celebrity Studies," an article that summarizes the progress made by celebrity theorists but ends with a rousing call-toaction: "the research question...that must be at the heart of celebrity studies, is what to make of celebrity culture as a social or cultural formation" (17). Cultural formation refers to Turner's theorization of celebrity in Understanding Celebrity, and, most simply, describes how "not only is celebrity implicated in the production of communities such as fan groups or subcultures, not only does it generate celebrity culture and social networks, it also participates in the field of expectations that many, particularly the young, have of everyday life" (14). In other words, celebrity impacts not just our social relationships with others or our parasocial relationships with celebrities, it is also a fundamental part of contemporary culture that shapes how individuals and groups of people understand the world around them. Celebrity is not something that happens "out there," in Hollywood, on TV, or on social media; rather, it shapes our everyday lived experience through those forms of media and representation. Ultimately, this dissertation identifies medical celebrity as a type of celebrity that impacts our lived experiences of illness, treatment, diagnosis, the medical market, and the medical profession. I have created a typology of medical celebrity as it existed during the eighteenth century, to establish its beginning and emergence within the history of celebrity and the history of modern medicine.

Ultimately, the case studies that make up this typology serve as examples of how medical celebrity impacted the lived experiences of individual people. The case study of the Hunter brothers establishes how medical celebrity impacted the medical profession and legacies within medical history, but it also provides insight into how fame and celebrity impacted the Hunter brothers as medical practitioners and how fandom and public appeal influenced the perception of 
the medical practitioners around them. In Chapter 2, we saw how print culture, reputation, and fame had the ability to impact the medical market. While the focus of the chapter is not on the patient and practitioner's experience, it is easy to imagine how Ranby's condemnation of the lixivium impacted the decisions made by practitioners and patients. In that chapter, medical celebrity plays a direct role in the treatment that patients receive. For Cibber and Woffington, medical celebrity dramatically shaped their lived experiences both as patients and as actresses. Their experiences with illness and health cannot be extricated from their reputation as actresses, the relationship between themselves and their fans, and the eighteenth-century theater. Similarly, Burney's lived experience of her mastectomy was formed along the lines of fame, access, social networking, and reputation. Without celebrity, her practitioners, diagnosis, and treatment might have all been different. Moreover, as that case demonstrates, the cultural mechanisms of celebrity determined how her representation of that experience was written, published, and kept for posterity. As such, this dissertation serves as a response to Turner's call-to-action by establishing a new theoretical framework whereby we can analyze how celebrity shapes our culture. Beginning in the eighteenth century, medical celebrity, as a sociocultural phenomenon, shaped the development of medicine's role in our everyday lives, our economy, and our culture. The effect of this is our contemporary culture of medical celebrity, whereby cultural mechanisms such as fame, reputation, public appeal, marketing, advertising, and all forms of media are fundamental to our individual and cultural relationship to and experience with medicine.

One of the best examples of how our medical celebrity culture functions is the ability celebrities have to impact which doctors, treatments, and diagnoses people are exposed to, and those that they will seek out or ignore. Perhaps the most well-known instance of that particular function of medical celebrity is Oprah Winfrey's endorsement and promotion of Dr. Oz. Dr. 
Mehmet Oz first became famous as a guest star on The Oprah Winfrey Show (Tikkanen n.p.). The endorsement he received was different in degree but similar in kind to the patient testimonials discussed in Chapter 2. While Ranby used the system of patient testimonials to help denigrate a drug, Oprah used the system of endorsement to promote a medical practitioner. Since then, he has become the star of his own daytime talk show, written several bestselling books, and achieved a significant amount of celebrity as “America's Doctor” (Tikkanen n.p.). His presence on TV, both on The Oprah Winfrey Show and on his own daily program, enabled him to establish a public persona that captivated audiences, similarly to John Hunter's ability to draw public interest. His presence on TV brought him into the homes of audiences who might otherwise have never encountered a medical practitioner so regularly or so intimately. Whereas many patients struggle to build relationships with their doctors, Dr. Oz used his talent and skill as a performer to create a relationship of trust and loyalty with viewers. This, he has in common with Susannah Cibber and Peg Woffington. While TV and live theater in the eighteenth century are incredibly different, they both enable audiences to establish a relationship of public intimacy.

Inevitably, those cultural mechanisms of celebrity that enable Dr. Oz's fame as a medical practitioner, impact the experience patients have of illness, diagnosis, and treatment. Many of his audience members could be patients or could become patients seeking advice from a trusted doctor, and they may rely on the advice he gives in his television program. They may selfdiagnose themselves or others based on his advice and seek or avoid certain treatments for the same reason. Additionally, they might experience visiting a doctor's office, speaking to a doctor, getting a diagnosis, etc. differently because of the representation of Dr. Oz that has been presented to them. While very different than Burney's experience of illness, diagnosis, and treatment, the patient is similarly forced to participate in a medical culture that has developed 
along the lines of celebrity. This is neither a positive nor negative consequence of medical celebrity. For some patients, Dr. Oz may make them feel comfortable enough with a medical practitioner that they are more likely to seek medical treatment. For others, he may serve as a replacement to a medical practitioner, or they may follow his often-misinformed advice.

Dr. Oz has received a significant amount of criticism from others in the medical profession because of the treatments, advice, and general medical knowledge he advocates. This criticism includes a study from the British Medical Journal which essentially told viewers not to listen to his advice (Koronwnyk et al. n.p.) Despite this criticism, fans have remained loyal to Dr. Oz, much as Cibber and Woffington's fans remained loyal. Some of this is because of the relationship he has developed with his audiences as an entertainer and celebrity, and some of it can be connected to his initial endorsement from Oprah Winfrey. Oprah, more than any celebrity, has the ability to influence what people do in their everyday lives—what they buy, what they eat, what they think. Oprah's show and her brand as a whole were revolutionary in their ability to commodify Oprah's endorsements and advice. If Oprah disavowed Dr.Oz tomorrow, his viewership would remain but it would most likely decline. Her initial and continued endorsement supports the dubious advice and practices that Dr. Oz promotes. Celebrity in this case, as well as the multitude of cultural mechanisms that create celebrity, fuels the consumption of what many have referred to as "junk science." This is an example of how patients, and viewers in this case, trust the relationship they have with Dr. Oz and Oprah Winfrey over the medical evidence that suggests they not listen to Dr. Oz. Celebrity, rather than medical knowledge, determines how patients make decisions about whom they consult for medical advice. That impact is the effect of our contemporary culture of medical celebrity. 
Medical celebrity as a theory provides a framework whereby we may analyze how eighteenth-century medical culture developed as a result of the commercialization, commodification, and democratization of eighteenth-century culture and not simply as a result of the changes in medical knowledge and practice. Being able to identify medical celebrity as a sociocultural phenomenon helps us account for cultural developments where popularity and medicine intersect. The case studies in this dissertation are ultimately examples of how celebrity deeply influences our individual and cultural experiences with medicine as a profession, medical practitioners, treatment, illness, and how we represent those experiences. Medical celebrity as a theoretical framework allows us to analyze that influence and ultimately interrogate how celebrity impacts individual experiences with medicine in the eighteenth century and in contemporary culture.

Medical celebrity is not something we should fix or promote, but it does impact the medical culture in which we operate. As such, we should be critical of it in the ways that we are of contemporary celebrity culture. For instance, we should question the motives behind promotional material like pharmaceutical ads or commercials for hospitals, scrutinize sensationalized representations of medicine, examine the impact social media has on the perception of medicine, etc. We should interrogate our culture of medical celebrity with the same amount of vigor, if not greater, that we use to interrogate popular celebrity culture. Doing so in early celebrity studies and eighteenth-century studies will illuminate how the commercialization, professionalization, and development of medical culture was a result not only of medical, scientific, political, and economic changes, but also because of social networks, the cultivation of desire, fame, and reputation. 


\section{Works Cited}

Abernethy, John. The Hunterian Oration for the Year 1819. Straham and Spottiswoode, 1819.

Adams, Joseph. Memoirs of the Life and Doctrines of the Late John Hunter, Esq: Founder of the Hunterian Museum, at the Royal College of Surgeons in London. London, W. Thorne, 1817.

Advice to John Ranby, Esq; Principal Sergeant Surgeon to his Majesty and F.R.S. with Some Observations on his Narrative of the Last Illness of the Right Honourable The Earl of Orford, 1745. Wellcome Library, www.wellcomelibrary.org/item/b28705403\#?c=0 $\& m=0 \& s=0 \& c v=0 \& z=0.1735 \% 2 C 0.7152 \% 2 \mathrm{C} 0.9083 \% 2 \mathrm{C} 0.6713$. Accessed 18 August 2018

Ambrose, Charles T. "The property dispute over the function of the lymphatic system and Glisson's ghost (the 18th-century Hunter-Monro Feud).” Cellular Immunology, vol. 245, n. 1, January 2007, pp. 7-15.

Andrews, Henry Russell. "William Hunter and His Work in Midwifery." The British Medical Journal, vol. 1, n. 2824, 13 Feb. 1915, pp. 277-282.

Andrews, Jonathan and Clark Lawlor. “"An Exclusive Privilege...to Complain’: Framing Fashionable Diseases in the Long Eighteenth Century." Literature and Medicine, vol. 35, no. 2, 2017, pp. 239-269.

“Ascariasis.” MayoClinic, 17 May 2018, www.mayoclinic.org/diseasesconditions/ascariasis /symptoms-causes/syc-20369593

Baker, George Pierce. Some Unpublished Correspondence of David Garrick, 1907. Archive, www.archive.org/stream/b28034995\#page/n11/mode/2up

Beatty, Heather R. Nervous Disease in Late Eighteenth-Century Britain. Pickering \& Chatto, 2012. 
"Beginnings." The Hunterian Society, www.hunteriansociety.org.uk/index.html.

Bell, Benjamin. A System of Surgery. vols. 1-2 and 6, 1783-1788. Archive. www.archive.org/ details/1systemofsurgeryb06bell.

Bennett, Alan. The Madness of George III. Faber \& Faber, 1991.

Bilger, Audrey. "Comedy in Manners: Making Fun of the Angel in the House." Laughing Feminism: Subversive Comedy in Frances Burney, Maria Edgeworth and Jane Austen. Wayne State UP, 2002.

Black, Jeremy. George III: America's Last King. Yale UP, 2006.

-. Walpole in Power. Sutton, 2001.

Blankaart, Stephen. The Physical Dictionary. 7th ed., 1726. Eighteenth Century Collections Online, www.find.galegroup.com.www.libproxy.wvu.edu/ecco/infomark.do? \&source= gale \&prodId=ECCO\&userGroupName=morg77564\&tabID=T001\&docId=CW33072476 97\&type=multipage $\&$ contentSet=ECCOArticles \&version=1.0\&docLevel=FASCIMILE.

Blizard, Sir William. The Hunterian Oration: Delivered in the Theatre of the Royal College of Surgeons, on the 14th Day of February, 1815. Rivingston, 1815.

Braudy, Leo. The Frenzy of Renown: Fame and Its History. Oxford UP, 1986.

Brock, Claire. The Feminization of Fame, 1750-1830. Palgrave Macmillan, 2006.

Brock, Helen. Correspondence of Dr. William Hunter, 1740-1783. Pickering and Chatto, 2008, 2 vols.

---. "William Hunter: A Reassessment.” William Hunter, 1718-1783, edited by C.H. Brock, U. of Glasgow Press, 1983, pp. 43-81.

Burney, Frances. Diary and Letters of Madame d'Arblay. Edited by Charlotte Barrett, London, H. Colburn, 1854. 7 vols. 
-. The Early Diary of Fanny Burney 1768-1778. Edited by Annie Raine Ellis, London, George Bell and Sons, 1889. 2 vols.

-. The Journals and Letters of Fanny Burney (Madame D'Arblay). Edited by Joyce Hemlow, et al. Vol. 6, Clarendon Press, 1972-84. 12 vols.

---. The Wanderer: or, Female Difficulties. Vol. 1, Longman, Hurst, Rees, Orme, and Brown, 1814. 5 vols.

Burnim, Kalman A., et al. A Biographical Dictionary of Actors, Actresses, Musicians, Dancers, Managers \& Other Stage Personnel in London, 1660-1800. vol. 16, Southern Illinois UP, 1993.

Burton, June K. Napoleon and the Woman Question: Discourses of the Other Sex in French Education, Medicine, and Medical Law. Texas Tech UP, 2007.

Bynum, W.F. and Roy Porter. William Hunter and the Eighteenth-Century Medical World. Cambridge UP, 1985

Carlisle, Anthony. The Hunterian Oration, Delivered Before the Royal College of Surgeons, in London, on Monday, February 21, 1820. Longman, Hurst, Rees, Orme, and Brown, 1820.

Carlson, Marvin. The Haunted Stage: The Theatre as Memory Machine. University of Michigan Press, 2003.

Cave, Richard Allen. "Woffington, Margaret [Peg] (1720?-1760), actress." Oxford Dictionary of National Biography, 23 September 2004, http://www.oxforddnb.com/view/10.1093/ref: odnb/9780198614128.001.0001/odnb-9780198614128-e-29820

Cheung, Philip. Public Trust in Medical Research?: Ethics, Law, and Accountability. Radcliffe, 2007. 
Chevalier, Thomas. The Hunterian Oration, Delivered Before the Royal College of Surgeons, in London, on the Fourteenth Day of February, 1821. J. Barfield, 1821.

Cheyne, George. The English Malady; or a Treatise of Nervous Disorders. London, G. Strahan, 1733.

Chisholm, Kate. Fanny Burney: Her Life. Chatto \& Windus, 1998.

Cibber, Susannah. "Mrs. Cibber to Mr. Garrick, Woodhay, Nov. 15th, 1765." The Private Correspondence of David Garrick. Vol. 2, Henry Colburn and Richard Bentley, 1860, pp. 207-208.

---. "Mrs. Cibber to Mr. Garrick, Woodhay, Oct. 3, 1765." The Private Correspondence of David Garrick. Vol. 2, Henry Colburn and Richard Bentley, 1860, pp. 200-201.

Conway, Alison. Private Interests: Women, Portraiture, and the Visual Culture of the English Novel, 1709-1721. University of Toronto Press, 2001.

Cullen, Fintan. The Irish Face: Redefining the Irish Portrait, 1700-2000. National Portrait Gallery, 2004.

Cust, Eduard. Annals of the Wars of the Eighteenth Century. v. 1796-1799. Gilbert and Rivington, 1862.

Daly, Augustin. Woffington: A Tribute to the Actress and the Woman, 2nd ed., 1888. Archive, www.archive.org/stream/woffingtontribut00dalyuoft\#page/n11.

Davenport, Hester. Faithful Handmaid: Fanny Burney at the Court of King George III. Sutton, 2000.

Davies, Thomas. Memoirs of the Life of David Garrick, Esq. Interspersed with Characters and Anecdotes of His Theatrical Contemporaries the Whole Forming a History of the Stage, Which Includes a Period of Thirty-Six Years. Wells and Lilly, 1818. 2 vols. 
Day, Carolyn. "Dying to be Beautiful: Fragile Fashionistas and Consumptive Dress in England, 1780-1820." Journal for Eighteenth-Century Studies, vol. 40, n. 4, pp. 603-620, doiorg.www.libproxy.wvu.edu/10.1111/1754-0208.12512

Dictionary of National Biography. Woffington.

Doody, Margaret Anne. Frances Burney: The Life in the Works. Rutgers UP, 1988.

Engel, Laura. Fashioning Celebrity: Eighteenth-Century British Actresses and Strategies for Image Making. Ohio State UP, 2011.

An Epistle from a Physician at Bath to Dr. Rock, Practitioner in Town: Occasion'd by the Letter from a Physician in Town to Another at Bath, 1745. Eighteenth Century Collections Online, www.find.galegroup.com.www.libproxy.wvu.edu/ecco/infomark .do? \&source=gale \&prodId=ECCO\&userGroupName=morg77564\&tabID=T001\&docId= CB3327742908\&type $=$ multipage $\&$ contentSet $=E C C O A r t i c l e s \& v e r s i o n=1.0 \&$ docLevel $=F$ ASCIMILE.

Epstein, Julia. "Writing the Unspeakable: Fanny Burney's Mastectomy and the Fictive Body." Representations, no. 16, Autumn 1986, pp. 131-166.

Farr, Martin and Xavier Guegan. The British Abroad Since the Eighteenth Century, Volume 1: Travelers and Tourists. Palgrave Macmillan, 2013.

Flood, Alison. “ 'The evil was profound': Fanny Burney letter describes mastectomy in 1812.” The Guardian, 22 June 2018, www.theguardian.com/books/2018/jun/22/the-evil-wasprofound-fanny-burney-letter-describes-mastectomy-in-1812.

Fox, R. Hingston. William Hunter, Anatomist, Physician, Obstetrician, (1718-1783), With Notices of His Friends Cullen, Smellie, Fothergill, and Baillie. H.K. Lewis, 1901. 
Garrick, David. The Private Correspondence of David Garrick. vols. 1-2 Henry Colburn and Richard Bentley, 1860.

Goode, Otilia. Review of The Reluctant Surgeon. Bulletin of the Medical Library Association, 1960. PubMed,www-ncbi-nlm-nih-gov.www.libproxy.wvu.edu/pmc/articles/PMC 200535/? page $=1$

Grigson, Caroline. The Life and Poems of Anne Hunter: Haydn's Tuneful Voice. Liverpool UP, 2009.

Gruber, Jacob W. “John Hunter.” Oxford Dictionary of National Biography, 27 May 2010, http://www.oxforddnb.com.www.libproxy.wvu.edu/view/10.1093/ref:odnb/97801986141 28.001.0001/odnb-9780198614128-e-14220?rskey=51293Q\&result=3.

Handley, W. Sampson. “Makers of John Hunter.” The British Medical Journal, vol. 1, n. 4076 18 February 1939, pp. 313-317.

Harris, Tessa. The Dead Shall Not Rest. Kensington Books, 2013.

Hartung, Heike. “'Doleful Ditties' and Stories of Survival: Narrative Approaches to Breast Cancer in Frances Burney, Maria Edgeworth, and Susan Sontag." Gender Forum, vol. 19, 2007, pp. 45-65.

Haslam, Fiona. From Hogarth to Rowlandson: Medicine in Art in Eighteenth-Century Britain. Liverpool UP, 1996.

Hemlow, Joyce. The History of Fanny Burney. Clarendon Press, 1958.

Hitchcock, Robert. An Historical View of the Irish Stage; from the Earliest Period Down to the Close of the Season 1788. William Folds, 1794. 2 vols.

Hogan, Charles Beecher, editor. The London Stage: 1660-1800, Volume 5: 1776-1800. Southern Illinois UP, 1968. 
Hogarth, William. A Harlot's Progress. 1732, engraving with etching, The Queen's Gallery, Buckingham Palace, London. Royal Collection Trust, www.royalcollection.org. uk/collection/811512/a-harlots-progress.

-. A Rake's Progress. 1733, engraving with etching, The British Museum, London.

"Home Affairs." Westminster Journal [London, England], 23 February 1745.

Howe, Elizabeth. The First English Actresses: Women and Drama 1660-1700. Cambridge UP, 1992.

Illingworth, Sir Charles. The Story of William Hunter. E \& S Livingstone, 1967.

Inglis, Fred. A Short History of Celebrity. Princeton UP, 2010.

Jarvis, R.C. "The Death of Walpole: Henry Fielding a Forgotten Cause Celebre." The Modern Language Review, vol. 41, no. 2, April 1946, pp. 113-130. JSTOR. doi:10.2307/ 37.17030.

“Jenny McCarthy: We're Not an Anti-Vaccine Movement...We're Pro-Safe Vaccine.” Frontline, PBS, 23 March 2015, www.pbs.org/wgbh/frontline/article/jenny-mccarthy-were-not-ananti-vaccine-movement-were-pro-safe-vaccine/.

Johnson, Samuel. A Dictionary of the English Language: In Which the Words Are Deduced from Their Originals, and Illustrated in Their Different Significations by Examples from the Best Writers; to Which Are Prepared, A History of the Language, an English Grammar. vol. 1 and 2, 6th ed., 1785. Archive, www.archive.org/stream/dictionaryofengl01jo hnuoft\#page/n685/mode/2up.

Jordanova, Ludmilla. Defining Features: Scientific and Medical Portraits 1660-2000. National Portrait Gallery, 2000.

Jurin, James. An Epistle to John Ranby, Esq; Principal Serjeant Surgeon to His Majesty, And 
F.R.S. On the Subject of his Narrative of the Last Illness of the late Earl of Orford, As far as it relates to Sir Edward Hulse, Dr Jurin, and Dr Crowe, Golden Lyon, 1745, Hathitrust Digital Library, www.babel.hathitrust.org/cgi/pt?id=ucm.5329215008 ;view=1 up;seq $=4 ;$ size $=75$

Kaartinen, Marjo. Breast Cancer in the Eighteenth Century. Pickering \& Chatto, 2013. Kaye, Heidi. “ “This breast- It’s Me': Fanny Burney’s mastectomy and the defining gaze.” Journal of Gender Studies, vol. 6, no. 1, 1997, pp. 43-53.

Keith, Arthur. "A Discourse on the Portraits and Personality of John Hunter." The British Medical Journal, vol. 1, no. 3501, 11 February 1928, pp. 205-209.

Kelly, Ian. Mr. Foote's Other Leg. Picador, 2012.

King, Lester Snow. The Road to Medical Enlightenment, 1650-1695. Macdonald \& Co., 1970.

Kobler, John. The Reluctant Surgeon: A Biography of John Hunter. Doubleday, 1960.

Koronwnyk, Christina, et al. "Televised medical talk shows - what they recommend and the evidence to support their recommendations: a prospective observational study." The BMJ, 349, 2014, doi https://doi.org/10.1136/bmj.g7346.

Lawlor, Clark. “ 'The History of Half the Sex': Fashionable Disease, Capitalism, and Gender in the Long Eighteenth Century." Literature and Medicine, vol. 35, no. 2, 2017, pp. 355386.

Leroy-Dupre, Louis Alexandre Hippolyte. Memoir of Baron Larrey, Surgeon-in-Chief of the Grande Armee. London, H. Rensaw, 1861.

A Letter from a Physician in Town from Another at Bath Concerning the Case of the Right Honourable the late Earl of Orford, 1745. Eighteenth Century Collections Online, 
www.find.galegroup.com.www.libproxy.wvu.edu/ecco/infomark.do?\&source=gale\&prod $\mathrm{Id}=\mathrm{ECCO} \&$ userGroupName $=\operatorname{morg} 77564 \&$ tabID $=\mathrm{T} 001 \& \mathrm{docId}=\mathrm{CW} 3309063025 \&$ type $=$ multipage \&contentSet=ECCOArticles\&version=1.0\&docLevel=FASCIMILE

"London." Daily Advertiser [London, England], 6 February 1745.

“London.” Daily Advertiser [London, England], 13 February 1745.

"London." Daily Gazetteer [London, England], 5 February 1745.

“London.” Daily Post [London, England], 22 February 1745.

“London, February 5." General Evening Post [London, England], 5-7 February 1745.

“London.” London Evening Post [London, England], 7-9 February 1745.

"London.” London Evening Post [London, England], 14-16 February 1745.

“London, March 19." General Evening Post [London, England], 16-19 March 1745.

“London.” Penny London Post [London, England], 8-11 February 1745.

"London." Penny London Post [London, England], 11-13 February 1745.

Luckhurst, Mary, and Jane Moody, editors. Theatre and Celebrity in Britain, 1660-2000. Palgrave Macmillan, 2005.

Macintyre, Iain. "Scientific surgeon of the Enlightenment or 'plagiarist in everything': a reappraisal of Benjamin Bell (1749-1806)." Journal of the Royal College of Physicians of Edinburgh, vol. 41, 2011, pp. 174-181, www.rcpe.ac.uk/sites/default/files/ma cintyre_1.pdf

Macleod, John. Dynasty: The Stuarts, 1560-1807. St. Martin's Press, 1999.

The Madness of King George, directed by Nicholas Hytner, The Samuel Goldwyn Company, 1994.

Maehle, Andreas-Holger. Drugs on Trial: Experimental Pharmacology and Therapeutic 
Innovation in the Eighteenth Century, Rodopi, 1999.

Mather, George R. Two Great Scotsmen, the Brothers William and John Hunter. Glasgow, Maclehose, 1893.

McCormack, Helen. William Hunter and His Eighteenth-Century Cultural Worlds: The Anatomist and the Fine Arts. Routledge, 2018.

-. "The Great Windmill Street Anatomy School and Museum." William Hunter's World: The Art and Science of Eighteenth-Century Collecting. Ashgate, 2015, pp. 13-28.

McGirr, Elaine. “Authorial Performances: Actress, Author, Critic.” Women's Writing, 16601830: Feminisms and Futures, edited by Jennie Batchelor and Gillian Dow, Palgrave Macmillan, 2016, pp. 97-116.

McKendrick, Neil, et al. The Birth of a Consumer Society: The Commercialization of Eighteenth-Century England. Europa Publications, 1982.

Monaghan, Jessica. "Authenticity and Fashionable Disease in Eighteenth-Century Britain.” Literature and Medicine, vol. 35, no. 2, 2017, pp. 387-408.

Montgomery, Alexander. The Illustrated Magazine of Art, vol. 3, Montgomery, 1854.

Moore, Wendy. The Knife Man: Blood, Body Snatching, and the Birth of Modern Surgery. Broadway Books, 2007.

Nash, Mary. The Provoked Wife: The Life and Times of Susannah Cibber. Little Brown, 1977.

Nestor, Phil. "Baron Dominique Jean Larrey 1766-1842." Australasian Journal of Paramedicine vol. 1, no. 3, 2003, n.p.

Noble, Iris. Master Surgeon: John Hunter. New York, J. Messner, 1971.

Nussbaum, Felicity. Rival Queens: Actresses, Performance, and the Eighteenth-Century Theater. University of Pennsylvania, 2014. 
Olson, James S. Bathsheba's Breast: Women, Cancer, \& History. Johns Hopkins UP, 2002.

Oppenheimer, Jane M. New Aspects of John and William Hunter. Henry Schuman, 1946.

Owen, Edmund. "The Hunterian Oration on John Hunter and His Museum.” The British Medical Journal, vol. 1, n. 2616, 18 February 1911, pp. 341-347.

Oxford English Dictionary.

Paget, Stephen. John Hunter: Man of Science and Surgeon. T. Fisher Unwin, 1897.

Peachey, G. C. Memoir of William and John Hunter. Plymouth, 1924.

Pécastaings, Annie. "Frances Burney’s Mastectomy and the Female Body Politic.” Prose Studies, vol. 33, no. 3, 2011, pp. 230-240.

“Peg Woffington.” National Portrait Gallery, www.npg.org.uk/collections/search/portrait/mw06 883/Peg-Woffington?LinkID=mp04897\&role=sit\&rNo=2

Pepys, Samuel. The Diary of Samuel Pepys. edited by Robert Latham and William Mathews, vol. 9, Harper Collins Publishers, 1995.

Pointon, Marcia. Hanging the Head: Portraiture and Social Formation in Eighteenth-Century England. Yale UP, 1993.

Porter, Roy. Bodies Politic: Disease, Death, and Doctors in Britain, 1650-1900. University of Chicago Press, 2001.

-. The Greatest Benefit to Mankind. W. W. Norton and Company, 1997.

--. Health for Sale: Quackery in England 1660-1850, Manchester UP, 1989.

---. "William Hunter: a Surgeon and a Gentleman." William Hunter and the Eighteenth-Century Medical World, edited by W. F. Bynum, W.F. and Roy Porter. Cambridge UP, 1985, pp. 7-34.

Porter, Roy, and George Sebastian Rousseau. Gout: The Patrician Malady. Yale UP, 1998. 
"Portrait of John Hunter.” The Royal Society, pictures.royalsociety.org/image-rs-9551.

"Portraits of William Hunter." British Medical Journal, vol. 2, n. 3060, 1919, pp. 247-248.

Power, D’A. “Ranby, John (1703-1773), surgeon.” Oxford Dictionary of National Biography, 23 September 2004, http://www.oxforddnb.com/view/10.1093/ref:odnb/9780198614128. 001.0001/odnb-9780198614128-e-23106

Ranby, John. A Narrative of the Illness of the Right Honourable the Earl of Orford: From May 1744, to the Day of his Decease, March the Eighteenth following, 1745. Archive, www.archive.org/details/narrativeoflasti1745ranb. Accessed on 10 August 2018.

---. A Narrative of the Illness of the Right Honourable the Earl of Orford: From May 1744, to the Day of his Decease, March the Eighteenth following, with an Appendix: Occasioned by the Letter from a Physician in Town to Another at Bath, 1745. https://archive.org/details/narrativeoflasti00ranb. Accessed 18 August 2018.

Reade, Charles, and Tom Taylor. Masks and Faces: Before and Behind the Curtain. Richard Bentley, 1852.

---. Peg Woffington. James Rusk and David Widger, 1852.

"Review of The Knife Man: The Extraordinary Life and Times of John Hunter, Father of Modern Surgery, by Wendy Moore.” Publisher's Weekly, 29 Aug. 2005, www.publishersweekly.com/978-0-7679-1652-3.

Richardson, R.G. "Larrey: What Manner of Man?" Proceedings of the Royal Society of Medicine, vol. 70, 1977, pp. 490-494.

Roach, Joseph. It. University of Michigan Press, 2007.

-. "Public Intimacy: The Prior History of 'It'." Theatre and Celebrity in Britain, 1660-2000, 
edited by Mary Luckhurst and Jane Moody, Palgrave Macmillan, 2005, pp. 15-30.

Robertson-Steel, Iain. "Evolution of Triage Systems." Emergency Medicine Journal, vol. 23, no. 2, 2006, pp. 154-155.

Rojek, Chris. Celebrity. Reaktion Books, 2001.

Rusnock, Andrea. The Correspondence of James Jurin (1684-1750): Physician and Secretary to the Royal Society, Rodopi, 1996.

A Second Letter from a Physician in Town from Another at Bath Occasioned by Sergeant Ranby's Appendix to his Narrative of the Last Illness of the Right Honourable the Earl of Orford 1745. Eighteenth Century Collections Online, www. find.galegroup.com.www. libproxy.wvu.edu/ecco/infomark.do?\&source=gale \&prodId=ECCO\&userGroupName=m org 77564\&tabID=T001\&docId=CW3309063064\&type=multipage \&contentSet=ECCO Articles\&version $=1.0 \&$ docLevel=FASCIMILE

Shuttleton, David E. "The Fashioning of Fashionable Diseases in the Eighteenth Century." Literature and Medicine, vol. 35, n. 2, 2017, pp. 270-291.

Simmons, Samuel Foart. An Account of the Life of the Late William Hunter. W. Richardson, 1783.

Slagle, Judith Bailey. "Opposing the Medical World: The Poetry of Anne Home Hunter.” The Wordsworth Circle, vol. 39, n. 3, 2008, pp. 102-107.

South, John Flint. Memorials of the Craft of Surgery in England, 1886. Archive, www.archive.org/stream/memorialsofcraft00soutuoft\#page/n7/mode/2up

Stevenson, Robert Louis. The Strange Case of Dr. Jekyll and Mr. Hyde. Longmans, Green, and Company, 1886.

Stone, George Winchester Jr. The London Stage: 1660-1800, vol. 4, 1962. Archive, 
www.babel.hathitrust.org/cgi/pt?id=mdp.39015012277045;view=1up;seq=7

Straub, Kristina. Sexual Suspects: Eighteenth-Century Players and Sexual Ideology. Princeton UP, 1992.

Sutherland, Eileen. ““A little sea-bathing would set me up forever': The History and Development of the English Seaside Resorts.” Journal of Jane Austen Society of North America, n. 19, 1997, pp. 60-76, http://www.jasna.org/persuasions/printed/number19 /sutherland.pdf

Taylor, Stephen. "Walpole, Robert, first Earl of Orford (1676-1745), prime minister." Oxford Dictionary of National Biography, 3 January 2008, www.oxforddnb.com/view /10.1093/ref:odnb/9780198614128.001.0001/odnb-9780198614128-e-28601

“This Day is publish'd.” Daily Advertiser [London, England], 22 April 1745.

Tikkanen, Amy. "Mehmet Oz.” Encyclopaedia Britannica, 7 May 2010, www.britannica.com /biography/Mehmet-Oz

“Tomorrow Will Be Published.” Daily Gazetteer, [London, England], 9 April 1745.

Turner, Graeme. “Approaching Celebrity Studies.” Celebrity Studies, vol. 1, no. 1, 2010, pp. 1120.

-. Understanding Celebrity. SAGE Publications, 2004.

Vasset, Sophie. Medicine and Narration in the Eighteenth Century. Voltaire Foundation, 2013.

Victor, Benjamin. The History of the Theatres of London and Dublin, From the Year 1730 to the present Time, 1790. 2 vols. Archive, www.archive.org/stream/bub_gb_eAcJAAAAQAAJ \#page/n5/mode/2up/

Viseltear, Arthur J. “The Last Illnesses of Robert and Horace Walpole.” The Yale Journal of 
Biology and Medicine, vol. 56, 1983, pp. 131-152, www.ncbi.nlm.nih.gov/pmc/articles /PMC2589702/pdf/yjbm00104-0069.pdf.

Walpole, Horace. The Yale Edition of Horace Walpole's Correspondence, vol. 29, edited by William Stanley Lewis and Warren Hunting Smith, Yale UP, 1955.

Wanko, Cheryl. Roles of Authority: Thespian Biography and Celebrity in Eighteenth-Century Britain. Lubbock, Texas Tech UP, 2003.

-- "Celebrity Studies in the Long Eighteenth Century: An Interdisciplinary Overview." Literature Compass, v. 8, n. 6, 2006, pp. 351-362.

"What are Bladder Stones?” WebMD, https://www.webmd.com/kidney-stones/what-are-bladderstones\#1

“What are Kidney Stones?” Urology Care Foundation, https://www.urologyhealth.org/urologicconditions/kidney-stones

“William Hunter.” The Hunterian, http://collections.gla.ac.uk/\#details=ecatalogue.34373.

Wilkinson, Tate. Memoirs of His Own Life, vol. 1, 1790. Archive, www.archive.org/stream/ memoirshisownli02 wilkgoog\#page/n5

Withey, Alun. Physick and the Family: Health, Medicine, and Care in Wales, 1600-1750, Manchester UP, 2011.

Woodall, Joanna, editor. Portraiture: Facing the Subject. Manchester UP, 1997. 